\title{
Poetik der meraviglia in den Werken Giambattista Marinos
}

\subsection{Einleitung}

Ist von einer Poetik der meraviglia die Rede, wird Giambattista Marino nicht selten als barocker Kulminationspunkt einer solchen bezeichnet. Der Grund dieser Zuordnung wird auf folgende Zeilen zurückgeführt - besondere Beachtung gilt allerdings der Tatsache, dass es sich bei besagtem Gedicht um einen satirischen Text gegen Marinos Konkurrenten und Widersacher Gaspare Murtola handelt:
Vuo' dar una mentita per la gola a qualunque huom ardisca d'affermare che il Murtola non sa ben poetare, e ch'ha bisogno di tornar a scuola.
E mi viene una stizza marïola quando sento ch' alcun lo vuol biasmare; perché nessuno fa meravigliare come fa egli in ogni sua parola.
È del poeta il fin la meraviglia (parlo dell'eccellente, non del goffo): chi non sa far stupir, vada alla striglia.
Io mai non leggo il cavolo e 'l carcioffo, che non inarchi per stupor le ciglia, com'esser possa un uom tanto gaglioffo. ${ }^{1}$

1 MARIno, La Murtoleide, Fischiata XXXIII, S. 627: « Du willst aus deiner Kehle eine Lüge verkünden / für jeden, der es wagt zu behaupten, / dass Murtola es nicht verstehe, gut zu dichten, / und dass er zurück zur Schule müsse. // So kommt in mir spitzbübische Wut hoch, / wenn ich höre, dass jemand ihn rügen möchte; / denn niemand mag zu erstaunen / wie er mit jedem seiner Worte. // Das Staunen ist das Ziel des Dichters / (und ich rede vom exzellenten, nicht vom plumpen): / Und wer nicht zu erstaunen vermag, gehe an den Striegel. // Ich lese nie den Kohl und die Artischocke, / ohne dass sich mir die Augenbrauen vor Verblüffung heben, / wie ein Mann ein derartiger Tölpel sein könne.» // Alle Übersetzungen der Texte Marinos ausser von La Galeria - stammen von der Autorin (A.E.). 
Polemisch greift Marino darin Vokabular und Motive aus Murtolas Werk Della creatione del mondo ${ }^{2}$ auf, so «cavolo » und «carcioffo », insbesondere aber «meraviglia ». ${ }^{3}$ Für eine Vielzahl der Canti der Creatione werden die „meraviglie“ bereits in den eröffnenden Themen angekündigt: «i laghi e lor meraviglie» («die Seen und ihre Wunder»), «lo cristallo e maraviglia degli specchi» («das Kristall und das Wunder der Spiegel»), «il lino e sue meraviglie» («der Flachs und seine Wunder»), «la torpedine e suo stupore» («der Zitterrochen und sein Staunen»), «la pupilla e sue meraviglie» («die Pupille und ihre Wunder $») .{ }^{4}$ Marinos Nennung von stupore und meraviglia muss als ironischer Bezug auf diese gehäuften Anspielungen auf die Wunder der Schöpfung betrachtet werden. Dass Murtola mit jedem Wort Staunen erregt («nessuno fa meravigliare, / Come fa egli in ogni sua parola», V. 7-8), führt Marino in ironischem Sinne auf die Banalität ebendieser Worte zurück (V. 3-4, 12). « [C]avolo» und « carcioffo » werden gar zu Synonymen für das Werk («Io mai non leggo il cavolo e 'l carcioffo », V. 12): Man kann gar nicht darin lesen, ohne die Augenbrauen vor Staunen über den unfähigen Autor hochzuziehen (V.13-14). Gestaunt wird nicht über die Dichtung, sondern über den Autor und dessen inhaltliche und sprachliche Beschränktheit.

Die zentrale dritte Strophe ist bewusst ambivalent formuliert: Sie definiert eine Poetik der meraviglia («É del poeta il fin la meraviglia», V. 9), die aufgrund der Gesamtsituation als parodistisch betrachtet werden müsste, wäre da nicht der unmittelbar folgende, in Klammern gesetzte Vers, der das Gesagte an den exzellenten, nicht an den ungeschickten Dichter richtet (V. 10). Natürlich kann dies „a rovescio“ gelesen werden, sodass er sich nicht an den exzellenten, sondern den ungeschickten Dichter richtet. Denn kaum ist die Klammer geschlossen, nimmt der parodistische Unterton seinen Lauf: «chi non sa far stupir, vada alla striglia » (V. 11). Wer nicht zu erstaunen vermag, dem sollen die Leviten gelesen werden. ${ }^{5}$ Weiter deutet die Reimfolge « meraviglia », « striglia » und « ciglia » - in Kombination mit « goffo », « carcioffo » und « gaglioffo »auf eine negative Konnotation der meraviglia hin.

In einer zweiten, weit weniger bekannten Fischiata (XXXVIII) spielt Marino erneut parodistisch mit stupore und meraviglia, um Murtolas Werk zu charakterisieren:

2 Gaspare Murtola, Della creatione del mondo, poema sacro, Venetia 1608.

3 Guido Pedrojetta, Marino e la meraviglia, in: Giuse ppe Galli (Hg.), Interpretazione e meraviglia, XIV Colloquio sulla interpretazione Macerata 29-30 Marzo 1993, Macerata 1994, S. 98-99.

4 Pedrojetta, Marino, S. 99.

5 Ich lese « vada alla striglia » figurativ im Sinne von „strigliare“ („rimproverare“). 
Quando il tuo libro in man Murtola io piglio,

E in leggerlo mi spolpo, e mi disosso

Bisogna, ch'io stupisco, e far non posso,

Che 'l cul non stringa, e non inarchi'l ciglio.

Se tal'hor miro, con che bel consiglio,

A guisa d'un fachin, peso sì grosso

D'un Mondo intiero t'hai recato adosso,

Che non ti spalli almen mi merauiglio. ${ }^{6}$

Die Lektüre der Creatione bereichert nicht, sondern nimmt den Leser körperlich aus («mi spolpo, e mi disosso », V. 2), sodass dieser über die Reaktionen seines Körpers staunen muss, ohne diese verhindern zu können («e far non posso / che 'l cul non stringa, e non inarchi'l ciglio », V. 4) - wobei « cul » eindrücklich aufzeigt, auf welchem Niveau Marino Murtolas Werk situiert. ${ }^{7}$ Die zweite Strophe wird von Verwunderung und Staunen darüber umklammert, wie Murtola sich eine derart grosse Aufgabe - die Schöpfung der Welt in ein Poem zu fassen - habe auf sich laden können, ohne daran zu verzweifeln. ${ }^{8}$ "Stupore“ und "meraviglia“ sind Reaktionen auf den körperlichen Widerwillen einerseits und die zu grossen Ambitionen des Autors andererseits.

Charakteristisch in beiden Fischiate ist die körperliche Reaktion, die mit der meraviglia einhergeht, insbesondere das Hochziehen der Augenbrauen. Das Staunen wird stets auf Mängel von inventio und elocutio bezogen.

Zusammenfassend kann gesagt werden: Aus den Fischiate resultiert keine Poetik der meraviglia, da stupore und meraviglia mehrheitlich negativ und parodistisch konnotiert sind. ${ }^{9}$ Trotzdem weist die häufige Verwendung der

6 Wenn ich dein Buch, Murtola, zur Hand nehme, / und mich beim Lesen zerfleische und entbeine, / erstaune ich notwendigerweise, denn es geht nicht anders, / als dass der Hintern sich zusammen-, die Augenbraue sich hochzieht. // Wenn ich mich bisweilen wundere, nach welchem schönen Ratschlag / von der Art eines Packesels dieses grosse Gewicht / der ganzen Welt du dir aufgeladen hast. / Dass du dich nicht erschiesst, zumindest darüber staune ich. // Marino, La Murtoleide, Fischiata XXXVIII, in: Giambattista Marino, La Murtoleide fischiate del cavalier Marino, Spira [Speyer] 1629.

7 Pedrojetta nennt als Quelle dieser Zeile einen Vers aus Ariostos Orlando Furioso: « Io vi vo' dire e far di maraviglia / Stringer le labra et inarcar le ciglia ( «Das sag' ich jetzt, und will, dass ihr vor Staunen / die Lippen klemmt und wölbt die Augenbrauen », X, 4, Vv. 7-8). Siehe Pedrojetta, Marino, S. 98.

8 Wobei «spalli » natürlich auch eine Andeutung darauf ist, dass Murtola versucht hat, Marino zu erschiessen, weil dieser ihm die Stellung am Hof von Carlo Emanuele I in Turin streitig gemacht hat.

9 Zahlreiche Kritiker haben den parodistischen Unterton der Fischiate ignoriert und in ihnen ein klares Postulat für eine Poetik der meraviglia gelesen, so Giovanni Getto in Barocco in prosa e in poesia: «La meraviglia costituiva davvero la sostanza dell'emozione umana 
Staunensbegriffe darauf hin, dass sie poetisch auch für Marino relevant sein könnten. Die Frage lautet daher, ob aus den Werken Marinos eine positive Poetik der meraviglia resultiert und, wenn ja, wie diese meraviglia - im Gegensatz zu jener, die sich in den Fischiate niederschlägt - beschaffen ist. Anzumerken ist, dass die Fischiate frühe Texte Marinos sind - sie gehen auf die Jahre am Hof von Turin um $1609^{10}$ zurück -, während der Grossteil seiner Werke, insbesondere seine erfolgreichsten Texte, ${ }^{11}$ erst in den Jahren ab 1614 verfasst und publiziert wurden.

Kritiker wie Giovanni Pozzi und Guido Pedrojetta haben die These aufgestellt, dass es trotzdem eine marinianische Poetik der meraviglia gebe. Allerdings bezögen sich Marinos meraviglie nicht wie bei Murtola auf die göttliche, sondern auf die literarische Schöpfung. ${ }^{12}$ Damit wird die Unterscheidung von «meraviglia delle cose» («Wunder der Dinge») und «meraviglia delle parole («Wunder der Worte») bemüht, ${ }^{13}$ wobei gerade dieser vermeintlich barocke «Selbstzweck » von Stil und Form bedeutende Kritiker wie Benedetto Croce und Giuseppe Zonta dazu bewogen hat, Marinos Werk sowie insgesamt die Dichtung des Barocks abzuwerten. ${ }^{14}$ Die oben genannte Frage nach einer Poetik der meraviglia wird demzufolge erweitert um die Fragen, wo diese kategorial zu verorten und wie eine «meraviglia delle parole» genau beschaffen wäre. Diese Fragen sind nicht einfach zu beantworten, insbesondere deshalb, weil es ausserhalb der Fischiate nur wenige konkrete poetologische Formulierungen zugunsten einer Poetik der meraviglia gibt. Aufschlussreich ist ein Passus aus einem Brief Marinos an Guidubaldo Benamati aus dem Jahr 1614 - kurz vor der Publikation der Dicerie sacre -, denn dort wird nicht nur das Staunen als explizit prognostizierte Leserreaktion genannt, sondern es werden auch die literarischen Qualitäten aufgeführt, die zu dieser Reaktion führen:

Intanto qui in Torino fo stampare certi miei discorsi sacri, i quali ardisco di dire (e scusimi la modestia) che faranno stupire il mondo. Parrà cosa stravagante ed

e stilistica del poeta, il quale se ne rendeva ben conto quando la poneva alla base del suo programma, istituendola anzi come fine di ogni ricerca poetica, secondo scriveva nei celebri versi della XXXIII fischiata della Murtoleide [...] » Siehe Giovanni Getto, Introduzione al Marino, in: De Rs., Barocco in prosa e in poesia, Milano 1969, S. 19.

10 Ein genaues Entstehungsdatum ist nicht zu finden, denn gedruckt wurde die Murtoleide erst posthum (1626) in Frankfurt. Siehe James V. Mirollo, The Poet of the Marvelous. Giambattista Marino, New York / London 1963, S. 24.

11 Dicerie sacre (1614), La Galeria (1620), L'Adone (1623).

12 Pedrojetta, Marino, S. 99.

13 Ebd., S. 104.

14 Vgl. dazu u. a. Birgit Ulmer, Die Entdeckung der Landschaft in der italienischen Literatur an der Schwelle zur Moderne, Frankfurt a. M. 2010, S. 74. Ulmer verweist auf BENEDETTO Свосе, Storia dell'èta barocca in Italia, Milano 1993 [1929]. 
inaspettata, massime a chi non sa gli studi particolari ch'io fin da' primi anni ho fatti sopra la Sacra Scrittura. Ma è opera da me particolarmente stimata ed in cui io ho durata fatica lunghissima. Spero che piaceranno, sí per la novità e bizzaria della invenzione, poiché ciascun discorso contiene una metafora sola, sí per la vivezza dello stile e per la maniera del concettare spiritoso. ${ }^{15}$

Die Dicerie sacre, von denen hier die Rede ist, liegen dem Autor als aussergewöhnliches Werk besonders am Herzen und haben eine grosse Anstrengung seinerseits erfordert. Seine Texte sollen gefallen, und zwar aufgrund von «novità e bizzaria della invenzione » sowie «per la vivezza dello stile e per la maniera del concettare spiritoso ». Diese Faktoren ergeben einen Gesamteindruck, der mit grossem Staunen quittiert werden wird.

Das Prinzip der Neuheit („novità“) findet sich auch in La Sampogna ${ }^{16}$ prominent ausgedrückt. In der Idylle La ninfa avara fordert Filaura Fileno ${ }^{17}$ auf, vom gewöhnlichen und abgedroschenen «discorso » abzuweichen und neue Wege zu beschreiten:

Fileno, il tuo discorso

è vago e dotto invero;

ma sì trito e commune,

e già sì antico omai, che sa di vieto!

$[\ldots]$

Conviensi a non vulgare

spirito peregrino

dal segnato sentier sviarsi alquanto,

e per novo camino

dietro a novi pensier movere il corso. ${ }^{18}$ (Vv. 272-294)

15 Unterdessen werde ich hier in Turin einige meiner heiligen Diskurse drucken lassen, über die ich wage zu sagen (entschuldige meine Bescheidenheit), dass sie die Welt in Staunen versetzen werden. Es mag eine extravagante und unerwartete Sache sein, vor allem für jene, die meine Studien zur heiligen Schrift nicht kennen, die ich seit meinen jüngsten Jahren verfasst habe. Aber es ist ein Werk, das ich ganz besonders schätze und in das ich grösste Anstrengung gelegt habe. Ich hoffe, dass sie [die Diskurse] gefallen, sowohl aufgrund ihrer Neuheit als auch der Eigenheit der Erfindung, denn jeder Diskus enthält eine einzige Metapher, wie auch wegen der Lebendigkeit des Stils und der Art geistreichen Konzipierens. // Giambattista Marino, Lettera $n$. 97 a Guidubaldo Benamati, in: DE RS., Lettere, a cura di Marziano Guglielminetti, Torino 1966, S. 167.

16 La Sampogna erschien 1620 in Paris und versammelt mythologische und pastorale Idyllen, die im Zeitraum von 1607 bis 1619 entstanden sind. Ich zitiere aus: Giovan BATTISTA Marino, La Sampogna, a cura di Vania De Maldé, Parma 1993.

17 Fileno taucht in verschiedenen Werken Marinos als Alter Ego des Dichters auf. So hier in La Sampogna, erneut im neunten Canto des Adone.

18 Fileno, dein Diskurs / ist lieblich und wahrhaft gelehrt; / aber so abgenutzt und gewöhnlich / und so altertümlich, dass er verboten gehört. / [...] / Es gehört sich für einen unordinären / und ausgefallenen Geist, / dass er ab und zu vom vorgezeichneten Weg abkommt / und sich auf einem neuen Weg / hinter neuen Gedanken bewegt. 
Filaura erkennt in Filenos Rede Bezüge zu Tassos Aminta und Guarinis Il pastor fido $^{19}$ und fordert Fileno in schonungsloser Manier auf, seinen Geist anzustrengen («ingégnati pur dunque», V. 295) und neue « concett $[\mathrm{i}]$ » (V. 300) zu (er-)finden. Diese Worte Filaura, die sich selbst als « einfach und grob » (V. 153) bezeichnet, in den Mund zu legen und nicht Fileno, der « scharfsinnige Denksprüche und ernsthafte Aussagen » (V. 150) bemüht, um «hohe und erhabene Lehren » (V. 151) auszudrücken, ist wiederum ein interessanter Kniff Marinos. Denn Filaura kritisiert, dass sie Fileno aufgrund seiner elaborierten Sprache gar nicht mehr verstehe (Vv. 153-158), und fordert ihn auf, sich klarer auszudrücken. Sie will also durchaus verstehen, was er ihr mitteilen will, und ist nicht nur an seiner kunstvollen Sprache interessiert.

Wie schon im Brief an Benamati erläutert Marino auch in einem sehr viel späteren Brief von 1624 an Antoni Bruni die Faktoren, die Staunen und Gefallen hervorrufen. Zu ihnen zählen insbesondere das Aussergewöhnliche («stravagante », « peregrino ») und das Unerwartete (« inaspettato $)^{20}$

Io l'ho letta [una canzone per Emanuele Filiberto di Savoia da Antonio Bruni] e riletta più volte, e sempre con nuovo gusto e con nuova maraviglia; perché la sua frase è peregrina, i concetti nobili, il numero gentile, e da quando in quando il lettore s'incontra in quel non so che inaspettato che così da Aristotile si commenda. ${ }^{21}$

Ho letto più volte l'ultimo foglio delle poesie di V. S., e per dirgliene il mio parere da vero amico, mi par che debbano recar maraviglia e diletto insieme agl'ingegni delicati, perché i suoi versi hanno spirito e maestà nobile, e non caminano per la strada battuta degl'ingegni plebei. Io le ammiro come gioie preziosissime. ${ }^{22}$

Es ist eine Vielzahl von Lesereindrücken, die in Marino «maraviglia» hervorrufen - und zwar immer wieder von Neuem («sempre con [...] nuova

19 Siehe den Kommentar von Alberto Asor Rosa in Giambattista Marino, Opere, a cura di Alberto Asor Rosa, Milano 1967, S. 568.

20 Mirollo, The Poet, S. 119.

21 Ich habe sie gelesen und mehrere Male wieder gelesen [ein Lied von Antonio Bruni für Emanuele Filiberto di Savoia], immer wieder mit neuem Genuss und erneutem Erstaunen; denn seine Ausdrücke sind aussergewöhnlich, die Konzepte edel, der Rhythmus freundlich, und immer wieder wird der Leser mit Unerwartetem überrascht, so wie Aristoteles es empfohlen hat. // MARINo, Lettera n. 23 ad Antonio Bruni, S. 417.

22 Ich habe mehrere Male die letzte Seite Ihres Gedichtes gelesen, und um ihnen meinen Eindruck als denjenigen eines wahren Freundes zu schildern, so scheint mir, dass es sowohl Staunen als auch Vergnügen in den feinen Geistern hervorrufen wird, denn Ihre Verse sind geistreich und majestätisch, und sie gehen nicht auf den festgestampften Pfaden des gemeinen Volkes. Ich bewundere sie wie wertvollste Schmuckstücke. // MARINo, Lettera n. 232 ad Antonio Bruni, S. 418. 
maraviglia»): Der sprachliche Ausdruck ist extravagant, die Inhalte sind erhaben, das Metrum schmiegsam, die Wendungen unerwartet. Auch im zweiten Brief nennt Marino den geistreichen und vornehmen Inhalt der Verse sowie deren Neuartigkeit als Ursachen seines Staunens. Die «maraviglia » ist damit weder nur auf den Inhalt noch einzig auf die Sprache bezogen, sondern stellt sich als Gesamteindruck ein, der aus dem Zusammenspiel aller Aspekte des Textes resultiert. ${ }^{23}$

Auch das Prinzip der Lebendigkeit, das schon im Brief an Benamati genannt worden ist («vivezza dello stile»), wird in einem späteren Brief an Bruni ebenfalls von 1624 - wieder aufgegriffen. Die Forderung nach einem lebendigen Stil begleitet Marino demzufolge in seiner gesamten Schaffenszeit:

[...] e mi piacciono oltre modo quei brilli di poesia viva. ${ }^{24}$ I poeti, che dettano rime senza vivezze, fabricano cadaveri, non poesie $[\ldots]^{25}$

Neuartigkeit und Lebendigkeit reichen aber noch nicht aus, um aussergewöhnliche Dichtung zu schaffen. Es benötigt zudem eine geistreiche Erfindungsgabe und Fantasie. „Spiritosità“ („Findigkeit“) wird im frühen Brief an Benamati («concettare spiritoso») genauso erwähnt wie im Vergleich des Adone mit der Gerusalemme Liberata, wobei Marino den Adone als « viel umfangreicher und $[\ldots]$ gespickt mit viel lebendigeren und geistreicheren Farben der Dichtung » bezeichnet. $^{26}$

Das Vorbild fantasievoller Dichtung ist Ovid. So schreibt Marino in einem Brief an Girolamo Preti von 1624:

[...] mi basterà dire che troppo bene averò detto che le poesie d'Ovidio sono fantastiche, poiché veramente non vi fu mai poeta, né vi sarà mai, che avesse 0 che sia per avere maggior fantasia di lui. Ed utinam le mie fossero tali! ${ }^{27}$

23 Vgl. dazu Getтo, Introduzione, S. 55 .

24 Marino bezieht sich auf die „lettera eroica“ Venere ed Adone von Antonio Bruni, gesammelt und erschienen im zweiten Buch der Epistole eroiche (Milano 1626). Siehe dazu den Kommentar von Guglielminetti zum Brief Nr. 233, S. 420.

$25[\ldots]$ und mir gefallen diese Glanzstücke lebendiger Poesie über alle Massen. Dichter, die Verse ohne Lebendigkeit von sich geben, fabrizieren Kadaver, keine Poesie [...] // MARIno, Lettera n. 233 ad Antonio Bruni, S. 420.

26 Marino, Lettera n. 218 ad Antonio Bruni, S. 400.

27 [...] es wird mir genügen zu sagen, dass ich zurecht gesagt haben werde, dass die Gedichte von Ovid grossartig sind, denn tatsächlich hat es nie einen Dichter gegeben noch wird es je einen geben, der mehr Fantasie hat als er. Oh, dass doch meine Gedichte so wären! // MARIno, Lettera n. 216 a Girolamo Preti, S. 396. Der Hinweis auf diesen Brief stammt aus GETTO, Introduzione, S. 24. 
Fantasie geht einher mit künstlerischer Freiheit, die sich insbesondere auch dem aristotelischen Regelwerk widersetzt:

Intanto i miei libri, che sono fatti contro le regole, si vendono dieci scudi il pezzo a chi ne può avere; e quelli che son regolati, se ne stanno a scopar la polvere delle librarie. Io pretendo di saper le regole più che non sanno tutti i pedanti insieme, ma la vera regola (cor mio bello) è saper rompere le regole a tempo e a luogo, accomodandosi al costume corrente ed al gusto del secolo. ${ }^{28}$

Aus den bisher zitierten, vorwiegend paratextuellen Ausschnitten lassen sich zusammenfassend folgende poetologische Kriterien eruieren: 1. novità, 2. stravaganza $a^{29}$, 3. vivezza, 4. spiritosità und fantasia sowie 5 . libertà. ${ }^{30}$ In den folgenden Kapiteln soll analysiert werden, inwiefern diese Kriterien den Werken Marinos inhärent sind und ob sie sich als produktionsästhetische Bedingungen für die Wirkung der meraviglia nachweisen lassen. Die Wahl der analysierten Werke fällt bewusst auf folgende drei Werke, da sie gattungstechnisch und inhaltlich neuartig sind und keinem vorgegebenen Schema folgen: Dicerie sacre, La Galeria und Adone.

\section{Dicerie sacre}

Die Dicerie sacre wurden im Brief an Benamati als «stravagant[i] ed inaspettat $[\mathrm{i}]$ » angekündigt und tatsächlich handelt es sich um eine

28 Unterdessen verkaufen sich meine Bücher, die gegen die Regeln geschrieben sind, für zehn Scudi das Stück an jene, die es sich leisten können; und diejenigen, die nach den Regeln geschrieben wurden, kehren den Staub in den Buchhandlungen. Ich behaupte, die Regeln besser zu kennen als alle Pedanten zusammen, aber die wahre Regel (mein schönes Herz) ist es, die Regel am richtigen Ort und zur richtigen Zeit zu brechen, den Sitten und dem Geschmack der Zeit gemäss. // MARIno, Lettera n. 216 a Girolamo Preti, S. 396. Dass Marino die aristotelischen Regeln meint, wie sie unter anderem von Castelvetro propagiert werden, erläutert er an mehreren Stellen desselben Briefes. Es scheint also nicht unproblematisch, dass Marino in Kritik und Forschung häufig als poetologischer Vorläufer Tesauros genannt wird - folgt Tesauro doch sehr streng dem Regelwerk des Aristoteles. Vgl. dazu Ulmer, Die Entdeckung, S. 75; ebenso Beatrice RIMA, Novità, stupore e meraviglia nella retorica del Seicento, in: GALLI, Interpretazione e meraviglia, S. 79 .

29 An das Ausserordentliche ist zudem das Unerwartete gekoppelt.

30 1. Neuheit, 2. Extravaganz, 3. Lebendigkeit, 4. Findigkeit/Witz und Fantasie, 5. Freiheit. 
[o]pera di concezione originalissima, che fonde l'oratoria sacra [...] con la trattatistica artistica (la pittura, la musica), l'astronomia, l'erudizione e la poesia. $^{31}$

In both content and style the Dicerie sacre are indeed somewhat "unexpected and fantastic." There are three discourses: La Pittura, on Christ's shroud; La Musica, on the seven last words; and Il Cielo, on the sacred order of which the poet was a knight. Each of the discourses is offered as a sermon, although their author was not a cleric and there was no intention of delivering them on sacred occasions. ${ }^{32}$

Die Ankündigung von « discorsi sacri » (« heiligen Diskursen »), die aus Studien der Heiligen Schrift resultieren, ${ }^{33}$ lassen Texte zur Heiligen Schrift erwarten, wobei aber schon die Kapitelüberschriften - La pittura, La musica, Il cielo (Die Malerei, Die Musik, Der Himmel) - weltliche Themen bzw. eine künstlerischweltliche Perspektive verkünden.

Ich werde mich im Folgenden insbesondere auf den ersten und den zweiten Teil der Dicerie - La pittura und La musica - konzentrieren, denn in diesen Kapiteln werden neben der Figur des Künstlers auch die Beschaffenheit und das Verhältnis von Bild, Klang und Wort behandelt.

La pittura gliedert sich in drei Teile, ${ }^{34}$ wobei der erste Teil als Wettstreit (paragone) zwischen Malerei und Bildhauerei beginnt. Zuerst wird auf die handwerkliche, aber trotzdem edle Beschaffenheit beider Künste hingewiesen:

Che fra tutte l'arti fabrili [...], abiti della ragione inferiore, il cui fine non è con l'intelletto conoscere, ma con la mano operare, le più nobili e le più degne sieno la scultura e la pittura [...] [...] arti certamente [...] non solo nobili e degne, ma rare e mostruose, sí perché quasi di niente rappresentano stupori incredibili e miracoli alla gente, sí anche perché sono i piú atti e acconci strumenti da risvegliar la memoria, la quale essendo tesoriera e depositaria della parte intellettiva, le serve di non picciolo aiuto co' fantasimi che da questa le sono esteriormente somministrati. $^{35}(D S, 81)$

31 http://dizionaripiu.zanichelli.it/biblioteca-italiana-zanichelli/giovan-battista-marinodicerie-sacre/ (Stand April 2O21)

32 Mirollo, The Poet, S. 3 o.

33 Marino, Lettera n. 97 a Guidubaldo Benamati, S. 167.

34 Der erste Teil ist dem „pittore“, der zweite der "pittura“ und der dritte der „cosa dipinta“ gewidmet.

35 Ich zitiere aus folgender Ausgabe unter der Abkürzung DS: Giovanbattista MARino, Dicerie sacre e La strage de gl'innocenti, a cura di Giovanni Pozzi, Torino 196o. Die Übersetzungen stammen wie erwähnt von der Autorin (A.E.): «Von allen manuellen Künsten [...], die Ausdruck der niederen Vernunft sind und deren Ziel nicht die intellektuelle Erkenntnis ist, sondern das Arbeiten mit den Händen, sind die Bildhauerei und die Malerei die edelsten und würdigsten [...] [...] nicht nur edel und würdig, sondern selten 
Malerei und Bildhauerei sind deshalb die edelsten und aussergewöhnlichsten Kunsthandwerke, weil sie « quasi di niente » unglaublich Staunenswertes und Wunderbares schaffen und weil sie mit ihren «fantasimi» die Erinnerung «tesoriera [...] della parte intellettiva» - anstossen. Trotzdem zählen sie zu den Handwerken und zielen nicht auf intellektuelles Erkennen ab.

Der Streit zwischen den Künsten wird zugunsten der Malerei entschieden, denn sie ist « prima figlia della Idea, madre del modello, reina della maraviglia, principessa della simmetria, nutrice della proporzione $[\ldots] »^{36}(D S, 86)$. Die Malerei begründet ihre Erhabenheit unter anderem damit, dass für sie nicht nur Handwerk, sondern „ingegno“ („Geist“) notwendig sei, denn sie bilde nicht die Realität nach, sondern schaffe aus dem Nichts eine zweidimensionale Fläche, die dank Licht, Schatten und Perspektive den Effekt von Dreidimensionalität erwecke. Vor dieser illusorischen Leistung könnten die Betrachter gar nicht anders, als zu staunen:

Io ho la preminenza (dice la Pittura) [sovra la Scultura] per cagione della fatica: havvi fatica di corpo, e questa come ignobile lascio a te [la Scultura]; havvi fatica d'ingegno, e questa come nobile serbo per me. Più è difficile e maggior fatica intellettuale si richiede in dare ad intendere quello che non è, che in far parere quel che realmente è. Laonde chi non istupisce, mentre io porgendo ad una figura i lumi e l'ombre ben osservate, la fo scorciare, sfondare, andar lontano, ed in campo piano parer rilevata e ritonda, e per forza di linee, in un corpo dove non è se non larghezza e lunghezza, rappresento all'occhio la terza dimensione che è la grossezza? ${ }^{37}(D S, 83-84)$

und ungeheuerlich, sowohl weil sie den Leuten quasi aus dem Nichts unglaublich Erstaunliches und Wunderbares vorführen, sondern auch, weil sie die fähigsten und passendsten Instrumente sind, um die Erinnerung zu wecken. Diese ist ein Schatzhaus und ein Verwahrungsort des intellektuellen Bereichs, sie hilft ihm in nicht geringem Ausmass mit den Fantasiegebilden, die ihr von aussen zugetragen werden. » // Vgl. dazu ebenfalls die Stanze X, 127, des Adone.

36 [...] erstgeborene Tochter der Idee, Mutter des Modells, Königin der Wunder und des Staunens, Prinzessin der Symmetrie, Amme der Proportion [...]

37 Ich bin [der Bildhauerei] überlegen (sagt die Malerei) aufgrund der Anstrengung: körperliche Anstrengung, die unedel ist, überlasse ich dir [der Bildhauerei]; geistige Anstrengung, die edel ist, bewahre ich mir. Es braucht grössere und diffizilere intellektuelle Anstrengung, um etwas darzustellen, das es nicht gibt, als etwas abzubilden, das es in Realität gibt. Und wer erstaunt nicht, wenn ich einer Figur das genau studierte Licht und den Schatten zukommen lasse, wenn ich sie verkürze, durchbreche, in die Ferne bringe. Im flachen Feld erscheint sie rund und losgelöst, und aufgrund der Linien in einem Körper, der nichts ist ausser Breite und Länge, stelle ich dem Auge eine dritte Dimension dar, die der Umfang ist? 
Die eigentliche Begründung der Vorrangstellung der Malerei liegt darin - und so kehren wir zum religiösen und enkomiastischen Inhalt zurück -, dass Gott sich den Menschen nicht als Bildhauer, sondern als Maler gezeigt habe $(D S$, 86-87). Einschlägiger Ausdruck davon scheint dem Autor das als Reliquie verehrte Turiner Grabtuch - die «Santa Sindone »-, das geheimnisvolle Tuch aus der Sammlung des «Don Carlo Emanuello Duca di Savoia», dem die Dicerie sacre gewidmet sind $(D S, 79)$. Gott habe sich auf dem Grabtuch mit unvergänglichen und göttlichen Farben figurativ verewigt. Das Tuch wird als Geschenk Gottes verehrt, es konstituiert das sichtbare und zu bestaunende Gedächtnis aller seiner Wunder:

E veramente con ragione può dirsi ch'Iddio ci abbia il proprio cuore donato dandoci la somiglianza di questo ritratto santo: prodigalità che dava molto da maravigliare al pazientissimo amico di Dio $[\ldots]^{38}(D S, 89)$

[...] riposo dentro un tabernacolo cristallino, a ciascuno è lecito di mirarlo: pittura mirabile, anzi memoriale di tutte l'altre sue maraviglie: memoriam fecit mirabilium suorum. ${ }^{39}(D S, 89)$

Die Erinnerungskraft des Bildnisses ist enorm. Das Wunderbare zeigt sich in ihm von allen Seiten:

[...] è mirabile [...] dal canto del pittore, chè Iddio; mirabile dal canto della pittura, chè forma divina; mirabile dal canto della cosa dipinta, chè tutta divinità. ${ }^{40}(D S, 89)$

Von Gott, der den erstaunlichen Maler des Grabtuches darstellt, werden die Eigenschaften des perfekten Malers abgeleitet: Wissen, Weisheit und Sorgfalt $(D S, 89)$. Diese Qualitäten müssen sich zu einem ausgezeichneten « ingegno » fügen, damit die Werke lobes- und bewunderungswürdig (« degne di loda e di maraviglia ») sind. Staunen stellt sich dann ein, wenn die Idee des Werkes dank der « arguzia » des Malers das reine Handwerk übersteigt.

38 Und wahrlich kann man mit Vernunft sagen, dass Gott uns mit der Ähnlichkeit des heiligen Bildnisses sein eigenes Herz geschenkt hat: eine Verschwendung, die dem geduldigen Freund Gottes viel zu bestaunen gab [...]

$39[\ldots]$ aufbewahrt in einem kristallinen Tabernakel ist es jedem erlaubt, es zu bestaunen: wunderbare Malerei, ja sogar Erinnerung seiner anderen Wunder: Er hat ein Gedächtnis gestiftet seiner Wunder. // Die kursiven Stellen in den Zitaten der DS stammen aus der Bibel, deren Übersetzungen entnehme ich aus http://www.bibel-verse.de/ oder http:// vulgata.info/index.php?title=Kategorie: Vulgata (Stand April 2021).

$40[\ldots]$ sie ist wunderbar [...] seitens des Malers, der Gott ist; wunderbar seitens der Malerei, die göttliche Form ist; wunderbar seitens der dargestellten Sache, die ganz Göttlichkeit ist. 
Ingegno, conciosiacosaché quelle sieno le dipinture degne di loda e di maraviglia nelle quali si sottointende più che non si dimostra e tuttoché l'arte per se stessa sia grande, l'arguzia nondimeno l'eccede; e cotali è fama che fussero l'opere particolarmente di Timante. ${ }^{41}(D S, 89-90)$

Die seitenlange Aufzählung der verschiedenen Komponenten, die die bewundernswerte Meisterschaft des Malers ausmachen - von der «Frische der Farbgebung» über die richtige Proportionalität bis hin zu den adäquat dargestellten Emotionen -, kulminiert in der Aufmerksamkeit auf die «maraviglie » («l'attenzione nelle maraviglie »).

[...] e insomma quella maniera maravigliosa, in cui la gentilezza de' tratti non ceda alla bizarria de' concetti, la fierezza si accoppi del pari con la dolcezza e l'artificio si congiunga ugualmente con la leggiadria. ${ }^{42}(D S, 94)$

Erneut werden die « concetti » über das Handwerk gestellt, die «bizzaria » des Künstlers hervorgehoben.

Vom Maler geht es weiter zum Kunstwerk: Das perfekte Kunstwerk vereint in sich gegenläufige Tendenzen zu einem ausgewogenen Ganzen. Ausdruck par excellence dieses umfassenden Gemäldes ist die Schöpfung:

[...] è stato sempre solito Iddio di dipingere, e [...] ha nella creazione dell'Universo varie e diverse maraviglie dipinte. ${ }^{43}(D S, 95)$

Chi è che vegga il cinabro della rosa, il minio del garofano, l'incarnato del papavero, il candido del gelsomino, il giallo del girasole, il cilestro della viola, l'azzurro del lin fiorito, e che non ammiri la sapienza e lo stile di quel gran Coloritore? qual labro è che non si stringa? qual ciglio che non s'inarchi? qual fronte che non s'increspi nel rimirar la variabile spoglia di cui si veste il Camaleonte? il pomposo monile che porta al collo la Colomba? o la fiorita ghirlanda che s'intesse della coda il Pavone? qual uomo è tanto stolido, ch'alzando gli occhi alla vaga dipintura che, per l'opposizione del Sole, negli umidi nuvoli forma l'arco baleno, di ceruleo, di purpureo e di verdiccio, stupido non dica: vide arcum et benedic eum qui fecitillum. Valde speciosus est in splendore suo? ${ }^{44}(D S, 96-97)$

41 Der Geist ist es, weshalb die Malereien des Lobes und des Staunens würdig sind, in denen mehr beinhaltet ist, als sie effektiv zeigen, und auch wenn die Kunst an sich gross ist, ist der Scharfsinn noch grösser; das zeigt sich, dem Hörensagen nach, vor allem in den Werken Timantes.

$42[\ldots]$ es ist also diese erstaunliche Art und Weise, in der die Freundlichkeit der Züge nicht der Eigenwilligkeit der Konzepte erliegt, in der die Kühnheit sich paart mit der Sanftheit und das Kunstwerk sich ebenso mit der Anmut verbindet.

$43[\ldots]$ es war immer und für gewöhnlich Gott, der gemalt hat, und [...] er hat bei der Schöpfung des Universums vielfältige und unterschiedliche Wunderwerke gemalt.

44 Wer sieht das Zinnoberrot der Rosen, das Mennigrot der Nelke, das Fleischfarbene des Mohns, das Weiss des Jasmins, das Gelb der Sonnenblume, das Hellblau des Veilchens, 
Die Schöpfung wird in farbigen Bildern beschrieben. Vor ihr kann der Mensch nur Bewunderung und Staunen empfinden: Die Lippen ziehen sich zusammen, die Augenbrauen heben und die Stirn runzelt sich. Das Staunen wird als einzige Reaktion auf das Gesehene präsentiert, zurückgeführt auf die Fantasie und Schöpfungslust des deus artifex. Im Gegensatz zu Murtola, der in seinem Werk die Schöpfung in ihrer natürlichen Gegebenheit als Wunder verehrt, macht Marino sie zu einem riesigen Gemälde, entstanden aus der fantasievollen Künstlerhand Gottes.

So ist denn auch der Mensch als «vollkommenstes Werk und wunderschönes Bild Gottes» ein Kunstwerk, ein «höchstes Kunstwerk» (DS, 234). Der Mensch stellt als Abbild Gottes den Kulminationspunkt der Schöpfung dar.

Somma e compimento di tutte l'altre sue fatture, epitome ed epilogo del maggior mondo, arbore alla rovescia che ha le radici nel Cielo, animale mansueto, legame fra l'intelligenza ed i corpi, compagno degli Angioli, Vicario e Luogotenente di Dio, anzi Vicedio in terra, vivo teatro delle divine maraviglie; di forze debole, d'aspetto umile, di statura picciolo, ma d'animo vasto, di mente eccelsa, di spirito potente; oracolo degli oracoli, miracolo de' miracoli. Così conchiude quel grande tre volte massimo: Magnum miraculum est homo $[\ldots]^{45}(D S, 107)$

Das weltliche Leben der Menschen ist ein Schauspiel aus göttlicher Hand, ein «vivo teatro delle divine meraviglie ». Dabei ragt insbesondere der menschliche Geist - mit Wurzeln im Himmel - als « miracolo de' miracoli » heraus. ${ }^{46}$

das Azurblau des blühenden Leinens und bewundert nicht die Weisheit und den Stil des grossen Malers? Welche Lippen, die sich nicht zusammenpressen? Welche Augenbraue, die sich nicht hochzieht? Welche Stirn, die sich nicht kräuselt beim Bestaunen der unterschiedlichen Gewänder, mit denen sich das Chamäleon kleidet? Des prunkvollen Halsbandes der Taube? Oder der geblümten Girlande, die sich mit dem Schwanz des Pfaus verwebt? Welcher Mensch ist derart töricht, dass er nicht erstaunt ausruft, wenn er die Augen zum anmutigen Bild erhebt, das als Gegenstück zur Sonne in den wässrigen Wolken einen Regenbogen formt, aus himmelblau, purpur und grün: Siehe den Regenbogen an und preise den, welcher ihn gemacht hat; gar prachtvoll ist er in seinem Glanze.

45 Summe und Vollendung all seiner Werke, Inbegriff und Epilog der höheren Welt, umgekehrter Baum, der seine Wurzeln im Himmel hat, zahmes Tier, Verbindung zwischen Intellekt und Körper, Gefährte der Engel, Vikar und Statthalter Gottes, ja VizeGott auf Erden, lebendiges Theater der göttlichen Wunderwerke; von schwacher Kraft, bescheidenem Anblick, von kleiner Statur, aber weiter Seele, von auserwähltem Verstand, von mächtigem Geist; Orakel der Orakel, Wunder der Wunder. So schliesst dieser Grosse und dreifach Höchste:Der Mensch ist ein grosses Wunder [...] // Im zweiten Teil der Dicerie, der der Musik gewidmet ist, wird der Mensch als perfekter Mikrokosmos beschrieben, der alle Elemente des Makrokosmos in perfektionierter Form abbildet (DS, 234).

46 Analog zum menschlichen Geist, der von bescheidener körperlicher Hülle bedeckt ist, ist auch das Grabtuch ein «grobes Tuch », dessen wertvolles Inneres nicht unmittelbar sichtbar ist $(D S, 139)$. 
Dieser Geist ist dem göttlichen nachgebildet, denn so wie Gott in seinem Geist («mente») die ganze Welt einschliesst, umfasst der Mensch mit seiner Imagination die Welt und alle Dinge $(D S, 116)$.

Analog zu Petrarca in seinem Brief über die Besteigung des Mont Ventoux fordert Marino die Zuhörer auf, nicht das Äusserliche - die Sterne oder das Meer - zu bewundern, sondern den «portico stupendo » in ihr Inneres zu passieren und die Grenzenlosigkeit des Geistes zu bestaunen. Der Leser wird eingeladen, die «divina architettura » des Geistes, voller «artifici » und «meraviglie », zu betreten und zu erkunden:

Entra entra, o uomo, ne' penetrali di questo portico stupendo [verso la parte interiore dell'uomo], spazia entro i recessi di questo bel teatro, considera le prospettive, gli artifici e le maraviglie di questa divina architettura, se vuoi stupire. Dimmi, e di che ti maravigli? dell'altezza delle stelle o della profondità del mare? Maravigliati dell'abbisso dell'anima tua, che non ha meta né fondo. Che cosa miri, o anima? Miri forse la terra? Tu sei più bella della terra, perché hai il carattere e la similitudine di Dio. Miri il Sole? Tu sei più lucida del Sole, perché hai un intelletto luminoso ch'arriva al conoscimento di Dio. Miri il Cielo? Tu sei più alta del cielo, perché hai da calcare gl'istessi Cieli, i quali sol per te furono fabricati da Dio. ${ }^{47}(D S, 120-121)$

Die Häufung der Staunensbegriffe manifestiert die Zusammengehörigkeit von « anima », «stupore » und «maraviglia ». Der menschliche Geist überragt das Meer, die Sterne, die Erde, die Sonne und den Himmel dank seiner Ähnlichkeit mit Gott. Der „leuchtende Intellekt“ ist zum einen Kunstwerk Gottes, zum anderen ist er der Ort, für den die Kunstwerke Gottes hergestellt werden.

Im Geist kulminiert die sinnliche Wahrnehmung, wie dies im zweiten Teil der Dicerie, der der Musik gewidmet ist, dargelegt wird. Unter anderem wird dort zwischen Ton («suono») und Harmonie («armonia») unterschieden: Während der Ton nur das Ohr erreicht, beglückt die Harmonie den Geist mit dem Ausdruck der « concetti» - wenn beides passend zusammenkommt, wie bei Pan beispielsweise, entsteht « erstaunliche Musik» («musica

47 Komm herein, komm herein, oh Mensch, in das Innerste dieser erstaunlichen Arkaden, breite dich aus in den Winkeln dieses schönen Theaters, nimm die Perspektiven zur Kenntnis, die Kunstwerke und Wunder dieser göttlichen Architektur, wenn du staunen willst. Und sag mir, worüber staunst du? Über die Höhe der Sterne oder die Tiefe der Meere? Staune über die Tiefen deiner Seele, die weder Ziel noch Boden hat. Worüber staunst du, oh Seele? Staunst du etwa über die Erde? Du bist schöner als Erde, denn du hast den Charakter und die Ähnlichkeit Gottes. Staunst du über die Sonne? Du leuchtest stärker als die Sonne, weil du einen strahlenden Intellekt hast, der bis zur Erkenntnis Gottes gelangt. Staunst du über den Himmel? Du bist höher als der Himmel, weil du auf diese Himmel trittst, die von Gott für dich gemacht wurden. 
maravigliosa », $D S, 260$ ). Einer hedonistischen, rein sinnlichen Ästhetik, wie sie Marino gerne nachgesagt wird, läuft dieser Fokus auf die « concetti », ja insgesamt die religiös-humanistische Konzeption von Kunst entgegen.

Neben dem Menschen, der als Höhepunkt der Schöpfung ein Abbild Gottes darstellt, zählt auch das Wort - «il Verbo » - zu den göttlichen „ritratti“:

Ritratto di Dio senza paragone alcuno più raro e più singolare è dunque il Verbo. ${ }^{48}(D S, 135)$

Das Wort stand am Anfang, aus ihm ist alles - auch der menschliche Geist hervorgegangen $(D S, 135)$. Das Wort ist « unerschaffen » (« increato ), « übernatürlich» («sopranaturale») und «unsichtbar» («invisibile»). Bevor Gott die Welt geschaffen hat, «hat er nichts anderes getan, als dieses Bild [des Wortes] zu malen », $(D S, 135)$.

[...] egli, per entro la grossa bozza di quella informe mescolanza d'abissi e di quella indistinta e confusa massa che Caos s'appellava, vagheggiando se stesso dentro lo specchio limpidissimo della propria essenza, [...]; venne eternamente col pennello dell'intelletto suo produttivo e fecondo a ritrarre se medesimo, anzi $[\ldots]$ a medesimarsi ed a formare [...] un altro sé; e questi fu il Verbo eterno. ${ }^{49}$ $(D S, 136-137)$

Elementi e cieli, stelle e Sole, corpi ed anime, uomini ed Angioli, cose belle (chi ne dubita?) imagini tutte stupende, ma imagini e cose le quali non prescrivono il divino potere, non ristringono il divino sapere, onde Iddio (questo è certo) ancora molto piú belle saprebbe e potrebbe farle [...] [...] E mentre ne giva componendo il modello, come se opera cosí maravigliosa fusse una burla, altro non faceva che scherzare e giuocare: ludens in orbe terrarum. Allo incontro poi nel ritratto del Verbo eterno applicò questo eterno effigiatore tutto il suo ingegno, tutto il suo studio $[\ldots]^{50}(D S, 141-142)$

48 Das seltenste und einzigartigste Bildnis Gottes ohne jeglichen Vergleich ist also das Wort.

$49[\ldots]$ er, der durch den grossen Entwurf dieser formlosen Mischung aus Abgründen und dieser undefinierten und verworrenen Masse, die sich Chaos nannte, sich ersehnend im reinsten Spiegel der eigenen Essenz, [...]; mit dem produktiven und fruchtbaren Pinsel seines Intellekts begann er zeitlos, sich selbst zu porträtieren, ja sogar [...] sich selbst nachzubilden und ein [...] anderes Selbst zu formen; und das war das ewige Wort.

$5^{\circ}$ Elemente und Himmel, Sonne und Sterne, Körper und Seelen, Menschen und Engel, schöne Dinge (wer zweifelt daran?), alles erstaunliche Bilder, aber keine Dinge und Bilder, die die göttliche Macht vorschreiben oder die göttliche Weisheit beschränken, denn Gott (das ist sicher) wüsste und könnte sie noch viel schöner machen [...] [...] Und während er umhergeht und das Modell formt, als wäre ein solch erstaunliches Werk ein Jux, machte er nichts anderes als zu scherzen und zu spielen: er spielte auf seinem Erdboden. Mit der Begegnung im Abbild des ewigen Wortes hat dieser unvergängliche Maler sein ganzes Genie, sein ganzes Studium angewandt $[\ldots]$ 
Während die Schöpfung lediglich eine lustvolle und spielerische Fingerübung ist - aus der notabene zahlreiche «maraviglie » und «imagini [...] stupende » resultierten -, so wohnt nur dem Wort die ganze Potenz Gottes inne $(D S$, 141143). Die Welt ist eine vieler möglicher Welten, in Gott und im Wort aber sind alle Möglichkeiten enthalten.

Il Padre [...] dipinge se stesso, il Verbo generando: e tu né piú né meno dipignesti ancora, lasciando la propria imagine impressa in questa sacra tela $[\ldots]^{51}(D S, 150)$

Das Wort als ursprünglichstes Abbild Gottes findet seine Inkarnation in Jesus, ${ }^{52}$ wobei die Taten Jesu in der Passionsgeschichte kulminieren und Himmel und Erde in Staunen versetzen:

[...] essendo state tutte l'operazioni sue indiritte a questo fine solo dalla passione sua e redenzione nostra, può ragionevolmente dirsi, che tutte l'azzioni della sua vita siano state un atto solo, un'opera sola, e quest'opera è tale che fa maravigliare non pur la terra ma il Cielo: aspicite in gentibus et videte admiramini et obstupescite quia opus factum est in diebus vestris quod nemo credet cum narrabitur..$^{53}$ $(D S, 155)$

Die Philosophen mögen über die Gegebenheiten der Natur und des Menschen staunen, die christliche Passion aber - wunderbar und ausserordentlich stellt das weltliche Staunen in den Schatten. Die Kreuzigung Jesu übersteigt das menschlich-intellektuelle Fassungsvermögen, kann einzig bestaunt und bewundert werden:

[...] il figliuol di Dio viene a patire, a morire: qui non giunge l'umana filosofia, l'intelletto s'abbaglia, il discorso si perde, la ragione vien meno, la curiosità riman confusa; dottrina, che simpara solo nella Catedra della Croce. [...] nuovo portento io ti propongo, maraviglia non più veduta, mistero inaudito, prodigio mirabile, paradosso incredibile, dissonanza sonora: gloria ed ignominia, beatitudine e passione, divinità e croce, immortalità e morte. [...] qual sottilità d'ingegno penetrò mai un tal secreto? [...] Audite et opstupescite et admiramini. [...] Effetti

$5^{1} \quad$ Der Vater [...] malt sich selber und kreiert das Wort; und du würdest nicht mehr und nicht weniger malen, wenn du dein eigenes Abbild in dieses heilige Tuch einprägst [...]

52 Jesus wird als « inkarniertes Wort» («Verbo incarnato ») bezeichnet $(D S, 184)$.

$53[\ldots]$ da alle seine Handlungen auf dieses Ziel ausgerichtet waren, hervorgegangen aus seiner Leidenschaft und zu unserer Erlösung, kann besonnenerweise gesagt werden, dass alle Handlungen seines Lebens ein einziger Akt waren, ein einziges Werk, und dieses Werk hat nicht nur die Erde, sondern auch den Himmel zum Staunen gebracht: Schaut hinunter die Völker, seht und verwundert euch! Denn ich will etwas tun zu euren Zeiten, was ihr nicht glauben werdet, wenn man davon sagen wird. 
tutti alla nostra capacità impossibili, ma agevoli alla divina Sapienza $[. . .]^{54}$ $(D S, 305)$

Die Passionsgeschichte ist einzigartig («non più veduta », « inudito »), ein Rätsel und Wunder - zusätzlich gesteigert im Pleonasmus « prodigio mirabile »-, ein kaum zu fassendes Paradox. Letzteres wird unmittelbar sprachlich vorgeführt im Oxymoron der „wohlklingenden Dissonanz“ («dissonanza sonora»). Christus' Worte und Taten können nicht rational gedeutet, sondern müssen als Kunst aufgefasst werden. Entsprechend wird im zweiten Teil ${ }^{55}$ der Dicerie die Kreuzigung musikalisch ${ }^{56}$ interpretiert: Das Kreuz als « ein harmonisches und gut gestimmtes Instrument » $(D S, 209)$, Christus' letzte Worte als Gesang. Um diese neue Darstellung von Christus als Sänger zu bekräftigen, werden mythologische Bilder und Vergleiche aufgerufen. Und wer anders als Orpheus käme hier infrage?

Chi dirà che Cristo auttore della nostra amorosa musica non sia egli il vero Orfeo? Orfeo desviò col suo canto il corso de' fiumi, facendogli mirabilmente tornare indietro verso le prime foci loro: e Cristo converte Pietro dal suo sinistro camino $[. .$.$] Orfeo con la forza del suo plettro tirava le fiere selvaggie: e Cristo con$ la virtù della sua croce tira a sé non pur gli altri peccatori, ma i crocifissori istessi, animi più che ferini $[\ldots]^{57}\left(D S, 3^{27}-328\right)$

$54[\ldots]$ der Sohn Gottes kommt, um zu leiden und zu sterben: bis dahin reicht die menschliche Philosophie nicht, der Intellekt ist geblendet, der Diskurs verliert sich, die Vernunft wird weniger, die Neugier bleibt verwirrt; eine Doktorin, die nur am Lehrstuhl des Kreuzes erlernt wird. [...] ein neues Wunder schlage ich dir vor, ein Wunderwerk, das so nicht mehr gesehen ward, unerhörtes Geheiminis, unglaubliches Paradox, wohlklingende Dissonanz: Ruhm und Schmach, Glückseligkeit und Leidenschaft, Göttlichkeit und Kreuz, Unsterblichkeit und Tod. [...] welche Subtilität des Geistes hat je ein derartiges Geheimnis durchdrungen? [...] Hört und erstarrt und staunt. [...] Wirkungen, die ausserhalb unserer Fähigkeiten liegen und für uns unmöglich, aber für die göttliche Weisheit mühelos sind.

55 La Musica. Diceria seconda sopra le sette parole dette da Cristo in croce (DS, 209-374).

56 Musik beinhaltet für Marino immer auch die parola im Sinne des immateriellen Parts des concetto.

57 Wer sagt, dass nicht Christus Autor unserer Liebesmusik, der wahre Orpheus sei? Orpheus hat mit seinem Gesang den Gang der Flüsse verändert, indem er sie auf erstaunliche Weise hat rückwärts fliessen lassen, zurück zu ihren Mündungen; und Christus hat Petrus von seinem falschen Weg abgebracht [...] Orpheus hat mit der Kraft seines Plektrons die wilden Tiere angezogen: Und Christus hat mit der Kraft seines Kreuzes nicht nur die anderen Sünder an sich gezogen, sondern selbst jene, die ihn gekreuzigt hatten, bestialische Seelen $[\ldots]$ 
Die Kraft zur Konversion ist sowohl den Worten des Orpheus als auch jenen von Christus eigen. Durch die Gleichsetzung mit Orpheus wird Christus' Worten poetischer Charakter verliehen, doch während Orpheus' Qualitäten auf seinem «canto» und seinem «plettro» beruhen, kommen Christus zusätzlich die moralischen Eigenschaften der « virtù » und der « bontà » zu:

E questa non so s'io mi dica orazione o musica fu di tanta forza, che non altra cosa [...] diede alla conversione del Ladrone spinta; il qual [...], stupido ed attonito a bontà così insolita, straordinaria e sopranaturale $[\ldots]$ subito ne tira la divinità in conseguenza, e muovesi a chiedergli parte nel suo reame, onde gli è risposto: Hodie mecum eris in paradiso. ${ }^{58}(D S, 340-341)$

Qual maraviglia dunque se tra' ladroni conversi, e se all'un de' due con detti così cortesi ti volgi?59 $(D S, 342)$

Zusätzlich poetisch konnotiert werden Christus' Worte in einem weiteren Vergleich, wobei hier die barockpoetologische Qualität der arguzia ins Spiel kommt. Mit dem Vergleich demonstriert der Autor seine eigene arguzia, was er mit dem Ausruf «Oh welch erstaunliche Übereinstimmung» («Oh che stupenda conformità!», $D S, 338$ ) selbst bekräftigt.

Quando il Cigno conosce d'essere arrivato al termine della vita, dicono che si ferma sopra il margine d'una sponda, e quivi, dopo l'aver fatto certo circolo con l'ali, postosi nel mezo, incomincia a sciogliere l'arguzia del suo canto. [...]

Mentre il Cigno canta tutti gli altri uccelli ascoltatori [...] pieni di maraviglia e d'ammirazione ammutiscono. ${ }^{60}(D S, 337-338)$

$5^{8}$ Und diese, ich weiss nicht, ob ich sie als Gebet oder als Musik bezeichnen soll, war von solcher Kraft, denn nichts anderes [...] hat zur Konversion des Diebes den Anstoss gegeben; dieser [...], dumm und verblüfft über solch ungewöhnliche Güte; sofort zieht ihn die Göttlichkeit an sich, ausserordentlich und übernatürlich [...], und bewegt sich, um ihn in ihr Reich aufzunehmen, wo ihm geantwortet wird: Heute wirst du mit mir im Paradies sein.

59 Welch Wunder also, wenn unter den konvertierten Dieben du dich an einen der beiden mit derart freundlichen Worten wendest?

6o Wenn der Schwan spürt, dass er am Ende seines Lebens angelangt ist, lässt er sich - so sagt man - am Ufer nieder, und dort beginnt er, nachdem er mit seinen Flügeln einige Kreise gezogen und sich in die Mitte gesetzt hat, mit seinem scharfsinnigen Gesang. [...] / Während der Schwan singt, verstummen alle anderen Vögel, die seine Zuhörer sind, [...] voller Staunen und Bewunderung. 
Der Todesgesang der Schwäne entspricht den letzten Worten von Christus am Kreuz: ${ }^{61}$ Er erstaunt die Zuhörer und bringt sie vor Bewunderung zum Schweigen.

Dass das Schweigen schliesslich der Raum ist, in dem «maraviglia» und «stupore» ihre volle Entfaltung finden, zeigt sich in den abschliessenden Worten der ersten Diceria - bezogen auf die Santa Sindone:

Ora per non offuscare in parte, col rozzo pennello della mia lingua imperfetta e con gli oscuri colori del mio dir basso, le bellezze di questa non mai appieno lodata imagine, le quali assai meglio che con istile facondo si possono esprimere con modesto e pietoso silenzio, voglio più tosto tacere: e passando con una profonda meditazione dalla loda alla maraviglia e dalla loquacità allo stupore, chiudere il giro de la mia lunga parlata con quella sentenza auttorevole: A Domino factum est istud et est mirabile in oculis nostris. ${ }^{62}(D S, 201)$

Zusammenfassend lässt sich sagen: Marino fasst Gott und Jesus als Künstler, ihre Werke als Kunstwerke. Als Künstler verfügen sie über einen ausserordentlichen ingegno sowie arguzia und dank diesen Eigenschaften vermögen ihre Werke die Zuschauer bzw. Zuhörer in ihrem Innersten zu berühren. Diese „Berührung“ zeigt sich im Ausdruck des Staunens und verfügt über die Kraft der Konversion. Das religiöse Staunen über die Wunder Gottes und Jesu wird in ein ästhetisches Staunen transformiert. Die Metapher im ersten Teil der Dicerie wird die Schöpfung als Kunst, im zweiten Teil die Passion als Gesang gefasst - wird aufgebrochen, ja sogar umgekehrt, wenn die Qualitäten, über die Gott und Jesus verfügen, auf den weltlichen Maler und Sänger übertragen werden. Der Künstler und das Kunstwerk sind nicht mehr Metaphern für Gott und Jesus sowie deren Werke, sondern Gott und Jesus werden zu Metaphern des Künstlers und des Kunstwerkes: Wir befinden uns in einem originellen Spiel mit der Metapher, das seinerseits alle Qualitäten

61 Marino führt die Gleichsetzung auf ein Zitat Horaz’ zurück, das die Flügel der Schwäne als purpurfarben bezeichnet: «Ich sehe nicht, welchen Schwan man als purpurfarben bezeichnen könnte, wenn nicht Christus. Weiss, ja, aufgrund der unbefleckten Reinheit seiner Unschuld, aber purpurfarben von seinem leuchtend roten Blut » $(D S, 336)$. Siehe dazu den Kommentar von Pozzi, ebenfalls auf S. 336.

62 Um die Schönheiten dieses nie genug gelobten Bildnisses, die sich viel besser als mit einem wortgewandten Stil mit einem bescheidenen und demütigen Schweigen ausdrücken lassen, nicht zu trüben mit dem groben Pinsel meiner unvollendeten Sprache und den düsteren Farben meines bescheidenen Sprechens, möchte ich viel eher schweigen: und mit einer tiefgründigen Meditation vom Lob zur Verwunderung übergehen und von der Gesprächigkeit zum Staunen, den Kurs meines langen Sprechens mit dieser einflussreichen Sentenz beenden: Das ist vom Herrn geschehen, und ist ein Wunder vor unsern Augen. 
des Staunens beinhaltet, wie wir sie aus den Briefen herausgearbeitet haben: novità, stravaganza, vivezza, spiritosità und fantasia sowie libertà.

\subsection{La Galeria}

Nie zuvor seit der Antike sind sich Dichtung und Kunst, Poetik und Kunsttheorie so nahe gekommen wie in Giambattista Marinos Galeria (1619). [...] In dichterischer Form entfaltet die Galeria eine Poetik, die in lyrischer Form die zentralen Konzepte des Barock artikuliert, und zwar bevor sie in den Theoriegebäuden der zeitgenössischen Dichtungstheorie ausgeführt werden. ${ }^{63}$

Während in den Dicerie sacre die formalen und inhaltlichen Qualitäten von Bild, Klang und Wort in einem christlichen Kontext erläutert werden, stehen die Wort- und die Bildkunst sowie deren Wirkung in der Galeria im Mittelpunkt. In 624 Gedichten werden Gemälde und Skulpturen literarisch dargestellt, wobei die Gruppe zu den Gemälden gegliedert ist in «1. mythologische und 2. biblische Themen bzw. Heiligengeschichten, 3. eine umfangreiche Porträtgalerie und 4. eine kleine Reihe von Capricci ».64 Sie ist sehr viel umfangreicher als die Gruppe der Skulpturen. Letztere gliedert sich in die drei Teilbereiche Statuen, Reliefs und erneut wenige Capricci.

Die Galeria ging aus einem Projekt hervor, das Marino «rund zwei Jahrzehnte vorbereitet hatte ${ }^{65} \mathrm{Er}$ plante, sich eine eigene Gemälde- und Skulpturensammlung - eine "Galeria“ - anzulegen, wobei er sich sowohl für den Kauf bereits bestehender Kunstwerke als auch für neue, eigens für die Galeria geschaffene Gemälde interessierte. So bat er beispielsweise Ludovico Carracci, seine Salmace für ihn aufzubewahren:

[...] io avevo pensato di rapir la Salmace di V. S. e condurla con esso meco, ché non è preda da confidare in altre mani, né da esporre ai casi di fortuna per via di mulattieri. [...] Poiché io ho aspettato tanto tempo reprimendo il desiderio, che n'aveva con la speranza di possederla, piaccia a V. S. d'aspettare questo poco d'intervallo infino al sudetto mio passaggio e di guardarla intanto cautamente, accioché ella non faccia qualche altra nuova tansformazione, perché so che le

63 Christiane Kruse und Rainer Stillers, Nachwort, in: Giambattista Marino, La Galeria, zweisprachige Auswahl (Italienisch/Deutsch), ausgewählt und übersetzt von Christiane Kruse und Rainer Stillers unter Mitarbeit von Christine Ott, Mainz 20o9, S. 387. Die Übersetzungen der Gedichte aus La Galeria stammen, wenn nicht anders vermerkt, aus dieser Ausgabe. Die Übersetzungen aus den Briefen stammen, wie bereits in den vorangegangenen Unterkapiteln, von der Autorin (A.E.).

64 Kruse / Stillers, Nachwort, S. 400.

65 Ebd., S. 399. 
sue pitture hanno forza di cangiare gli uomini in istatue per la maraviglia che dànno altrui. ${ }^{66}$

Besondere Vorsicht sei deshalb geboten, weil die Bilder Caraccis analog zur Medusa die Kraft hätten, ihre Betrachter in Staunen zu versetzen und dadurch in Statuen zu verwandeln.

Wenn Marino Künstler anschrieb mit der Bitte, ein Bild zu schaffen und es ihm für seine Galerie zukommen zu lassen, nannte er ihnen meist eine bestimmte Idee - «irgendeine kleine antike Geschichte ${ }^{67}-$, zu der er sich ein Bild wünschte. ${ }^{68}$ Von Bernardo Castello erbat er sich ein Bild und überliess Inhalt und Gestaltung ganz dessen Gutdünken:

Pure quando volesse degnarmi di tanto [di un'opera della sua mano], rimetterei in tutto e per tutto le condizioni al suo arbitrio ed alla sua cortesia: o profana o sacra, pur che sia fantasia di suo capriccio, me ne riputerò fortunatissimo, assicurandola che sarà non meno da me e dal mio stile, ancorché indegno, celebrata che ammirata da tutta Roma [...] Per ora non ho tempo di diffundermi troppo, e perciò resto baciandole affettuosamente quella mano facitrice di maraviglie. ${ }^{69}$

Ob der Inhalt profan oder religiös sei, spielt für Marino keine Rolle; wichtig ist ihm, dass das Bild aus Castellos origineller Fantasie resultiert. ${ }^{70}$ Dank dieser nämlich ist seine Hand « facitrice di maraviglie ».

$66[\ldots]$ ich hatte daran gedacht, die Salmace von Ihnen zu stehlen und sie mir zuzuführen, denn sie ist keine Beute, die anderen Händen anvertraut werden sollte, ebensowenig sollte sie über die Saumpfade dem Schicksal überlassen werden. [...] Denn ich habe so lange gewartet und den Wunsch unterdrückt, den ich hegte mit der Hoffnung, sie zu besitzen, dass es Ihnen vielleicht gefallen möge, die kurze Zeit bis zu meinem Vorbeikommen abzuwarten und sie umsichtig zu behüten, sodass sie keine weitere Veränderung durchmacht, denn ich weiss, dass ihre Gemälde die Kraft haben, Menschen in Statuen zu verwandeln wegen des Staunens, das sie in ihnen auslösen. // MARINo, Lettera n. 41 a Ludovico Caracci, S. 64.

67 Marino, Lettera n. 40 a Ludovico Caracci, S. 62.

68 Vgl. dazu beispielsweise MARINo, Lettera n. 6o a Bernardo Castello, S. 113.

69 Auch wenn Sie mich mit etwas derart Grossem würdigen möchten, überlasse ich alles den Bedingungen Ihres Gutdünkens und Ihrer Gefälligkeit: Ob profan oder heilig, es soll einfach voll Ihrer extravaganten Fantasie sein, und ich werde mich als überglücklich bezeichnen, und Ihnen versichern, dass es nicht weniger von mir und meinem Stil, wenngleich unwürdig, in ganz Rom gefeiert und bewundert werden wird [...] Im Moment habe ich keine Zeit, um ich weiter auszulassen, und so verbleibe ich Ihnen innig jene Hand küssend, die solche Wunder schafft. // MARıno, Lettera n. 21 a Bernardo Castello, S. 36.

70 Die Bedeutung von „capriccio“ lautet « espressione artistica estrosa, ricca di fantasia; invenzione, trovata bizzarra: capricci dell'architettura barocca». Siehe http://www. garzantilinguistica.it/ricerca/?q=capriccio (Stand April 2021). 
Dem «Plan eines privaten Museums [...] stellte er ein imaginäres gegenüber ${ }^{71}$ Ursprünglich war geplant, jedem Text einen «Holzschnitt oder Stich » voranzustellen - Vorbilder fand er in Philostrats Eikones sowie in der von Bernardo Castello illustrierten Ausgabe der Gerusalemme Liberata. ${ }^{72}$ Da sein Vorhaben finanziell und auch vom Umfang her schwierig, ja fast unmöglich war, konzipierte er die Galeria als imaginär-literarische «Idealgalerie ».73

Der Grossteil der Bilder, von denen in der Galeria die Rede ist, haben nie existiert, und bei denen, die existiert haben, ist der Bezug des literarischen zum realen Bild nur schwer eruierbar. ${ }^{74}$

Die Gedichte auf eindeutig zuschreibbare Werke verraten nämlich keinerlei Intention des Dichters, das jeweilige Werk im Sinne der enargeia (evidentia) einer Ekphrasis dem Leser vor Augen zu stellen. Das Kunstwerk, mehr noch das Bildthema ist Marino vor allem ein Impulsgeber für die eigene dichterische Transformation mit der Intention, die Bildqualität, vor allem die Bildwirkung in die lyrische Sprache und Form zu bringen. ${ }^{75}$

Was wir in den Gedichten der Galeria vorfinden, sind keine Bildbeschreibungen - keine Ekphrasen -, sondern einerseits die affektive, andererseits die reflektierende Bild- bzw. Skulpturwahrnehmung des betrachtenden Ichs. Der Dichter versucht, über das lyrische Ich das (Sprach-)Bild und dessen Wirkung für die Leser erlebbar zu machen, wobei die «sprachliche Intensität » mit der «Wirkungsästhetik barocker Bildkunst [wetteifert] ». ${ }^{76}$ Der Leser soll als «Zeuge[] der Kunstbetrachtung » nicht zwingend dasselbe sehen wie das lyrische Ich, sondern über die Sprache dasselbe erleben. ${ }^{77}$

Wiederkehrendes Motiv der Galeria ist die Gegenüberstellung von Kunst und Natur, wobei insbesondere das Vermögen der Kunst, das Dargestellte zu verlebendigen, hervorgehoben wird. Einen Höhepunkt bildlich lebendiger Darstellung ist die Madalena di Titiano, denn durch das Bild werden nicht nur Anblick, Stimme, Gesten, sondern auch Gedanken und Gefühle wahrnehmbar:

\footnotetext{
71 Kruse / Stille Rs, Nachwort, S. 399.

72 Ebd., S. 400.

73 Ebd., S. 401. „Ideal“ in Bezug auf den Autor, „ideal“ aber auch in Bezug auf die typischen Ausprägungen des Frühbarocks.

74 Ebd., S. 405-406.

75 Ebd.

76 Ebd., S. 407.

77 Ebd.
} 
[37b.]

MADAlENA Di Titiano.

VI.

Oh come bella ala solinga grotta,

Pouerella romita, entro ti stai!

Oh come chiara, oue più quiui annotta,

L'ombra rallumi co' celesti rai!

Oh come dolce in flebil voce e rotta

A ragionar col sommo Amor ti stai!

Sì viui espressi son gli atti, e i lamenti,

Ch'io vi scorgo i pensier', n'odo gli accenti.

XIV.

Ma ceda la Natura, e ceda il vero

A quel che dotto artefice ne finse,

Che qual l'hauea nel'alma e nel pensiero,

Tal bella e viua ancor qui la dipinse.

Oh celeste sembianza, oh magistero,

Oue nel'opra sua sé stesso ei vinse!

Pregio eterno de' lini, e dele carte,

Merauiglia del mondo, honor del'Arte. ${ }^{78}(G A, 93-96)$

Mit zahlreichen staunenden « $\mathrm{Oh} »-A u s r u f e n$ wird auf den Höhe- und Schlusspunkt des Gedichts hingeführt: Die Kunst Tizians übertrifft die Realität, sie ist «merauiglia del mondo ». Interessant ist, dass dieser Höhepunkt sowohl aus den Vorzügen der «lini» als auch aus jenen der «carte» resultiert: Bild und Sprache bedingen sich gegenseitig, um eine derart überragende Wirkung herbeizuführen.

Im folgenden Gedicht wird die Natur selbst zur erstaunten Betrachterin der Abbildung ihrer selbst: So wie Narziss sein Spiegelbild im Wasser bewundert, bestaunt die Natur ihr täuschend echtes Abbild im Kunstwerk.

${ }_{78}$ Ich zitiere aus folgender Ausgabe mit der Abkürzung $G A$ : Giambattista Marino, La Galeria, a cura di Marzio Pieri e Alessandra Ruffino, Lavis 2005. Die Übersetzungen stammen wie erwähnt aus der Ausgabe von KrUSE / StILLERs: « Magdalena von Tizian // VI. Oh wie schöne, arme Einsiedlerin, / wohnst du in der einsamen Grotte! / Oh wie hell, je dunkler hier die Nacht wird, / erleuchtest du den Schatten mit den himmlischen Strahlen! / Oh wie süß und mit schwacher, gebrochener Stimme / spricht du mit der höchsten Liebe! / So lebendig sind die Gesten und die Seufzer dargestellt, / dass ich darin die Gedanken erkenne und die Worte höre. // XIV. Doch es weiche die Natur und es weiche das Wirkliche, / dem, was für uns ein gelehrter Künstler erfand, / der, so wie er sie in der Seele und im Geist hatte, / so schön und lebendig auch hier malte. / Oh himmlisches Ebendbild, oh Meisterschaft, / mit der er in seinem Werk sich selbst übertraf, / ewiger Ruhm des Leinens und des Papiers, / Weltwunder, Ehre der Kunst. » 
[7b.]

Narciso di Francesco Maria

VANNI.

Quel Narciso, che stanco ed assetato

Su'l fonte a vagheggiar sé stesso alletta,

E del'arco d'Amor segno e saëtta

È ferito, e ferisce, amante amato;

Dal tuo diuin pennel, VANNI, animato

Par le parole ad hor'ad hor prometta;

E la fauella libera e perfetta,

Ch'ala lingua negasti, agli occhi hai dato.

Nel lino, onde l'imagine è contesta,

Sé stessa intenta e stupida Natura

Qual Tigre in specchio, a rimirar s'arresta.

Tal che fa doppio inganno una figura,

E delude, e schernisce e quello, e questa;

L'un la fontana, e l'altra la pittura. ${ }^{79}(G A, 14)$

Die täuschende Spiegelung, das Kernmotiv des Mythos und des Gedichts, wird in der ersten Strophe sprachspielerisch eingeführt. Sie bahnt sich an in Wortpaaren wie «stanco [...] stesso », « assetato [...] alletta» sowie «segno [...] saëtta» und kulminiert in der vierten Zeile mit «ferito [...] ferisce» und «amante amato». Der Aktive ist zugleich passiv und umgekehrt. Die Animierung der Worte, von der in der zweiten Strophe die Rede ist, wird damit nicht nur vom Bild Vannis geleistet, sondern spiegelt sich von Beginn an in der Sprachgestaltung. Sie ist Ausdruck der sprechenden Augen, zu der sich der Topos der Malerei als muta poesis (« la fauella [...] Ch'ala lingua negasti ») transformiert. 80

Die Natur betrachtet sich spiegelbildlich im Gemälde und staunt über sich selbst, wobei sie in der Betrachterrolle das lyrische Ich ablöst. In diese Spiegelung ist eine literarische Spiegelung eingeflochten. Der Vergleich des

79 Narziss von Francesco Maria Vanni // Jener Narziss, den es, müde und durstig, / über der Quelle sich selbst liebevoll zu betrachten verlockt / und der als Ziel und Pfeil von Amors Bogen / verwundet wird und verwundet als geliebter Liebender, // scheint, von deinem göttlichen Pinsel, VANni, belebt, / jetzt gleich reden zu wollen; / und die freie und vollkommene Sprache, / die du der Zuge verweigerst, hast du den Augen geschenkt. // Auf die Leinwand, in die das Bild gewoben ist, / starrt verblüfft die Natur und verharrt, / um sich, wie ein Tiger im Spiegel, selbst zu bewundern. // So bewirkt eine Gestalt eine doppelte Täuschung / und enttäuscht und verhöhnt jenen und diese: / den einen die Quelle, die andere die Malerei.

Pieri / Ruffino, Commento, S. LV. 
Narziss mit dem Tiger ist ein bekannter Topos, unter anderem wird er in den Stanze des Poliziano (I, V. 39) ausgeführt. ${ }^{81}$

Das lyrische Ich betrachtet ab der dritten Strophe nicht mehr das Gemälde, sondern die Natur und deren Reaktion auf das Gemälde. Sein eigenes Staunen, das in der zweiten Strophe implizit anklingt, wird vom expliziten Staunen der Natur abgelöst. Die Täuschung des Narziss durch das Wasser wird auf die Täuschung der Natur durch die Kunst übertragen. Diese originelle Zusammenführung der favola mit der staunenswerten Wirkung des Werkes manifestiert sich in der vierten Strophe in einer « typischen rhetorischen ,meraviglia $»: 82$

[...] sarà facile da constatare che la coppia verbale delude e schernisce ha per soggetto, da un lato una figura (la quale fa doppio inganno e illude e Narciso e la Natura), dall'altro la fontana (che inganna l'un, Narciso) e la pittura (ch'illude l'altra, la Natura). Il tutto in maniera ellittica e labirintica: le acque (la natura) ingannano Narciso; la pittura (dell'ingannato Narciso) inganna la natura; la poesia, mediante una sintassi illusioria, inganna il lettore. ${ }^{83}$

In der Tat ist es nicht die Beschreibung des Bildes von Narziss, das den Leser einnimmt, sondern das concetto der Überlagerung von Mythos und Bildwirkung, die Transformation des mythologischen Kernelementes der Täuschung in eine wirkungsästhetische Pointe.

Auch im folgenden Bildgedicht ist es die Täuschung, die den Betrachter ins Staunen bringt: Handelt es sich um ein Gemälde, eine Skulptur oder um einen natürlichen Gegenstand? Das Spiel der Täuschung lässt das betrachtende Ich erstarren und raubt ihm die Sinne, während es gleichzeitig den Sinn des Bildes konstituiert.

[3०A."]

Nel medesimo SVggetto. [SAN Bastiano di Titiano]

Chi di quest'Idol sacro

Rimira il simulacro,

Dubbio se sia pittura,

O scultura, o fattura

Verace di Natura,

Immobile riman per merauiglia.

Così l'un per il senso, e l'altro il piglia. ${ }^{84}(G A, 83)$

81 Ebd., S. LV.

82 Ebd.

83 Ebd.

84 Der hl. Sebastian von Tizian // Wer von diesem heiligen Idol / das Abbild betrachtet, / im Zweifel, ob es Malerei ist, / oder Skulptur oder wahres / Geschöpf der Natur, / wird reglos vor Staunen. / So verliert der eine den Sinn, und das andere empfängt ihn. 
Die Reime dieses Gedichts sind wiederum sprechend: «sacro / simulacro», «pittura / fattura / Natura» und «merauiglia / piglia». Das Heilige ist neben dem heiligen Sebastian auch das Bild - entsprechend wird es bewundernd betrachtet («rimira»). Analog erscheint die «pittura» als «fattura [della] Natura ». Das Heilige und das Natürliche werden auf das Bild hingeführt und von diesem in der Wirkung der «merauiglia » abgelöst.

Allerdings sind die Bilder Tizians derart stark und lebendig in ihrer Wirkung, dass es kein Wunder (mehr) ist, dass sie zu den Betrachtern sprechen - ein Wunder wäre es, wenn sie das nicht täten. Das Staunenswerte ist somit nicht auf eine bestimmte Art von Wirkung beschränkt, sondern resultiert immer aus dem Ungewöhnlichen und Unerwarteten. ${ }^{85}$

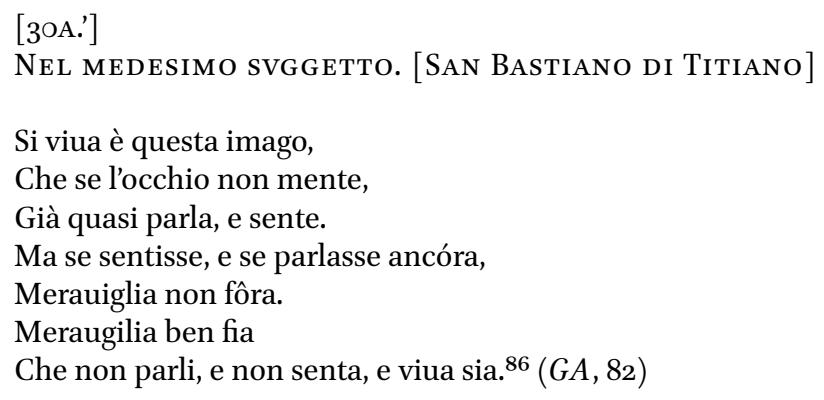

Die bisher erwähnten Gedichte nannten das Staunen im Kontext visueller Wahrnehmung. Staunenswertes begegnet uns jedoch auch in Gedichten, die von der auditiven Wahrnehmung handeln oder Bewegung im Bild

85 Eine ähnliche Umkehrung finden wir auch in folgendem Gedicht: [25A.] / MAdonNA Del Coreggio / Folle chi crede agli occhi! Il veggio il veggio / Vera non è, ma finta, / Viua no, ma dipinta / La Vergin madre, e seco il caro pegno. / Ben nato ingegno, hor con qual'arte il fai? / Quelle, ch'io già pensai / Membra, membra non son, ma son colori, / E quegli atti, e que' moti, ombre, e splendori. / Opra è del gran CORREGGIO, / È finta, il veggio il veggio. (Madonna von Correggio // Wahnsinnig, wer den Augen glaubt! Ich sehe es, ich sehe es, / sie ist nicht wirklich, sie ist vorgetäuscht, / nicht lebendig, sondern gemalt, / die jungfräuliche Mutter, und ihr teures Unterpfand mit ihr. / Wohlgeborener Geist, mit welcher Kunst machst du dies? / Jene, die ich für Glieder hielt, / sind keine Glieder, Farben sind es, / und jene Gebärden, jene Regungen Schatten und Lichter. / Ein Werk des großen CORREg gio ist es: / Es ist vorgetäuscht, ich sehe es, ich sehe es. $G A, 77$ ) // Mit staunenden Ausrufen wird berichtet, dass es sich gar nicht um ein wahres, sondern um ein fiktives Bild handelt.

86 Derhl. Sebastian von Tizian // So lebendig ist dieses Bild, / dass, wenn das Auge nicht lügt, / es schon beinahe redet und fühlt. / Doch, selbst wenn es fühlte und redete, / wäre das kein Wunder. / Ein Wunder wäre es wohl, / wenn es nicht redete und nicht fühlte und lebendig wäre. 
thematisieren. ${ }^{87} \mathrm{Im}$ Gedicht über den heiligen Hieronymus konkurrieren die Geräusche des Bildes miteinander, wobei die dargestellte Handlung - die Selbstkasteiung - in den Hintergrund rückt.

\author{
[22.] \\ SAN Girolamo di LVCA CANGiasi \\ IN CASA DEL MEDESIMO. \\ Oh come espresso al viuo \\ Con le ginocchia a terra il santo Vecchio \\ Nel'antro ombroso, a piè d'un chiaro riuo \\ Si batte il petto, e sospirando a Dïo \\ Del suo graue fallir chiede perdono! \\ Sentirebbe l'orecchio \\ Del sasso i colpi, e dela voce il suono, \\ Se del vicino rïo \\ Non fusse il mormorio. 88 (GA, 74)
}

Die Lebendigkeit des plätschernden Bächleins wird durch die reinen und unreinen Endreime unterstrichen: -iuo, -io und -ono führen auf «mormorio » hin, das sowohl als „Gerede, Gemurmel“ als auch als „Rauschen“ interpretiert werden kann - das Rauschen des Bächleins, das Murmeln des Gedichts. Die auditive Bild- und Sprachwirkung „übertönt“ den Inhalt des Bildes und rückt das religiöse Element - die Busse des heiligen Hieronymus - in den Hintergrund. Während das Ich die Fähigkeit des Malers bestaunt, das Gemalte lebendig erscheinen zu lassen («Oh $[\ldots] »)$, bestaunt der Leser die Fähigkeit des Autors, seine Betrachtung mit einer fantasievollen Pointe abzuschliessen. ${ }^{89}$

Ähnliche Pointen finden wir in Madonna del Correggio und Testa del Salvatore del Correggio, wobei in beiden auf originelle Art und Weise dargelegt wird, weshalb die lebendigen Bilder sich nicht bewegen. Die

$87 \quad$ Auch olfaktorische Eindrücke werden thematisiert.

88 Der heilige Hiernonymus / von Luca Cambiaso / im Haus des Giovan Carlo Doria // Oh wie lebendig dargestellt / schlägt der heilige Greis auf der Erde knieend, / in der schattigen Höhle, am Ufer eines klaren Baches, / an seine Brust, und seufzend bittet er Gott / um Vergebung für seine schwere Schuld! / Die Schläge des Steins und den Laut der Stimme / würde das Ohr vernehmen, / wäre nicht das Murmeln / des nahen Baches.

89 In unzähligen Beispielen wird die Artifizialität des Bildes bzw. der Skulptur von der Lebendigkeit des Dargestellten „übertönt“, so zum Beispiel in der folgenden Skulptur: [7C.] / AMOR, CHE DORME in vNA fontana / [...] Spira, ma'l mormorìo che l'addormenta / Mentr'ei su'l viuo sasso appoggia il fianco, / È cagion ch'ei spira, altri nol' senta. (Amor, der an einem Brunnen schläft // [...] Er atmet, doch das Murmeln, das ihn einschläfert, / da er auf den lebenidgen Stein die Seite stützt, / ist Grund dafür, dass, auch wenn er atmet, man ihn nicht hört. $G A, 375$ ) 
Ursache dafür wird im ersten Gedicht dem dargestellten Inhalt, im zweiten dem Erbarmen und dem Eifer des Künstlers zugeschrieben.

[25.]

Madonna del Correggio.

Finto non è, ma spira

Il diuin pargoletto,

Ch'ala Vergine madre in grembo posa.

Mira i dolci atti, mira

Con qual pietoso affetto

Le ride, e scherza. $E$ ben mouer vedresti

I bei membri celesti

Ma non vuole, o non osa

(Sì lo stringe d'amor tenace laccio)

Ala gran genitrice uscir di braccio. ${ }^{90}(G A, 76)$

[26.]

Testa del Salvatore

Del Correggio.

Tu, che di Christo il vero

Simulacro spirante

Stupido in atto contemplando stai,

Perché non egli intero

Sia qui dipinto, la cagion non sai.

Fu sol pietà, fu zelo

Del gran Pittor, ché già da noi fors'hora

Partito fôra - e sù poggiato in Cielo,

S'hauesse al bel sembiante

(Come lo spirto già) dato le piante. ${ }^{91}(G A, 78)$

In MAdonna Del CoReggio wird der Betrachter aufgefordert, die lieblichen Gesten und die Zuneigung des Jesuskindes gegenüber seiner Mutter $\mathrm{zu}$ betrachten und zu bestaunen. Durch den Reim von «spira» und «mira »

9o Madonna von Correggio // Vorgetäuscht ist es nicht, sondern es atmet, / das göttliche Kind, / das im Schoß der jungfräulichen Mutter ruht. / Sieh die sanften Gebärden, sieh, / mit welch barmherzigen Gefühl / es ihr zulächelt und mit ihr scherzt. Und du würdest wohl / die göttlichen Glieder sich bewegen sehen, / doch es will oder wagt nicht / (so sehr bindet es das feste Band der Liebe), / die Umarmung der hohen Mutter zu verlassen.

91 Das Haupt des Erlösers von Correggio // Du, der in Christi wahres, / atmendes Abbild / gerade staunend dich versenkst, / warum er hier nicht ganz / gemalt ist, den Grund weißt du nicht. / Es war nur Frömmigkeit, es war Eifer / des großen Malers: denn vielleicht wäre er jetzt schon / von uns gegangen und thronte oben im Himmel, / wenn er dem schönen Bild / (wier ihm Geist gab) Füße gegeben hätte. 
wird die Lebendigkeit des Bildes erneut als besonders bewunderungswürdig markiert. Selbst die Bewegungen des Kindes wären sichtbar, würde es nicht von seiner Mutter festgehalten. In Testa del Salvatore wird der sich wundernde Betrachter als Du angesprochen. Mit «vero / Simulacro» und «spirante / stupido » wird das erstaunlich Lebendige von Correggios Malerei sprachlich hervorgehoben. Allerdings wundert sich das betrachtende Du nicht (nur) über die Lebendigkeit des Bildes, sondern darüber, weshalb nur der Kopf und nicht der ganze Körper dargestellt sei. Damit wird der Fokus weg vom Bild und hin zur geistreichen "Erklärung" des Dichters geleitet, die im zweiten Teil des Gedichts folgt: Christus wäre längst weggegangen und im Himmel angekommen, hätte der Maler nicht nur das Gesicht («sembiante»), sondern auch Fusssohlen ( « piante ») gemalt..$^{92}$ Interessant sind die Scharnierzeilen 7 und 8: « [...] ché già da noi fors'hora / Partito fôra ». Diese Zeilen lesen sich anfänglich in Bezug auf den « Pittor » und erweisen sich erst mit der Fortsetzung der achten Zeile zugehörig zum Erlöser. Auch die Alliterationen auf „p“ verweisen gleichzeitig auf den «Pittor» und die «piante». Das Gedicht löst den Maler ab, gestaunt wird nicht in erster Linie über dessen Bild, sondern über das originelle concetto. ${ }^{93}$

Einen besonderen Stellenwert innerhalb der Galeria nehmen die Selbstporträts Marinos sowie die Porträts seiner Geliebten ein. In den Selbstporträts beschreibt er zum einen die Transformation des Sterblichen ins Unsterbliche, zum anderen die des Bildes in Sprache.

92 Ähnlich humorvolle „Erklärungen“ finden sich in der Galeria immer wieder, sowohl in den PITTURE als auch in den SCVLTURE; ein einschlägiges Beispiel aus Letzteren ist die Statue [26.] La Notte di Michelagnolo Bvonaroti $(G A, 396)$.

93 Dass die Bilder nur dann ihre volle Ausdruckskraft entfalten, wenn sie poetisch betrachtet werden, wird auch hier deutlich: [69.] / Angelica / Del Cavalier Giovanni / BAGLIONI. / Virtù dela tua mano / Ha tra noi suscitata / BAGLION, le bella ingrata. / Né certo era a formar volto sì bello / Huopo d'altro pennello. / Lammira Apollo, e non sa dir qual sia / Di maggior leggiadria, / In carne, in carte, in tela o vera, o finta, / Viua, scritta, o dipinta. (Angelica / von Giovanni Baglione // Die Macht deiner Hand / hat unter uns, / BAGLIONE, die schöne Undankbare wiedererweckt. / Und gewiss, um ein so schönes Gesicht zu gestalten, / bedurfte es keines anderen Pinsels. / Apollon bewundert es und weiß nicht zu sagen, welches / von größerer Anmut sei: / im Körper, im Buch, auf der Leinwand, wahr oder vorgetäuscht, / lebendig, geschrieben oder gemalt. $G A, 55)$ // Dadurch, dass Apollon - und nicht Apelles - als Bewunderer des Bildes genannt wird, rückt die poetische Wahrnehmung ins Zentrum. Unterlegt wird dieser Fokus auf die Dichtung mit einer Verschränkung von griechischer Mythologie und dem Stoff der „poemi cavallereschi“. 
[11.]

Sopra il Proprio Ritratto DELl'AVtore

DI MANO

Di Michelagnolo da Caravaggio.

Vidi, MICHEL, la nobil tela, in cui

Dala tua man veracemente espresso

Vidi un altro me stesso, anzi me stesso

Quasi Giano nouel, diuiso in dui.

Io, che'n virtù d'Amor viuo in altrui,

Spero hor mi fia (la tua mercé) concesso

In me non viuo, hor raviuarmi in esso,

In me già morto, immortalarmi in lui.

Piàcemi assai, che merauiglie puoi

Formar sì nôue, ANGEL non già, ma Dio:

Animar l'ombre, anzi di me far noi.

Ché s'hor scarso a lodarti è lo stil mio,

Con due penne e due lingue i pregi tuoi

Scriuerem, canteremo, et egli, et io. ${ }^{94}(G A, 280)$

Durch das Porträt Caravaggios verwandelt sich der Autor in ein Janusgesicht; er sieht in der Darstellung sowohl sich als auch sein zweites Selbst. Aufgrund seines Liebeskummers eigentlich schon nicht mehr lebendig, lässt das Bild ihn wieder aufleben und unsterblich werden. Caravaggio erweist sich dadurch nicht nur als «ANGEL » - Wortspiel mit seinem Vornamen -, sondern als Gott, der «merauiglie / nôue » wie die „Wiederauferstehung“ des Autors möglich macht. Doch nicht nur das Bild des Autors wird verdoppelt, sondern auch dessen Zunge bzw. Sprache, und nur in dieser Doppelung wird er fähig, den Künstler angemessen zu preisen. Die Transformation in ein Bild ist notwendig,

94 Über das Porträt des Autors / von Michelangelo da Caravaggio // Ich sah, MichelE, die edle Leinwand, auf der, / von deiner Hand wahrhaftig dargestellt, / ich ein anderes Ich erblickte, ja mich selbst, / zweigeteilt wie ein neuer Janus. // Ich, der durch die Kraft Amors in jemand anderem lebt, / hoffe, nun sei es mir (dir sein Dank) gewährt, / in mir leblos, nun in ihm zum Leben zu erwachen / und in mir schon gestorben, in ihm unsterblich zu werden. // Es bereitet mir größte Freude, dass du so neuartige Wunder / schaffen kannst, ein ENGEL nicht nur, sondern ein Gott: / die Schatten zu beleben, ja, aus mir ein uns zu machen. // Und wenn ich dich jetzt noch in dürftigem Stil lobe, / werden wir mit zwei Federn und zwei Zungen / von deinen Vorzügen schreiben und singen, er und ich. 
damit Sprache entsteht - das Bild erweist sich so als Initiation und Inspiration der Dichtung. ${ }^{95}$

Handelt das Porträt aus der Hand Caravaggios von der Transformation des Ichs in ein Bild und des Bildes in Sprache, rücken die Porträts der Geliebten die transformative Wirkung des Bildes auf den Betrachter in den Vordergrund.

Voraussetzung für das Gelingen eines Bildes bzw. für das Herstellen einer transformativen Wirkung ist das Staunen des Künstlers über sein Objekt.

[10.]

L'IMAGINE CRVDELE. ${ }^{96}$

I.

Ben più ch'altro Pittor felice assai

Il fabbro del tuo angelico ritratto

Donna bella e crudel, gradire homai

Deue l'alto fauor che tu gli hai fatto;

Quando temea, vicino ai chiari rai

Arrestando la man stupido in atto,

Quante glorie in molt'anni hebbe fra noi

Perder'a un guardo sol degli occhi tuoi. ${ }^{97}(G A, 348)$

Staunend hält der «fabbro » beim Anblick der « Donna bella e crudel » inne die Wirkung ihrer Augen ist so stark, dass er fürchtet, seinen Ruhm durch einen ihrer Blicke zu verlieren.

95 Im Porträt aus der Hand Francesco Purbìs' wird dem Autor einerseits auf wundersame Weise das Antlitz geraubt, auf der anderen Seite Geist geschenkt. Der Autor bittet darum, dass der Maler ihm auch die „Zunge löst“, damit sie ihn angemessen - mit « facondia di famoso ingegno »-loben kann: [11D.] / SOPRA IL MEDESIMO DI MANO / Di FRANCESCO Pvrbìs. / Tu, che'n sì rari modi / Rubato m'hai mirabilmente il volto, / E me medesmo a me medesmo hai tolto; / Poichél tuo furto è degno / D'alta facondia di famoso ingegno, / Né penna ho io sì chiara, o sì pregiata; / Come l'alma gli hai data, / Dàgli la lingua ancor, perché la snodi, / E dàgli anco lo stil, perché ti lodi. (Über das eigene Bildnis / von Frans Pourbus d. J. // Du, der auf seltene Art / mir wunderbar mein Angesicht geraubt hat, / und mir selbst mich selbst genommen hat, / da dein Raum würdig ist / hoher Redekunst eines ruhmreichen Geistes, / und ich keine Feder habe, die so berühmt oder geschätzt wäre, / so wie du ihm [dem Angsicht] die Seele gegeben hast, / gib ihm auch die Zunge, damit es sie löse, / und gib ihm auch den Stil, damit es dich lobe. $G A, 282$ )

96 Es handelt sich um ein Porträt von Marinos Geliebter.

97 Das grausame Bild // I. Mehr als jeder andere hochbeglückte Maler / muss der Schöpfer deines engelgleichen Bildnisses, / schöne und grausame Herrin, nun danken / für die hohe Gunst, die du ihm gewährt hast; / da er fürchtete, als er nahe deinen hellen Strahlen / mit verblüffter Geste die Hand zurückhielt, / allen Ruhm, den er in vielen Jahren unter uns erworben hatte, / durch einen einzigen Blick deiner Augen zu verlieren. 
XII.

Hor di questa, ch'al ver tanto somiglia,

Chi fu l'autor? chi fu, e seppe, e come

Latte ala fronte, et hebeno ale ciglia,

Ostro dar'ale guance, oro ale chiome?

Oh mirabil fattura, o merauiglia,

Presso a cui perde ogni altra il pregio, e 'l nome!

Opra non sei terrena, il tuo Pittore

Non fu (quant'io mi creda) altri ch'Amore.

XV.

Dimmi, sei tu beltà dipinta, o viua?

Vorrei sauer, sei pittura, o foco?

Se pittura sei tu, donde deriua

Quell'ardor, che mi strugge a poco a poco?

E chi de' dolci (oimè) detti mi priua,

Ch'usurpar non mi può tempo, né loco?

Se foco sei, deh con qual forza offendi,

Che la tela non ardi, e l'alma accendi?

XVI.

$[\ldots]$

Mirando i tuoi colori, io mi scoloro,

Tu spiri, e viui, et io sospiro, e môro.

$[\ldots]^{98}\left(G A, 348-35^{2}\right)$

Das Porträt der Geliebten kann nur aus göttlicher Hand stammen, so sehr gleicht es der Realität. Die Nähe zum realen Anblick konstituiert die «merauiglia » des Bildes, betont durch den Reim mit «somiglia». Die Verwunderung über die Lebendigkeit des Bildes sowie über die entflammende Wirkung bringt der Betrachter durch die aneinandergereihten Fragen in Strophe XV zum Ausdruck. Dabei transformiert sich der Betrachter antithetisch zum Bild: Während er die Farben bestaunt, erbleicht er. Während er den Atem des lebendig gewordenen Bildes spürt, geht er selbst langsam ein.

98 XII. Nun - von dieser, die der Wirklichkeit so gleicht, / wer war der Urheber? Wer war es, der es verstand, und wie, / Milch der Stirn und Ebenholz den Wimmpern, / Purpur den Wangen zu schenken, Gold den Haaren? / Oh bewundernswertes Geschöpf, oh Wunder, / neben dem jedes andere Wert und Namen verliert! / Kein irdisches Werk bist du, dein Maler / war niemand anderer (wie ich glaube) als Amor. // XV. Sag mir, bist du eine gemalte oder lebende Schönheit? / Ich möchte wissen, bist du ein Gemälde oder Feuer? / Wenn du ein Gemälde bist, woher kommt / jene Hitze, die mich nach und nach zerstört? / Und wer beraubt mich der süßen (weh mir) Worte, / die mir weder Zeit noch Raum entreißen können? / Wenn du ein Feuer bist, ach, mit welcher Kraft greifst du an, / dass du das Leinen nicht verbrennst, aber die Seele entflammst? // XVI. [...] im Anblick deiner Farben erbleiche ich, / du atmest und lebst, und ich seufze un sterbe. 
Das Staunen bahnt sich seinen Weg vom Künstler (I.) über das Bild (XII.) bis hin zum staunenden Betrachter (XVI.). Es bildet das Grundmotiv des Gedichts, denn deskriptive Elemente finden sich abgesehen von wenigen topischen Angaben zu den Farben von Augen, Stirn, Wangen und Haaren in den Strophen X und XII keine. Auch die weiteren der Liebeslyrik entlehnten Topoi - Schönheit und gleichzeitige Grausamkeit der Geliebten; der Liebende, der an der Abweisung leidet; das Liebesfeuer, das durch die Tränen des Liebenden verstärkt wird -,${ }^{99}$ werden bei Marino zu Begleiterscheinungen. Die Wirkung des Bildes geht aus der Lebendigkeit und der transformativen Kraft der Gestaltung hervor - und auf diese Wirkung, nicht auf den Inhalt ist das Staunen gerichtet.

Sind die Maler darum bemüht, ein täuschend echtes Abbild der Natur zu formen, zeichnet Marino sich dadurch aus, dem Gewohnten mit originellen concetti und fantasievollen Erweiterungen novità zu verleihen. So durchbricht er beispielsweise die Fatalität der griechischen Mythologie und stellt bekannte Mythen mit überraschenden Wendungen dar. Nicht mehr die Götter, sondern der Künstler - als Dichter im Gewand des Malers oder Bildhauers - spinnt die Schicksalsfäden. So heisst es über die Flucht von Galathea vor dem Riesen: «Miracol di tua man [dell'artista], che scampi e viua: / Se non le daui il moto, ella periua. $»^{100}$

Auch der Mythos des Orpheus, der mit seinem Gesang den Lauf der Natur verkehrt und die Zuhörer gefangen nimmt, wird um eine originelle Wendung angereichert:

[58.]

ORFEO, CHE CANTA \& SVONA NEL BOSCO

di Sinibaldo Scorza.

Canta, e'l canto sì dolce

Tempra il maëstro dela Thracia cetra,

Che le selue non pur lusinga e molce,

Non pur rapisce e spètra

Con la virtù de' ben spiegati carmi

I fiumi, i tronchi, i marmi,

Non pur le Tigri e l'Orse

Ferme gli stanno, e mansüete appresso;

Ma quell'Aspido istesso,

Che'l bianco piè della sua Donna morse,

99 Pieri / Ruffino, Commento, S. CXCVIII.

100 Es handelt sich um die letzten beiden Zeilen des Gedichts [20.] ACi con Galathea di Pier Francesco Morazzoni: Ein Wunder deiner Hand, dass sie flieht und lebt: / hättest du ihr nicht Bewegung verliehen, sie wäre umgekommen. $(G A, 22)$ 
Pentito forse, e senza tòsco et ira

Gli lambisce la lira. ${ }^{101}(G A, 47)$

Die Wiederholung der Formel « non pur » deutet darauf hin, dass der bekannte Mythos erweitert wird, die «ben spiegati carmi » übertroffen werden werden. Damit Marinos Gedicht genauso anziehend und erstaunlich wirkt wie Orpheus' Gesang, muss es Neues, Ausserordentliches beinhalten, das weder dem gängigen Mythos noch den Orpheus-Darstellungen von Scorza eigen ist. Die letzten vier Zeilen liefern diesen neuen Stoff: Sogar die Schlange, die seine Eurydike tödlich vergiftet hat, wird von seinem Gesang bezwungen und züngelt reuig an seiner Lyra.

Der zweite Teil der Galeria, die Scvulture, wird vom Motiv der Versteinerung dominiert. Die Versteinerung ist an das Staunen gekoppelt, allerdings führt Marino gegenüber dem Medusa-Motiv eine entscheidende Wendung ein: Das Staunen geht nicht mehr aus dem Anblick der Medusa, sondern aus der künstlerischen Darstellung - der „Versteinerung“ eines Stoffes bzw. einer Figur in eine Statue - hervor.

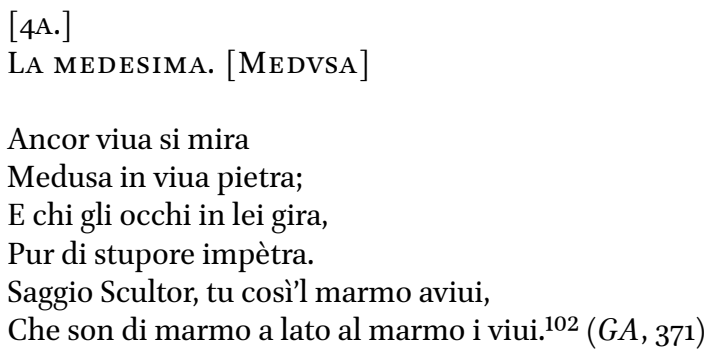

Das Motiv der Versteinerung vor Staunen («impètra») wird inhaltlich und sprachlich mit der Verlebendigung (« aviui », « viua pietra ») verschränkt. ${ }^{103}$

101 Orpheus, der singt \& spielt im Wald / von Sinibaldo Scorza // Er singt, und dieser liebliche Gesang / wird vom Meister der thrakischen Zither angestimmt, / sodass er die Wälder nicht nur verlockt und vergnügt, / er nicht nur gefangen nimmt und rührt / mit der Kraft seiner klar erläuterten Gesänge / die Flüsse, die Stämme, den Marmor, / nicht nur die Tiger und die Bären / stehen reglos und zahm bei ihm; / sondern sogar die Schlange, / die den bleichen Fuss seiner Geliebten biss, / reumütig vielleicht, und ohne Gift und Wut / leckt seine Leier. (Übersetzung A.E.)

102 Medusa // Noch lebendig betrachtet man / Medusa in lebendigem Stein; / und wer die Augen auf sie richtet, / wird vor Staunen selbst versteinert. / Kluger Bildhauer, du machst den Marmor so lebendig, / dass neben dem Marmor die Lebenden von Marmor sind.

103 Siehe dazu Elisabeth Oy-Marra, „Immobile riman per meraviglia“. Staunen als idealtypische Betrachterreaktion in den Bildgedichten Giovan Battista Marinos zu Tizians hl. Sebastian, in: Rainer Stillers und Christiane Kruse (Hgg.), Barocke Bildkulturen. Dialog der Künste in Giovan Battista Marinos „Galeria“, Wolfenbüttel 2013, S. 252. 
Das Motivpaar „Versteinerung - Verlebendigung“ sowie das damit verbundene Staunen kommen auch in Bezug auf andere Statuen zum Ausdruck. Die Statva di bella Donna lässt den Betrachter äusserlich vor Staunen versteinern, während die Statue selbst an Lebendigkeit gewinnt.

[36A.]

Ne medesimo SVggetto. [StatVa di bella Donna.]

$[\ldots]$

La figura ritràtta

Medusa mi rassembra

La scultura è sì fatta,

Ch'altrui cangia le membra.

Già già sento cangiarmi a poco a poco

Di fuor tutto in macigno, e dentro in foco.

Con la viuace imago

Disfogo il mio tormento.

Con occhio ingordo e vago

V'affiso il guardo intento.

E sì di senso lo stupor mi priua,

Ch'io son quasi la statua, ella par viua.

$[\cdots]$

Vinta, vinta è dal'Arte

La maëstra Natura.

L'una in ogni sua parte

Fredda l'ha fatta, e dura,

Aspra, sorda, qual'è piena d'orgoglio;

L'altra la fe' di carne, et è di scoglio!

In questo anco emendata

Dala falsa è la vera:

Che quella l'ha formata

Volubile, e leggiera;

Questa ha pur dato almeno ala sembianza

La fermezza marmorea, e la costanza.

$[\ldots]^{104}\left(G A, 405^{-407}\right.$, Vv. 13-24, 49-6o $)$

104 Statue einer schönen Frau // [...] / Das Porträt / scheint mir Medusa zu sein. / Die Skulptur ist so gemacht, / dass sie die anderen Glieder verwandelt. / Schon fühle ich nach und nach mich wandeln, / außen ganz in einen Felsblock und innen in Feuer. // Vor dem lebendigen Bild / lass ich meinen Qualen freien Lauf. / Mit begierigem und verliebtem Auge / richte ich gespannt den Blick darauf. / Und so sehr raubt mir das Staunen die Sinne, / dass ich beinahe die Statue bin und sie lebendig scheint. // [...] Ganz besiegt ist durch die Kunst / die Meisterin Natur. / Die eine hat sie in jedem Teil / kalt und hart gemacht, / spröde, taub 
Die Natur und die Kunst tauschen ihre Rollen: Wird die Natur als «falsa » proklamiert, formt die Kunst die wahren Züge der Geliebten. Die Materialität des Steins wird spielerisch verkehrt: Ist die Dame - metaphorisch gelesen - kalt wie Stein, ist es gerade der Stein, der ihr die Menschlichkeit zurückgibt. Oder aber der Stein dient dazu, die Unbeständigkeit der Dame in Standhaftigkeit zu verwandeln. Als Meister dieses Spiels entpuppt sich nicht in erster Linie der Bildhauer, sondern der Dichter.

Auch im folgenden Gedicht wird ein Spiel um falsità und verità initiiert, wenn davon berichtet wird, Adonis sei nicht in eine Blume, sondern in eine Statue verwandelt worden. Die Statue ist schöner als der "lebendige“ Adonis, „wahrer" als der Mythos, der von ihm erzählt wird. Als Exzess der « merauiglia » übersteigt die Figur das blosse Handwerk: Sie wurde nicht nur ausgehauen und geformt, sondern transformiert - und ist in dieser Transformation wirkungsvoller als in der Gestalt einer Blume.

[8.]

ADONE.

Chi vuol ch'Adon da fier Cinghial ferito

Cangiato fusse in vago fior nouello, Non ha forse, Signor, veduto quello, C'hai tu di marmo candido, e polito.

Giurerei, benché freddo e scolorito, Che già di carne ei non fu mai sì bello; E (con pace del fabro, e del martello) Ch'egli fu trasformato, e non scolpito.

Atlante del Gorgón sasso fu fatto, $\mathrm{E}$ per altra virtù venner l'istesso Niobe, Aglauro, Anassarète, e Batto.

Tal'ancor lui cred'io, ben'egli è desso! Ch'Arte non può, formando human ritratto, Giunger di merauiglia a tanto eccesso. ${ }^{105}(G A, 380)$

wie sie ist, voller Stolz: / die andre machte sie aus Fleisch, und sie ist doch aus Stein. // Auch darin verbessert / die Falsche die Wahre, / dass jene sie / flatterhaft und leichtfertig gebildet hat: / diese hat dem Abbild wenigstens / die marmorne Festigkeit und Beständigkeit gegeben. // [...]

105 Adonis // Wer will, dass Adonis von einem wilden Eber verwundet, / in eine anmutige junge Blume verwandelt würde, / hat vielleicht, mein Herr, jenen nicht gesehen, / den du aus weißem und glänzendem Marmor hast. // Ich würde schwören, obwohl er kalt und bleich ist, / dass er einst aus Fleisch und Blut niemals so schön war; / und (Künstler und Hammer mögen es mir verzeihen) / dass er verwandelt, und nicht skulptiert wurde. // 
Die genannten Gedichtbeispiele zeigen das Staunen als ständigen Begleiter der künstlerischen Transformation, wobei es meist als Reaktion auf die täuschende Lebendigkeit der Bilder und Skulpturen dargestellt wird. Als eigentlicher Meister des Spiels um Wahrheit und Fiktion aber erweist sich weder der Maler noch der Bildhauer, sondern der Dichter. Dies zeigt sich nicht zuletzt darin, dass die bildliche Darstellung der in den Gedichten beschriebenen Objekte an Bedeutung verliert, während das concetto des Dichters rund um das Bild und dessen Wirkung in den Vordergrund tritt. Dass diese Wirkung meist eine ist, die auf poetischer Fiktion beruht und gar nicht aus dem Bild - wenn es denn überhaupt real existiert - resultiert, verstärkt zusätzlich die Rolle des Dichters, der nie einfach nur abbildet, sondern immer verwandelt und neu erfindet.

\subsection{Adone}

Der Adone wurde 1623 in Paris autorisiert veröffentlicht und gilt als Marinos Hauptwerk. ${ }^{106}$ Was als "poemetto di tre canti» begann, wuchs über die Jahre «smisuratamente » ${ }^{107}$ zum « wohl längste[n] Verstext der italienischen Literatur» heran ${ }^{108}$ - «Dantes Divina Commedia umfasst gerade ein gutes Drittel ». ${ }^{109}$ Der Mythos von Adonis und Venus bildet die narrative Grundlage des Epos, ${ }^{110}$ in die zahlreiche Digressionen eingewoben sind:111 mythologische, christliche, moralische, autobiographische, enkomiastische, theatrale, romanzeske, bukolische, literatur- und kunstgeschichtliche, meditative,

Atlas wurde durch die Gorgo versteinert, / und durch andere Macht geschah dasselbe / mit Niobe, Aglauros, Anaxarete und Battus. // Solches, glaube ich, geschah auch ihm: denn er ist es selbst, / da Kunst, wenn sie ein menschliches Bildnis formt, / zu solchem Übermaß an Wundern nicht gelangen kann.

106 Marino begann mit der Arbeit am Adone bereits 1594 in seiner Zeit am Hof von Neapel, « die Hauptarbeit erfolgt[e] in der Zeit am französischen Hof». Siehe Ulmer, Die Entdeckung, S. 76 .

107 Giovanni Pozzi, Metamorfosi di Adone, in: Strumenti Critici 5 (1971), S. 334, 350: « Nel 1605 l'Adone era un poemetto di tre libri; nel 1614 ne contava quattro con meno di mille ottave; nel 1615 era come la Gerusalemme; nel 1616 come il Furioso; l'edizione del 1623 conta 5213 ottave, cioè 224 di più del Furioso. »

108 Florian Mehltretter, Das Ende der Renaissance-Episteme? Bemerkungen zu Giovan Battista Marinos Adonis-Epos, in: Andreas Höfele, Jan-Dirk Müller und Wulf Oester reicher (Hgg.), Die Frühe Neuzeit. Revisionen einer Epoche, Berlin 2013, S. 331.

109 Ulmer, Die Entdeckung, S. 74.

110 Ich definiere „Epos" an dieser Stelle relativ offen als fiktiven Langtext in Versform.

111 Ulmer, Die Entdeckung, S. 74. 
naturwissenschaftliche ${ }^{112}$ und fantastische. Cherchi spricht vom Prinzip der Nähe und der Analogie, das jenes der Kausalität ersetzt und dem Werk den Weg vom « poema epico » hin zum « carme figurato » bahnt. ${ }^{113}$

Die erste Hälfte des Epos umfasst einen Initiationsweg, der teils als Gegendarstellung zum Weg des Pilgers Dante [...] angelegt ist: Adonis wird von Venus und teils auch von Merkur über die Welt in Kenntnis gesetzt, von den fünf Sinnen über die Ordnung des Kosmos bis zu Geschichte und Naturwissenschaft, und zwar auf einer Reise, die im Garten der Sinne beginnt und im Himmel endet. Der zweite Teil erzählt Bewährung, Krönung und Tod des Adonis. Er dialogisiert mit weiteren Epen: zunächst mit Ariosts Rasendem Roland, wenn nämlich Adonis sich in kontingenten romanzesken Verwicklungen [...] bewähren muss [...] Nach seiner Heimkehr und Krönung zum König von Zypern erliegt Adonis den Folgen eines Jagdunfalls $[\ldots]^{114}$

Das Originelle an Marinos Werk besteht darin, dass er das Material, das unterschiedlichen Traditionen und Genres entstammt, fliessend und auf originelle Art und Weise in-, an- und übereinanderfügt. Dabei erweitert und verändert er seine Vorlagen - allen voran Ovids Metamorphosen, Ariostos Orlando Furioso und Tassos Gerusalemme Liberata -, ${ }^{115}$ so dass ein neuartiges Textgebilde entsteht.

Zentrales und strukturbildendes Prinzip des Adone ist die Transformation; die Metamorphose, die Adonis nach seinem Tod erfährt und die den tristen Höhepunkt des Mythos darstellt, wird zum produktiven Prinzip, das alle Ebenen des Epos durchdringt. Zuallererst wird die klassisch symbolische Leseweise verkehrt: Die Allegorien eines jeden Gesangs werden zu Beginn, quasi als Einleitung der Gesänge, offengelegt. Die genuin indirekte Ausdrucksweise

112 Dazu zählen unter anderem humanbiologische, botanische und astronomische Ausführungen.

113 Paolo Cherchi, La metamorfosi dell'Adone, Ravenna 1996, S. 16.

114 Menltretter, Das Ende, S. 333. Mehltretter vergisst bei seiner Inhaltszusammenfassung den XIX. und den XX. Gesang, die dem Begräbnis und den «giochi funebri in onore di Adone » gewidmet sind. Es wird sich zeigen, dass dieser Abschluss eine wichtige Rolle spielt, da er den Kern des Epos - die Metamorphose - inhaltlich und narrativ vollendet. Andere Autoren teilen das Werk in einen ersten Teil (I-XIV) und einen zweiten Teil (XV-XX). Dieses Schema folgt der Einteilung in Vereinigung und Trennung von Venus und Adonis, das zweimal wiederholt wird. Guardiani wiederum teilt binär wie Mehltretter (I-X und XI-XX), entsprechend der « doppia simmetria dei quattro tempi narrativi: ,innamoramento', ,trastulli', ,dipartita' e ,morte` », wobei er diese doppelte Symmetrie analog zur Struktur des Madrigals interpretiert. Siehe Francesco GuARdiani, La meravigliosa retorica dell'Adone di G. B. Marino, Firenze 1989.

115 Eine ausführliche Studie zu den Quellen des Adone findet sich in Carmela Cоцомво, Cultura e tradizione nell'Adone di G. B. Marino, 1967. 
der Allegorie wandelt sich in eine direkte und offene Kommunikation. Es gilt also nicht, die Allegorien aufzudecken, sondern der vielfältigen Ausgestaltung ihrer Inhalte beizuwohnen - sei dies in der jeweiligen Umsetzung im Gesang oder im Vergleich mit weiteren Allegorien. So schilt die Allegorie des achten Canto jene, die meinen, ihre Erfüllung läge in den « sinnlichen Vergnügen » gleichzeitig beginnt der Canto mit einem Lob der «zärtlichen und lasziven Dichtung» (VIII, 3, 3) $)^{116}$ und findet seinen Höhepunkt, als Abschluss der Gärten der Sinne, im Liebesakt zwischen Venus und Adonis.

Da von derart grundlegender Bedeutung, scheint es naheliegend, dass die Transformation auch die Basis von Marinos Poetik darstellt - basierend auf novità, stravaganza, vivezza, spiritosità, fantasia und libertà:117 Sie überrascht mit neuen, unerwarteten Wendungen, verlebendigt die Bedeutungen und Inhalte und zeugt von Fantasie und künstlerischer Freiheit. Entsprechend wird das Prinzip der Transformation auch in den drei Bereichen, die ich in den folgenden Kapiteln einer ausführlicheren Analyse unterziehen werde, von herausragender Bedeutung sein: der narrativen Struktur, der Liebe und der Kunst.

\subsubsection{Die narrative Struktur}

Die narrative Struktur des Adone wandelt sich stetig. Schon im ersten Buch geht die mythologische in eine bukolische Erzählung über, wobei diese auf die mythologische zurückverweist. Teil des innamoramento, das im dritten Canto den eigentlichen Auftakt des Epos bildet, sind ausgedehnte Liebesmonologe und -dialoge, die sich aus dem Repertoire der Liebeslyrik speisen. ${ }^{118}$ Im vierten Canto (LA NOVELLETTA, IV, Allegoria) wird der Mythos von Amor und Psyche als lebhaftes Eifersuchtsdrama inszeniert - zwischen Venus ( «Libidine») und Psyche («Anima») sowie zwischen Psyche und ihren Schwestern («Carne» und «Libertà »). Im fünften Canto wandelt sich die Szenerie in ein Theaterspektakel, in dem die Tragödie Atteones aufgeführt wird. Der «spettacolare rappresentazione con macchine teatrali e sorprendendti cambi di scena »119 wohnt der Protagonist - Adonis - allerdings nicht gespannt, sondern so gelangweilt bei, dass er dabei einschläft. Wird auf die aufwendigen Theaterszenerien zur Zeit Marinos normalerweise mit Staunen reagiert, wendet er die Reaktion darauf ins Gegenteil - um mit dieser unerwarteten Reaktion

116 Zu Beginn des siebten Cantos ist genau diese Laszivität von Poesie und Musik beklagt worden (VII, 1-6).

117 Neuheit, Extravaganz, Lebendigkeit, Einfallsreichtum, Fantasie und Freiheit.

118 Anspielungen an die Liebeslyrik finden sich insbesondere in den langen Monologen der Venus. Vgl. dazu die Einleitung zum dritten Gesang von Russo, S. 306.

119 Russo, Einleitung zum fünften Gesang, S. 518. 
wiederum den Effekt des Staunens zu erzeugen. Vom Theater geht es weiter in die Gärten der Venus (Gärten der Sinne), die sich entgegen der Erwartung nicht als überirdische Paradiesgärten präsentieren, sondern dem Menschen nachgebildet sind und dessen fünf Sinne sowie deren vielfältige Funktionen darstellen. Dabei wandeln sich die physischen in kulturelle Sinne - das Auge dient der Wahrnehmung von Kunst, das Ohr jener von Poesie und Musik -, um schliesslich in einem erotisch-taktilen Finale ihren Höhepunkt zu finden. In den Canti IX-XI werden die Reiche der Poesie und der Kunst sowie verschiedene himmlische Sphären erkundet. Venus und Adonis begeben sich zum «Brunnen Apollons» (IX, Allegoria), wo sie auf Fileno treffen:

Nella persona di Fileno, nome dell'amore, il poeta descrive sé stesso con gran parte degli avvenimenti della sua vita. Fingesi pescatore per aver egli il primo, almeno in quantità, composte in volgarlingua poesie marittime. ${ }^{20}$ (IX, Allegoria)

Marino-Fileno präsentiert sich als Liebes- und Meeresdichter, der zurückgezogen und einfach lebt - weit weg von den Höfen, deren Intrigen und Kriege er erlebte und die er an dieser Stelle wiedergibt. ${ }^{121}$ Doch entgegen seinem Wunsch, sich vom politischen Geschehen zu distanzieren, bindet er in die mythische die historische Zeit ein. Die Geschichte italienischer und französischer Adelsfamilien wird in den folgenden Canti immer wieder Thema sein. Genauso ambivalent verhält es sich mit seinen Aussagen: Propagiert wird die Überlegenheit erotisch-idyllischer Dichtung, insbesondere gegenüber den «carmi eroici e cavallereschi $»{ }^{122}$ Allerdings nimmt die mythologische Erzählung im zweiten Teil des Adone auch kavalleresk-heroische Züge an.

Fileno weist den beiden Liebenden den Weg zu Apollons Brunnen, dessen Ekphrasis eine spielerisch-humorvolle Poetik der Transformation offenbart: Das Wasser - «liquido e molle » - wandelt sich auf wundersame Weise in Himmelskörper, die es zu bestaunen gilt. Irdische Elemente wandeln sich zu himmlischen, wobei der erhöht-philosophische Charakter der ersten vier

120 Ich zitiere aus folgender Ausgabe: Giovan Battista Marino, Adone, a cura di Emilio Russo, 2 Bde., Milano 2013. Russo baut auf der zweibändigen Standardausgabe von Giovanni Pozzi (Milano 1976) auf - ich greife stellenweise auch auf die Ausgabe von Pozzi zurück und kennzeichne dies entsprechend. Die Abkürzung $A D$ verwende ich nur dann, wenn ohne die Nennung Unklarheiten entstehen könnten. Die Übersetzungen aus dem Adone stammen wie erwähnt von der Autorin (A.E.): «In der Person von Fileno, Name der Liebe, beschreibt der Dichter sich selbst und einen grossen Teil der Vorkommnisse seines Lebens. Er erfindet sich als Fischer, da er als erster, zumindest was die Menge betrifft, maritime Gedichte in der Volkssprache verfasst hat. »

121 Siehe dazu IX, 85, Vv. 7-8.

122 Pozzi, Metamorfosi, S. 344. 
Verse durch die humoristisch-onomatopoetischen Wortspiele der zweiten vier Zeilen unmittelbar relativiert wird.

Meraviglia talor, mentre s'estolle, arco stampa nel ciel simili ad Iri. Trasformasi l'umor liquido e molle: volto in raggi, in comete, in stelle il miri. Miri qui sgorgar globi, eruttar bolle, là girelle rotar con cento giri, spuntar rampolli e pullular zampilli e guizzi e spruzzi e pispinelli e spilli. ${ }^{123}$ (IX, 108)

Erneuter Ausdruck einer Poetik der Transformation sind die „bianchi cigni“ verstorbene, in Schwäne verwandelte Dichter (IX, 170) -, die sich vor Venus und Adonis zu einem «Wettstreit der Gesänge » versammeln (IX, 171). Die Aufzählung der Dichter beginnt bei Orpheus, geht über die griechischen Dichter (u. a. Pindar und Sappho) hin zu den lateinischen, wobei insbesondere Ovid hervorgehoben wird, und weiter zu den italienischsprachigen Dichtern: Petrarca, Dante, Boccaccio, Bembo, Sannazaro, Ariosto, Tasso und Guarini (IX, 173-183). Der Übergang von Tasso zu Guarini ist besonders signifikant, da er den Beginn einer neuen Dichtergeneration markiert, mit der das Humoristische wie auch die Erotik Eingang in die (hohe) Literatur finden. ${ }^{124}$

Vom Brunnen des Apollon brechen die Liebenden auf, die «äussersten Wunder » («meraviglie estreme », IX, 196) von Venus' Reich zu erkunden. Die Invokation der Muse Urania zu Beginn des zehnten Cantos macht die Neuartigkeit des in der Folge Erzählten deutlich:

$[\ldots]$

movi la penna mia, tu che 'l ciel movi

e detta a novo stil concetti novi.

Tifi primier per l'acque alzò l'antenne, con la cetra sotterra Orfeo discese, spiegò per l'aure Dedalo le penne, Prometeo al cerchio ardente il volo stese.

Ben conforme a l'ardir la pena venne

123 Ein Wunderwerk bisweilen, während er sich erhebt, / er einen Bogen in den Himmel prägt, ähnlich der Iris, / sich das flüssige und weiche Wesen verwandelt: / gewendet in Strahlen, in Kometen, in Sterne bestaunst du es. / Bewundere hier hervorquellende Kugeln, ausbrechende Blasen, / dort sich drehende Scheiben in hundert Wendungen, / Sprudel, die ausbrechen, und Fontänen, die strotzen, / und Zünglein und Spritzer und Strahlen und Nadeln. // Vgl. dazu Pozzi, Commento, S. 427.

124 Russo, Commento, S. 942. 
per così stolte e temerarie imprese;

ma più troppo ha di rischio e di spavento

la strada inacecessibile ch'io tento. ${ }^{125}(\mathrm{X}, 2-3)$

Im zehnten Canto wird erst die lunarische Sphäre beschrieben, wobei auf die Beschreibung des Mondes ein Lob Galileis und dessen Erfindungen insbesondere des Teleskopes - folgt. Der naturwissenschaftlich-didaktische Bereich wird verlassen und mit der Grotte der Natur und insbesondere der Insel der Träume ins Fantastische überführt. ${ }^{126}$ Höhepunkt dieser fantastischen Welt ist der Himmel Merkurs, in dem der Palast der Kunst beheimatet ist. Hier sind alle grossen menschlichen Erfindungen und Bücher versammelt. Neben der Ansammlung grosser Werke - viele davon in Form von Manuskripten entdeckt Adonis einen Haufen von Büchern, die in losen Blättern auf dem Boden liegen: Dies sind die Werke von Autoren, die mit einem «dürftigen Geist » (X, 162, V. 3) die grossen Werke nachahmen - darunter unter anderem Il mondo novo seines Widersachers Tommaso Stigliani. Die Prinzipien der novità und der spiritosità werden damit ex negativo betont. Doch nicht die Bibliothek bildet den Höhepunkt von Merkurs Himmel:

Qui tacque e'n ricca loggia e spaziosa

il condusse a mirar mirabil cosa. ${ }^{127}\left(\mathrm{X},{ }_{167}, \mathrm{Vv} .7-8\right)$

Die « rotierende Sphäre » Merkurs ist eine Art Globus, ${ }^{128}$ in der das ganze Universum abgebildet ist. Adonis wird mehrfach aufgefordert, über diese „sfera“ zu staunen:

E che sia ver, rivolgi a questa mia adamantina fabrica le ciglia;

dì se vedesti o s'esser può che sia istromento maggior di meraviglia.

$125[\ldots]$ bewege meine Feder, du, der du den Himmel bewegst, / und gib dem neuen Stil neue Einfälle [concetti]. // Tiphys erhob als erster die Masten auf den Wassern, / mit der Zither ist Orpheus in die Unterwelt hinabgestiegen, / Dädalus breitete in den Lüften seine Flügel aus, / Prometheus erstreckte seinen Flug auf den brennenden Ring. / Dieser Kühnheit entspricht der Jammer / über derart törichte und waghalsige Unterfangen; / aber vor allem ist sie voller Risiken und Schrecken, / die unzugängliche Strasse, die ich zu gehen versuche.

126 Russo, Einleitung zum zehnten Gesang, S. $95^{2}$.

127 Hier schwieg er und in eine reiche und grossräumige Loggia / führte er ihn, damit er dort eine erstaunliche Sache bestaune.

128 Wir erinnern uns an dieser Stelle an die « globi », die der « fontana d'Apollo » entspringen (IX, 108). 
Composta è con tant'arte e maestria

ch'al globo universal si rassomiglia;

mirar nel cerchio puoi limpido e terso

quanto l'orbe contien de l'universo. ${ }^{129}(\mathrm{X}, 172)$

Die Imperative «mira» und «rimira» leiten Adonis und die Leser durch die Darstellungen dieses wundersamen Globus: Zuerst werden die geographischen Zonen erläutert, bevor die zeitgenössischen Kriege aufgezeigt werden. Wiederum bricht die historische in die mythisch-fantastische Zeit ein - die beiden Welten erweisen sich als gegenseitige Abbilder.

Der zehnte Canto mit seinem Ausflug in die himmlischen Sphären funktioniert als Scharnier zwischen dem ersten Teil, der trotz vieler Digressionen im Mythos verankert bleibt, und dem zweiten Teil, der Adonis in eine Reihe romanzesker Abenteuer schickt (XII-XIV), bevor das innamoramento zwischen Venus und Adonis - von der ersten Begegnung bis hin zur (endgültigen) Trennung - auf humoristisch-spielerische Weise wiederholt wird (XV-XVIII). Was Fileno und Merkur im neunten und im zehnten Gesang propagieren - eine Dichtung, die sich blosser Nachahmung versagt und neue Wege beschreitet - wird unmittelbar umgesetzt.

In den Canti XII-XIV erlebt Adonis nicht nur die Transformation einer mythischen Figur in einen Ritter, sondern auch in einen Papagei ${ }^{130}$ und eine weibliche Gestalt (Licasta). Gleichzeitig ereignen sich neue innamoramenti, die das ursprüngliche innamoramento zwischen Venus und Adonis verkehren. Dazu mehr im folgenden Kapitel zur Liebe.

Im fünfzehnten Canto kehrt Adonis gemeinsam mit Merkur zu Venus zurück. Der Canto präsentiert sich spielerisch: Zum Zeitvertreib wird Schach gespielt, wobei sich das Spiel - analog zu Vidas Scacchia Ludus - schnell in Kämpfe und Gefechte» (XV, Allegoria) verwandelt. Die Transformation ins Spielerische wird fortgeführt im Schönheitswettbewerb des sechzehnten Cantos, der veranstaltet wird, um den neuen König von Zypern zu krönen. Das

129 Und dass es wahr sei, wende deine Augen / zu dieser meiner diamantenen Schöpfung; / sag, ob du je gesehen hast oder ob es je / ein grösseres Instrument der Wunder geben könne. / Es ist geschaffen mit derart viel Kunstfertigkeit und Meisterschaft, / dass es der Kugel des Universums gleicht; / bestaunen kannst du im Kreis, klar und rein, / wie viel die Kugel vom Universum beinhaltet.

130 Der Papagei ist Überbringer einer Rose in der Begegnung von Rinaldo und Armida. Der Papagei steht somit sowohl zum „elogio della rosa“ von Venus im dritten Canto als auch zu seinem tassesken Vorbild in Verbindung. Vgl. dazu Gerusalemme Liberata, XVI, 13, V. 6, und $A D$, XIII, 159, V. 1. Siehe Antonio Rossi, Fisionomia di un innamoramento (canto III:L'innamoramento), in: FrANCESCo GUARDiAni (Hg.), Lectura Marini., L'Adone'letto e commentato, Ottawa 1989, S. 41. 
Urteil von Paris, das im zweiten Canto besungen wurde, sowie der Schönheitswettstreit mit Psyche, von dem Amor im vierten Canto erzählt und als deren Protagonistin Venus fungierte, werden an dieser Stelle auf Adonis gemünzt: Venus tritt Adonis, der den Wettbewerb gewinnen wird, ihre ureigene Rolle ab. Im Gegensatz zu Venus allerdings, die ihre Schönheit in Szene setzt und vehement gegen ihre Wettstreiterinnen verteidigt, nimmt Adonis passiv am Wettbewerb teil und zeigt sich teilnahmslos gegenüber dem Spektakel. Auch die politische Rolle, die ihm als König von Zypern zukäme, wird unmittelbar an einen Statthalter übertragen - Adonis als apolitische Figur kontrastiert damit mit Marino-Fileno, der dem Geschehen, insbesondere in den Canti X und XX, eine historisch-politische Dimension verleiht.

Die Metamorphose des Adonis erweist sich nicht (nur) als Abschluss der mythologischen Handlung, sondern zeigt sich als Charakterprinzip des „Helden“. Wie in einem Kaleidoskop legen sich verschiedene Bilder übereinander, die aber kein kohärentes Ganzes ergeben. Neben den bereits genannten weiblichen und romanzesken Rollen werden Adonis unter anderem christologische Symbole zugeschrieben - was ihn mehr und mehr als kaum greifbare und ambivalente Figur erscheinen lässt. ${ }^{131}$

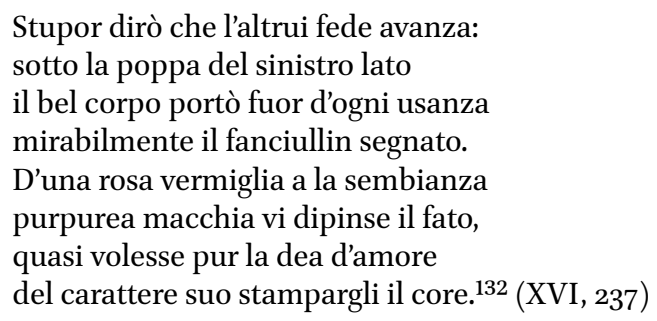

Die « purpurea macchia » stellt sowohl die „Erbschuld“ seiner inzestuösen Herkunft als auch die Rose als Symbol der Liebe - wie sie auch im dritten Canto beschrieben wird - dar. Der Vermischung von profanen bzw. mythologischen mit christlichen Motiven begegnen wir mehrfach im Adone, besonders explizit im Lob der Passionsblume, das ich im folgenden Kapitel näher analysieren werde.

\footnotetext{
131 Vgl. dazu die Kommentare von Russo, S. 1770, und Pozzi, S. 621.

132 Das Staunen ist es, sage ich, das den Glauben der anderen vorwärtstreibt: / Unter der Brust auf der linken Seite / trug der schöne Körper des kleinen Jungen / völlig ungewöhnlich und erstaunlich ein Zeichen. / Es hat das Aussehen einer leuchtend roten Rose, / einen purpurnen Fleck hat das Schicksal dort gemalt, / als wollte die Göttin der Liebe / ihr Wesen in sein Herz einprägen.
} 
Im achtzehnten Canto werden die mythologischen, die romanzesken und die humoristischen Fäden zusammengeführt: Die Magierin Falsirena informiert Mars über den Betrug von Venus mit Adonis, woraufhin Mars und Diana einen Hinterhalt für Adonis vorbereiten. Dieser stirbt durch das Wildschwein - allerdings nicht, weil dieses so grausam ist, sondern weil es sich in Adonis verliebt. Der klassische Tod des Adonis wird über das Motiv der Liebe ins Humorvolle gewandelt.

Adonis wird durch ein «göttliches Wunder» («miracolo divino», XIX, 420, V. 3) in eine Anemone verwandelt, seine eigentliche Metamorphose aber erfolgt im zwanzigsten Canto. Dieser Canto ist mit 515 Stanzen der umfangreichste von allen: Er ist betitelt mit «Die SCHAUSPIELE 》 (XX, Allegoria) und beinhaltet die «Beerdigungsspiele zu Ehren Adonis" ». ${ }^{133}$ Letztere erinnern an verschiedene literarische - antike und mittelalterliche - Vorbilder. ${ }^{134}$ Der dritte Spieltag ist der "giostra della quintana" gewidmet, wobei Vertreter nobler, vorwiegend italienischer Familien als Mitstreiter auftreten. Im finalen Duell ${ }^{135}$ stehen sich Spanien - in der Figur Austrias - und Frankreich - in der Figur Fiammadoros - gegenüber.

Ne l'incognita coppia ognuno affisse pien di diletto e di stupore il ciglio, e come un doppio sol quivi apparisse, d'ogni intorno ne nacque alto bisbiglio. Il nome d'amboduo prima si scrisse, il guerrier dal leone e quel dal giglio; indi fur da la sorte in egual loco a vicenda e del pari ammessi al gioco. ${ }^{136}(\mathrm{XX}, 383)$

Nach drei Unentschieden ringt Austria Fiammadoro zu Boden, verliert dabei aber ihren Helm und gibt ihre weibliche Identität preis ${ }^{137}$ - die tragische Szene zwischen Tancredi und Clorinda wird hier, unter neuen Vorzeichen,

\footnotetext{
133 Russo, Einleitung zum neunzehnten Gesang, S. 2143.

134 Ebd., S. 2143-2144.

135 Das Spiel der Quintana, in dem ein Streiter mit einer Lanze auf eine Puppe losgeht, wendet sich hier in ein „echtes“ Duell. Siehe Che RCHI, La metamorfosi, S. 21.

136 Auf das unbekannte Paar fixierten alle / mit Vergnügen und Staunen ihre Augen, / und als würde dort eine doppelte Sonne auftauchen, / entstand rundumher ein lautes Flüstern. / Zuerst wurde der Namen der beiden geschrieben, / der Krieger des Löwen und jener der Lilie; / danach wurden sie vom Schicksal am gleichen Ort / gegenseitig und ebenbürtig zum Spiel zugelassen.

137 Der ganze zwanzigste Canto weist eine Vielzahl von Verweisen auf den Orlando Furioso und die Gerusalemme Liberata auf. Diese Stelle ist wohl eine der offensichtlichsten in der Anspielung auf das Duell zwischen Clorinda und Tancredi (GL, III, 22).
} 
wiederholt. Fiammadoro ist so erstaunt über ihre Schönheit, dass er seinen Helm ebenfalls abnimmt - und umgekehrt auch Austria von seiner Schönheit hingerissen ist (XX, 397-4O3). Venus sieht in Fiammadoro «den teuren Adonis, wiederauferstanden » $(\mathrm{XX}, 4 \mathrm{O}, \mathrm{V} .4)$ - der Name des Adonis tritt an dieser Stelle zum letzten Mal auf. Erinnert die Begegnungsszene, geprägt vom Staunen über die jeweilige Schönheit, an das innamoramento zwischen Adonis und Venus, weisen sowohl Austria als auch Fiammadoro äusserliche Ähnlichkeit zu Adonis auf.

Fiammadoro trägt auf seiner Brust ein Zeichen, das an die « rosa vermiglia » von Adonis erinnert:

Sì vissi e crebbi et, oh stupor, del petto

scritte portai nela sinistra parte

note di sangue il cui tenor fu letto:

,Fiammadoro è costui, figlio di Marté.

Quindi poi Fiammador fui sempre detto,

e fu di quel gran dio mirabil arte

che come mi campò pria ch'io nascessi

così, credi, curò gli altri successi. ${ }^{138}(\mathrm{XX}, 468)$

Der Ausruf «oh stupor» kann sowohl auf die Parallele zu Adonis als auch auf den Fakt, dass Fiammadoro von Mars abstammt, bezogen sein.

Austria hingegen hat ihr Leben ähnlich wie Adonis der Jagd gewidmet, wobei sie einen Angriff zweier Wildschweine erfolgreich abgewehrt hat. Austria und Fiammadoro erweisen sich - im Gegensatz zu Adonis - als wahre Helden. ${ }^{139}$

Austria nome mi pose; e 'ntanto essendo già de' tre lustri oltre l'età cresciuta, in Austrasio, ch'un giorno a caccia uscendo avea de' suoi la compagnia perduto, mentre ch'a fronte avea cinghale orrendo a caso mabbattei non conosciuta. L'uno era inerme e l'altro fiero e forte, io questo uccisi e quel campai da morte. ${ }^{140}(\mathrm{XX}, 438)$

138 So lebte und wuchs ich, oh Erstaunen, und trug in der Brust, / eingeschrieben auf der linken Seite, / Zeichen aus Blut, in dem folgendes zu lesen war: / ,Das ist Fiammadoro, Sohn des Mars.' / So wurde er danach immer Fiammadoro genannt / und es war die erstaunliche Kunst dieses grossen Gottes, / die, so wie sie mich durchdrang, bevor ich geboren wurde, /glaube mir, auch die anderen Erfolge begleitete.

139 Cherchi, La metamorfosi, S. 25.

140 Austria hat er mir als Namen gegeben; und als ich / bereits älter als fünfzehn Jahre alt war, / an einem Tag, als er von der Jagd zurückkam, / weil er seine Begleiter verloren hatte / und vor sich ein schreckliches Wildschwein hatte, / stiess ich zufällig auf Austrasio, ohne 
Adonis, der im Laufe des Epos zahlreiche Male als androgyne Figur erschien,

rinasce nella nuova storia sdoppiandosi in una coppia di uomo e di donna. Questa è la vera metamorfosi di Adone. È una metamorfosi, s'intende, non di natura corporea bensì di una sostanza poetica che in questo caso non può essere che il personaggio. ${ }^{141}$

Die Geschichte von Austria und Fiammadoro weist eine ganze Anzahl weiterer Metamorphosen auf: Die mythische wird in eine politisch-prophetische Geschichte gewandelt. Der Tod, der am Ende von Venus' und Adonis' Liebe steht, wird in eine glückliche Hochzeit verkehrt. Die Handlung weicht am Ende des Epos einer langen Ekphrasis von Fiammadoros Schwert: Die erzählende wird zur figurativen Darstellung.

Dieser Abriss zeigt in groben Zügen zum einen die Wandlungen der Narration durch verschiedene Mythen und Genres, zum anderen die Ambivalenz der Figuren und Inhalte. Was sich äusserlich als kohärentes Werk präsentiert - durch den bekannten Mythos von Venus und Adonis sowie die vorweg erklärten Allegorien -, erweist sich als eine Überfülle verschiedener Motive und Inhalte, die nur zum Teil ineinandergreifen. Spricht Cherchi vom Prinzip der Nähe und der Analogie, ${ }^{142}$ würde ich den Adone eher mit dem Prinzip der Überlagerung und Aufschichtung - als Ergebnis der unzähligen Transformationen - bezeichnen.

Mit dieser Struktur realisiert der Adone alle Eigenschaften, die zu einem Gesamteindruck des Staunens führen, wie Marino sie in seinen Briefen gefordert hat: Das Erzählte präsentiert sich aufgrund der vielen Wandlungen ständig in neuem Gewand - in keinem vorangehenden Werk werden so viele traditionelle Genres unter neuen, teilweise verkehrten Vorzeichen spielerisch zusammengeflochten -, es zeugt von Marinos überbordender Fantasie sowie von künstlerischer Freiheit.

\subsubsection{Die Liebe}

Das innamoramento zwischen Venus und Adonis bildet das zentrale Motiv des Adone, wobei dieses sowohl Binnen- als auch Rahmenerzählung ist und als

erkannt zu werden. / Der eine war wehrlos und das andere stolz und stark, / ich tötete dieses und rettete jenen vor dem Tod.

141 Vgl. ebd. Vgl. dazu ebenfalls Francesco GuARdiani, Il gran teatro del mondo, ovvero il mondo a teatro (canto XX: Gli spettacoli), in: DERS., Lectura Marini, S. 334.

142 Cherchi, La metamorfosi, S. 16. 
Letztere zahlreiche weitere innamoramenti beinhaltet. ${ }^{143}$ Ausgangspunkt ist der dritte Canto:

Anche sul piano narrativo il canto è parte che rispecchia il tutto: per il sincopato attivismo di Venere, per il ruolo di agente cruciale di Amore, vero motore dell'azione su un piano reale e ideale, per la complementare passività di Adone, ripetutamente agito, a lungo persino addormentato e poi subito disposto a porsi sul piano inclinato del linguaggio tutto concetti e intarsi adottato da Venere. Il giovinetto si precisa man mano come oggetto di sguardi innamorati, o in alternativa come passivo portatore di uno sguardo ammirato a fronte delle meraviglie che gli vengono offerte, a partire dal palazzo e dalle fontane su cui si chiude il canto. ${ }^{144}$

Adonis wird zum Objekt verliebter Blicke mehrerer Figuren: zuerst von Venus, dann von Falsirena (XII) und Filauro (XIV) und schliesslich vom Wildschwein (XVIII), das ihn aus Versehen tötet. Diese vier innamoramenti weisen spezifische Konnotationen auf: mythologische, romanzeske und humoreske. Adonis ist zum einen das Objekt verliebter Blicke, zum anderen ist er erstaunter und bewundernder Zuschauer der Wunder, die ihm dargeboten werden. Ich werde im Folgenden zeigen, ob und wie dieser Blick sich analog zu den genannten innamoramenti transformiert.

Marino gestaltet das innamoramento zwischen Venus und Adonis als Spiel von Erscheinungen und Enthüllungen. Venus wird wider Willen vom Pfeil Amors getroffen und begibt sich anschliessend verkleidet als keusche Jagdgöttin Diana in den Wald, in dem Adonis sich ausruht. Referenzszene der Annäherung von Venus und Adonis ist die Episode zwischen Armida und Rinaldo aus Tassos Gerusalemme Liberata (XIV. Canto), ${ }^{145}$ ebenso klingt die

143 Im vierten Canto wird die Geschichte von Amor und Psyche erzählt, im fünften die unglücklich endenden Liebesgeschichten von Narziss, Ganimedes, Kyparissos, Ila und Atide. Im zwölften Canto verliebt sich Falsirena in Adonis, im vierzehnten Canto erzählt Sidone seine Geschichte mit Dorisbe, im achtzehnten Canto stirbt Adonis durch das Wildschwein, das in ihn verliebt war. Im neunzehnten Canto folgt erneut eine ganze Serie mit unglücklichen Liebesepisoden aus der Mythologie zum Trost der Venus, während der zwanzigste und letzte Gesang mit dem innamoramento von Austria und Fiammadoro schliesst.

144 Russo, Einleitung zum dritten Gesang, S. 306.

145 Rossi, Canto III, S. 37. Die Überlagerung von Adonis mit Rinaldo ist, wie Rossi klar aufzeigt, sowohl narrativer als auch thematischer, formaler und lexikaler Natur. Sowohl Rinaldo als auch Adonis gelangen auf eine Insel, wo sie schlafend von einer Frau bewundert und schliesslich geküsst werden, beide werden in einen Palast und in ein Theater geführt, in beiden Episoden werden « Liebespraktiken » vollzogen. Armida überlagert allerdings nicht nur die Figur der Venus, sondern auch jene von Falsirena, die im XII. Canto erscheint. 
erste Begegnung zwischen Angelica und Medoro des Orlando Furioso (XIX. Canto) an. ${ }^{146}$ In den mythologischen Figuren schwingen so von Beginn an auf fragmentarische Weise - ihre episch-romanzesken Pendants mit.

Adonis erlebt das innamoramento passiv im Schlaf und im Traum, ${ }^{147}$ Venus hingegen nimmt die aktive Rolle ein und nähert sich dem schönen Jüngling wie ein Spürhund:
Sì come sagacissimo seguso, poi che raggiunta ha pur tra fratta e fratta vaga fera talor, col guardo e 'l muso esplorando il covil fermo s'appiatta, e'n cupa macchia rannicchiato e chiuso par che voce non oda, occhio non batta, mentre il varco e la preda ov'ella sia immobilmente insidioso spia,
così la dea d'Amor, poi che soletta giunge a mirar l'angelica sembianza, ch'a le goie amorose il bosco alletta e del suo ciel le meraviglie avanza, resta immobile e fredda e 'n su l'erbetta, di stupor sovrafatta e di speranza, siede tremante, e il bel che l'innamora stupida ammira e reverente adora. ${ }^{148}$ (III, $7{ }^{1-72}$ )

Der Vergleich von Venus mit einem Spürhund ist ungewohnt, ${ }^{149}$ ebenso sind die beiden Bilder des jägerischen Aufspürens und der staunenden Bewunderung nur bedingt miteinander kompatibel. Weiter steht die « angelica sembianza » üblicherweise für eine wunderschöne (Jung-)Frau, nicht für einen Mann - der

146 Ebd., S. 40. Genauso wie Adonis Venus' Verletzung - ein Rosendorn steckt in ihrer Ferse kuriert, kümmert sich Angelica um den verletzten Medoro.

147 Ebd., S. 37.

148 Wie ein scharfsinniger Spürhund, der, / nachdem er zwischen Gestrüpp und Gesträuchern / ein anmutiges Tier aufgespürt hat, mit Blick und Nase / den festen Bau erforscht, der sich abflacht, / sich zuammengekauert versteckt in einer dunklen Ecke, / wo es scheint, als würde man keinen Laut hören, kein Auge zwinkern, / während er dem Durchgang und der Beute, wo diese auch sei, / unbeweglich und hinterhältig auflauert, // so verlockt die Göttin der Liebe, nachdem sie alleine / beim Bestaunen des engelsgleichen Antlitzes angelangt ist, / den Wald zu Liebesfreuden, / und aus ihrem Himmel bringt sie Wunder herbei, / sie bleibt unbeweglich und kalt und auf dem Gras, / vom Staunen überwältigt und von der Hoffnung, / sitzt sie zitternd, und den Schönling, der sie verliebt machte, / bewundert sie stumpfsinnig und betet ihn ehrfürchtig an.

149 Russo, Commento, S. 340. 
notabene eigentlich ein Jäger wäre. ${ }^{150}$ In der Folge werden Adonis weitere weibliche Attribute aus der Liebeslyrik zugeschrieben: die schöne Hand sowie die Augen, in den Stanzen 126-127 wird er sogar mit einer Jungfrau verglichen. ${ }^{151}$

Venus ist Trägerin des staunenden Blickes: Vor Staunen überwältigt («di stupor sovrafatta») bewundert sie zitternd den Schönling («stupida ammira»). Sinnbild der sinnlichen Liebe auf der einen Seite, schwingt mit « reverente adora » auf der anderen Seite ein religiöser Kontext mit. ${ }^{152}$

Der Vergleich der Venus mit dem Spürhund geht in den Vergleich der Venus mit einem Maler über: Venus beobachtet ihr Motiv genau, formt dann die Umrisse, um diese schliesslich - «mit der Hand, Schülerin der Kunst »- mit Farbe zu füllen: «Und mit ebendiesem Pfeil von Amor / nagelt und stösst sie sich mitten ins Herz » (III, 78, Vv. 7-8). Gleichzeitig bewundert Adonis das Bild der Venus, das Morpheus ihm in seinen Träumen platziert:
Apena ha queste ultime note espresse, che l'amico Morfeo, che l'è vicino, fabrica d'aria e di vapori intesse simulacro leggiadro e peregrino. Di tai forme si veste e scopre in esse di celeste beltà lume divino. Donna, chè tutta luce e foco spira, nel teatro del sonno Adone ammira. ${ }^{153}$ (III, 92)

Die Bewunderung der « Mutter Amors und Göttin der Schönheit» (III, 93, V. 8) steigert sich zum « alto stupore » und weicht schliesslich dem Schmerz, als die Göttin - immer noch im Traum - ihm die Flanke öffnet und das Herz entreisst:

Mentre d'alto stupore Adon vien manco, già pargli già la bella larva udire, che stendendo una man d'avorio bianco: «Adon, dammi il tuo cor» gli prende a dire. E fu quasi un sol punto aprigli il fianco, dispiccarglielo a forza e disparire.

\footnotetext{
150 Rossi, Canto III, S. 38. Als Ausnahme nennt Rossi Medoro (OF, XVIII, 166, V. 8).

151 Ebd.

152 Russo, Commento, S. 341.

153 Sobald sie diese letzten Laute gesprochen hat, / beginnt ihr Freund Morpheus, der neben ihr ist, / aus Luft zu formen und mit Dampf zu verweben / ein anmutiges und sonderbares Bild. / Mit diesen Formen kleidet er sich und enthüllt in ihnen / ein göttliches Licht von himmlischer Schönheit. / Die Frau, die ganz Licht ist und Feuer atmet, / bewundert Adonis im Theater des Schlafes.
} 
Sognando il bel garzon si dole e geme,

sì che la vera dea ne langue insieme, ${ }^{154}$ (III, 94)

Auch als Adonis aus dem Schlaf erwacht, reagiert er mit Staunen auf den Anblick der Göttin:
Al suon del bacio, ond'ella ambrosia bebbe, l'adormentato giovane destossi e poi ch'alquanto in sé rivenne et ebbe del grave sonno i lumi ebri riscossi, tanto quel vago oggetto in lui s'accrebbe stupor, ch'immoto e tacito restossi; indi da lei, ch'a l'improviso il colse, per fuggir sbigottito il pié rivolse. ${ }^{155}$ (III, 102)

Einerseits ist Adonis starr («immoto») vor Staunen, andererseits macht er sich zur Flucht bereit. Beides sind - entgegengesetzte - Reaktionen des Aussersichseins. Dieses wird durch die Position von «stupor» zusätzlich untermauert: «Stupor» steht als Enjambement ausserhalb der vorherigen Zeile, zu der es syntaktisch gehört, und ist - getrennt durch ein Komma - auch innerhalb seiner Zeile isoliert. Es weist rückwärts («immoto») und vorwärts («per fuggir sbigottito il pié rivolse»). Es ist das einzige Wort der Stanze mit einem „st"-Anlaut und reimt sich auf keines der anderen Wörter - seine herausragende Stellung wird dadurch untermauert.

Die Enthüllung der Venus vor Adonis speist sich aus dem künstlerischen Wort- und Bildschatz: Die Göttin erscheint als « eigenes Abbild », wobei sie an der Oberfläche das Bild einer « heiligen Figur / kunstvoll abgebildet », gezeigt hat und jetzt ein « anderes Gemälde / von laszivem Pinsel » zum Vorschein kommt (III, 125-126).

154 Während Adonis vor lauter Staunen fast ohnmächtig wird, / scheint er bereits den schönen Geist zu hören, / der eine elfenbeinfarbene Hand ausstreckt: / « Adonis, gib mir dein Herz », beginnt sie zu sagen. / Und es scheint ein Punkt, an dem sie ihm die Flanke öffnet / und ihm das Herz mit Gewalt herausreisst und verschwindet. / Träumend klagt und stöhnt der schöne Jüngling, / sodass sich die echte Göttin gleichsam verzehrt,

155 Beim Laut des Kusses, von dem sie Ambrosia trank, / erwachte der schlafende Jüngling, / und als er nach einiger Zeit zu sich kam und / den schlaftrunkenen Schein des tiefen Schlafes zurückstiess, / erzeugte das anmutige Objekt in ihm so viel / Staunen, dass er unbeweglich und schweigend dastand; / dann wendete er seinen Fuss, um vor ihr, die ihn / plötzlich erfasste, bestürzt zu fliehen. 
[...] lo svelamento è oggetto di maraviglia in costanzo $R$. inc. La Fama in celebrar or questa or quella: «E quel che dice è sol quasi una tela Sotto cui tal pittura ascosa tensi Che con stupor altrui poi si rivela ». ${ }^{156}$

So wird denn auch das «svelamento » der Venus von Adonis mit grossem Staunen zur Kenntnis genommen:
Al bel garzon, che stupefatto resta veduto il primo aspetto in aria sciolto, la bella dea discopre e manifesta in un punto medesmo il core e 'l volto: ${ }^{157}$ (III, 128, Vv. 1-4)

Über die staunenden Augen und die Ohren dringt Amor in Adonis' Herz ein:
Mentre languia l'innamorata dea,
Adon con fise ciglia in lei rivolto tutto rapito a contemplar godea le meraviglie del celeste volto, e quivi in vista attonito scorgea il bel del bello in breve spazio accolto.
Fra i detti intanto e fra gli sguardi Amore gli entrò per gli occhi e per l'orecchie al core..$^{158}$ (III, 136)

Was Venus sagt, bewegt ihn; was er sieht, erstaunt ihn und nimmt ihn gefangen («tutto rapito », « attonito »). Über die «meraviglie del celeste volto » wird er der Essenz des Schönen (« il bel del bello ) gewahr.

Das innamoramento zwischen Adonis und Venus speist sich aus gegenseitigen Blicken und entspringt dem jeweiligen Staunen über das « engelsgleiche» (III, 72, V. 2) bzw. das « göttliche, übermenschliche Aussehen » (III, 132, V. 8). Die Staunensmomente des Adonis sind damit schon fast ausgereizt, denn er staunt nur noch über Amors Erzählung seiner Liebesgeschichte mit Psyche (IV, 293) sowie über dessen Palast (V, Vv. 7-8), ebenso über Lascivia im achten Canto (VIII, 31). Trotzdem bleibt er weiterhin ein Staunensobjekt, seine Schönheit der Anlass für weitere innamoramenti.

156 Pozzi, Commento, S. 252. Vgl. ebenso Russo, Commento, S. 366.

157 Dem schönen Jüngling, der erstaunt zurückbleibt, / nachdem er die erste Erscheinung sich in Luft auflösen sah, / enthüllt sich die schöne Göttin und zeigt ihm / auf einmal ihr Herz und ihr Gesicht.

${ }_{158}$ Während die verliebte Göttin sich verzehrte, / richtete Adonis seine Augen ganz auf sie, / völlig gefangen in der Betrachtung genoss er / die Wunder des himmlischen Anlitzes / und entdeckte im erstaunten Anblick / das Schöne des Schönen auf kleinem Raum versammelt. / Zwischen den Worten und den Blicken kam / Amor in sein Herz, durch die Augen und die Ohren. 
Nachdem Adonis mit Venus die Gärten der Sinne durchwandert hat, gelangt er mit ihr zum Brunnen des Apollon und wird schliesslich von Merkur in himmlische Sphären eingeführt. Die beiden trennen sich, als Mars vom Betrug der Venus erfährt und Rache üben will. Das Epos öffnet sich für ein romanzeskes Zwischenspiel:

L'amore tra Venere e Adone conosce, nella terna dei canti XII-XIV, una parentesi di distacco, lontananza e persino tradimento, cun un'interpolazione inedita nella favola originaria che consente al Marino l'adozione ampia di moduli romanzeschi, a movimentare la struttura del poema mitologico. ${ }^{159}$

Adonis wird von der Dryade Silvania als umherirrender Liebender im Wald aufgegriffen. ${ }^{160}$ Seine Züge erinnern sowohl an Orlando als auch an jene von Angelica und Tassos Erminia. ${ }^{161}$ Sein Anblick erfüllt Silvania mit Staunen:

Quand'ella gli occhi in que' begli occhi affisa

che fan la dea d'Amor d'amor languire,

si sente il cor subitamente in guisa

tutto d'alta dolcezza intenerire,

ché stupida e da sé quasi divisa,

più oltre di parlar non prende ardire; ${ }^{162}$ (XII, 115, Vv. 1-6)

Obwohl vom Staunen überwältigt, findet Silvania schnell wieder zu sich und erklärt Adonis, was es mit dem Reich der Magierin Falsirena auf sich hat. Falsirena selbst verfüge nicht nur über grösstes Vermögen und Können, sondern auch über eine ausserordentliche Schönheit, die mit jener von Venus wetteifere (XII, 127). Allerdings sei ihr vorausgesagt worden, dass ihre Liebespassion immer mit Wut und Schmerz einhergehen werde, weshalb sie sich für ein enthaltsames und einsames Leben entschieden habe (XII, 129). Falsirena bildet als schöne und enthaltsame Jungfrau einen starken Kontrast zu ihren Vorgängerinnen: Alcina aus dem Orlando Furioso ist eigentlich eine hässliche und verruchte Alte («puttana vecchia », OF, VII, V. 79), die nur vorgibt, eine schöne junge Frau zu sein; ${ }^{163}$ Tassos Armida ist zwar ebenfalls eine schöne

\footnotetext{
159 Russo, Einleitung zum zwölften Gesang, S. 1177.

16o Siehe dazu XII, 95, Vv. 1-2.

161 Russo, Commento, S. 1221.

162 Während sie ihre Augen in diese schönen Augen vertieft, / die die Göttin der Liebe vor Liebe schmachten lassen, / fühlt sie ihr Herz unmittelbar wie / erfüllt von grösster Sanfheit weich werden, / sodass sie erstaunt und quasi von sich getrennt / es nicht wagt, weiterzusprechen;

163 Francesco Guardiani, Da Ariosto a Marino, da Alcina a Falsirena: La maga seduttrice fra tradizione e innovazione, 2009, S. 4. Online-Artikel auf https://tspace.library.utoronto. ca/handle/18o7/2499o (Stand April 2021).
} 
junge Frau, aber sie stellt ihre erotischen Reize offen zur Schau und setzt ihre Verführungskünste taktisch und politisch ein. Falsirena repräsentiert somit nicht nur eine «magische Umkehr [...] von Venus», ${ }^{164}$ sondern auch eine transformierte Version ihrer literarischen Vorgängerinnen.

Der Weg zu Falsirena führt über einen magischen Nussbaum:

Grande è la pianta et oltre l'esser grande, ciò che d'ogni stupor trascende i modi è che ne' rami che dintorno spande, son d'oro i frutti ben massicci e sodi. ${ }^{165}$ (XII, 133, Vv. 1-4)

Poi lo guidaro ufficiose e pronte con mille ossequi a l'ammirabil noce; e lasciato lo stral, deposto l'arco, gli apriro il passo e gli spediro il varco. ${ }^{166}$ (XII, 146, Vv. 5-8)

Repente allor de l'arbore ch'io dissi crepò la scorza e 'l voto ceppo aperse. Tutta per mezo (o meraviglia) aprissi et a la coppia il cavo ventre offerse. Quindi per una via che 'nver gli abissi scender parea Silvania il pié converse e, passando a le viscere più basse de la buccia capace, Adon vi trasse. ${ }^{167}$ (XII, 147)

Die Episode mit Falsirena wird durch den erstaunlichen Eingang als fantastische markiert. Palast und Garten sind gänzlich versteinert: Sie bestehen nur aus Edelsteinen $^{168}$ (XII, 151-154) und sind deutlich - viel mehr noch als Venus' Gärten der Sinne - der Realität entrückt.

164 Russo, Einleitung zum zwölften Gesang, S. 1178.

165 Gross ist die Pflanze und neben ihrer Grösse / übersteigt es jede Art des Staunens, / dass an den Ästen, die sie um sich ausbreitet, / goldene Früchte hängen, kräftig und fest.

166 Danach führten sie ihn geschäftig und bereit / mit tausend Empfehlungen zum erstaunlichen Nussbaum; / und nachdem Pfeil und Bogen abgelegt waren, / öffneten sie ihm den Durchgang und schickten ihn hindurch.

167 Plötzlich barst beim Baum, von dem ich erzählte, / die Rinde und der hohle Wurzelstock öffnete sich. / Direkt in der Mitte ging er auf (oh Wunder) / und bot dem Paar den hohlen Bauch dar. / Dann schien auf einen Weg in die Tiefen / Silvana ihren Fuss zu wenden / und Adonis mitzunehmen, soweit die Schale es aushielt, / in die inneren Eingeweide vordringend.

168 Im dritten Canto wurden Adonis und Venus abwechslungsweise mit Edelsteinmetaphern beschrieben. Siehe Rossi, Canto III, S. 43: « [...] perle sono le gocce di sudore sul volto di Adone $(9,7)$ e i denti del giovane $(96,2)$, urna di gemme la sua bocca $(96,5)$, di smeraldo è il suolo sul quale egli riposa $(13,6)$, d'oro sono le piume di Cupido $(23,5)$ e le branche della fibbia posta sull'omero di Venere-Diana, il cui vestito è sospeso ad uno zaffiro $(57,3-4)$, 
Analog zu Venus und Silvania reagiert auch Falsirena mit Staunen auf den Anblick des Adonis, die gesamte Szene ist ein (Wort-)Spiel rund um meraviglia und mirare:

Tosto ch'ella in Adon fermò le ciglia, pria ferita che vista esser s'accorse.

Stupor, timor, vergogna e meraviglia la tenner dubbia e de la vita in forse. Pallida pria divenne, indi vermiglia, e per le vene un gran tremor le corse. Sente quasi per mezo il core aprirsi né sa con l'arte sue punto schermirsi.

Falsirena, che miri? A che più stai sospesa sì? Quest'è il sembiante istesso lungo tempo temuto. Eccoti omai de l'ombra il ver. Che miri? Egli è ben desso. Questi son pur que' luminosi rai che già tanto fuggivi, or gli hai da presso. Perché non schivi il tuo dolor fatale?

Dov'è il tuo senno? O tua virtù che vale?

Mira e non sa che mira e mira molto ma poco pensa e sospirando anela. Varia il colore, il favellar l'è tolto, sta confusa e smarrita, avampa e gela. Tien fiso il guardo in quel leggiadro volto, non palesa i desiri e non gli cela. Abassa gli occhi per fuggir assalto, poi le mani incrocicchia e gli erge in alto. ${ }^{169}$ (XII, 174-176)

d'argento è Venere in fronte $(63,3)$ e la nube che avvolge l'amplesso dei due innamorati $(153,5)$, di rubino è la rosa di 67,4 e così via. » Ebenfalls im dritten Canto finden sich die Liebesmonologe der Venus, die mit jenen von Falsirena im XII. Canto kontrastieren.

169 Als ihr Blick auf Adonis ruhte, / nahm sie zuerst wahr, dass sie verletzt war, und dann, dass sie angesehen wurde. / Staunen, Angst, Scham und Verwunderung / liessen sie zweifeln, lebendig zu sein. / Zuerst wurde sie bleich, dann leuchtend rot, / und durch ihre Venen ging ein grosses Zittern. / Sie spürt, wie sich ihr Herz quasi in der Mitte öffnet, / und weiss sich mit ihren Künsten nicht zu wehren. // Falsirena, worüber staunst du? Weshalb bist du derart / aufgelöst? Das ist jenes Anlitz, / vor dem du dich lange gefürchtet hast. Hier ist jetzt / die Wahrheit dieses Schattens. Worüber staunst du? Er ist es. / Das sind lediglich die leuchtenden Strahlen, / vor denen du seit langem fliehst, jetzt hast du sie in deiner Nähe. / Weshalb meidest du nicht den Schmerz deines Schicksals? / Wo ist dein Verstand? Was nützt dir jetzt deine Kraft? // Sie staunt und weiss nicht, dass sie staunt, und staunt doch sehr, / aber denkt nur wenig und verzehrt sich seufzend. / Sie verändert ihre Farbe, das Sprechen wurde ihr genommen, / sie ist verwirrt und verstört, sie glüht und gefriert. / Sie hält ihren Blick an diesem anmutigen Gesicht fest, / ohne ihr Begehren zu offenbaren 
Die erste Stanze ist vom Reim «ciglia - meraviglia - vermiglia » durchdrungen: Das Staunen mischt sich mit Scham und zeigt deutliche körperliche Reaktionen. «[T]remor» fliesst durch Falsirenas Venen und sie fühlt, wie ihr das Herz herausgerissen wird (XII, 174). Sie stirbt, obwohl sie unsterblich ist - ein « unaussprechliches, unglaubliches Wunder» (« meraviglia ineffabile inaudita »), wie Falsirena selbst konstatiert (XII, 206, V.5). Die zweite Stanze ist durch die rhetorischen Frageausrufe («che miri?») des Erzählers strukturiert. Adonis ist nichts weiter als die Erfüllung ihres Schicksals: Wieso also staunen? Wo sind ihr Verstand und ihre magischen Fähigkeiten geblieben? Gegen das Staunen ist sie machtlos, „es“ staunt quasi in ihr: « Mira e non sa che mira e mira molto » (XII, 176, V. 1). Falsirena übernimmt die Rolle der „furiosen Geliebten“; das Schlussbild - die verschränkten Hände, die hochgehoben werden - gibt der Szene eine figurative, aber zugleich komische Wendung. ${ }^{170}$

So wie Venus Adonis in ihren Palast geführt hat, geleitet auch Falsirena Adonis in ihren prächtigen Palast. Analog zu Venus versucht Falsirena, sich dem schlafenden Adonis in verführerischer Aufmachung zu nähern und ihn zu küssen (XII, 240). Analog zum dritten Canto (III, 102) reagiert Adonis mit Staunen, wobei dieses auch an dieser Stelle durch die Antwort Falsirenas ins Komische konvertiert wird:

$\mathrm{Ei}$, che leggier dormiva e 'n parte tratto s'avea del sonno il natural desio, a quel moto si scosse e stupefatto le luci in prima e poi le labra aprio. «Chi se' tu? » disse. Et ella in languid'atto e 'n suon piano e sommesso: « Io mi son io ». Stupisce Adon quando di lei s'accorge e da le piume a reverirla sorge. ${ }^{171}$ (XII, 244)

Die Serie der Analogien wird weiter durchbrochen, als Adonis Falsirena zurückweist. Die Magierin bleibt erschüttert und verwirrt zurück:

oder zu verstecken, / sie senkt ihre Augen, um einem Überfall zu entgehen, / dann verschränkt sie ihre Hände und hebt sie nach oben.

170 Russo, Commento, S. 1254.

171 Er, der leicht schlief und sich teilweise / das natürliche Begehren des Schlafes zurückzog, / schüttelte sich bei dieser Bewegung und öffnete / erstaunt erst seine Augen und dann seine Lippen. / « Wer bist du? », fragte er. Und sie, schmachtend / und mit leisem, unterdrücktem Ton: «Ich bin ich. » / Adonis staunt, als er ihrer gewahr wird, /und erhebt sich aus den Federn, um sich ihr zu empfehlen. 
Poi che tra lo stupore e la pietate

Adon dubbio tra sé ristette alquanto,

e prestò più benigne e men turbate

l'orecchie a quel pregar, le luci al pianto,

in sua voglia ostinossi a l'ascoltate

note, non men che soglia aspe a l'incanto;

sopir però quelle faville accese

volse, se non pietoso, almen cortese. ${ }^{172}$ (XII, 251)

Muta, confusa, attonita mentr'egli

in tal guisa parlò, tacque e sofferse

Falsirena infelice e gli occhi begli

rugiadosi di perle al suol converse. ${ }^{173}$ (XII, 259, Vv. 1-4)

Die Magierin ist ihrer Wirkkraft beraubt - daher der Name „Falsirena“ -, was vor dem Hintergrund ihrer literarischen Vorbilder überrascht. Gleichzeitig leistet Adonis - bisher eine passive Figur - plötzlich aktive Gegenwehr. Es hat wiederum ein rovesciamento der Rollen stattgefunden.

Galt Adonis' Staunen gegenüber Venus deren überirdischer Schönheit, reagiert Adonis zwar erstaunt über Falsirenas nächtlichen Übergriff, staunt aber nicht über sie als Person oder über ihre Schönheit - obwohl diese als ebenbürtig zu jener von Venus angekündigt wurde. Im ganzen zwölften Canto finden sich keine weiteren staunenden Blicke aufseiten des Adonis ${ }^{174}-$ im Gegenteil wird über ihn gestaunt, dass er vor der Pracht, dem Reichtum und der Schönheit Falsirenas regungslos bleibt (XII, 267). Adonis ist damit nicht mehr (nur) seiner jugendlichen Schönheit ein Staunensobjekt, sondern aufgrund seiner unberechenbaren, vielgestaltigen literarischen Rolle.

Nach der Rückweisung beginnt Falsirena mithilfe von Idonias, Adonis mit ihrem Reichtum zu bezirzen. Als er auch diesen zurückweist, sperren sie ihn ein und beschliessen, Magie anzuwenden (XII, 292). Adonis hingegen bleibt standfest, auch als er - verwandelt in einen Vogel und über die gewonnene Bewegungsfreiheit staunend (XII, 165) - zurück nach Zypern fliegt und Venus und Mars zusammen sieht (XIII). Adonis kehrt zwar zurück zu Falsirena, aber

172 Als dann zwischen Staunen und Mitleid / Adonis zweifelnd dastand / und bald gütiger und weniger unruhig / seine Ohren diesem Bitten, seine Augen dem Weinen lieh, / bestärkten ihn in seinem Vorhaben die gehörten / Töne nicht weniger, als es die Schlange vor dem Zauber zu tun pflegt; / indes machte er sich daran, die entzündeten Funken / zu beruhigen, wenn nicht mitleidig, so doch höflich.

173 Sie war sprachlos, verwirrt, bestürtzt, während er / auf diese Weise sprach; es schwieg und litt / die unglückliche Falsirena und die schönen Augen, / wässrig von den Tränenperlen, richtete sie zu Boden.

174 Der Erzähler berichtet von der wunderbaren Pracht des Palastes (XII, 162, 189, 271), das Staunen Adonis' aber bleibt aus. 
nur, um seine menschliche Gestalt wiederzuerlangen und erneut zu fliehen. Er tut dies wiederum in verwandelter Gestalt, verkleidet als Frau.

Als weibliche Gestalt wird Adonis - erneut schlafend - von einer Gruppe von Banditen bestaunt, bevor diese ihn gefangen nehmen.
Appressati costoro al giovinetto, che dagli occhi dal sonno ancor sopiti spirava un dolce e languido diletto, stupefatti restaro e sbigottiti, quasi a la vista di quel primo aspetto da repentino folgore feriti.
De l'armi intanto al suon, che tocche e mosse facean strepito insieme, ei si riscosse. ${ }^{175}(\mathrm{XIV}, 20)$

Genauso wie Venus, Silvania, Falsirena und die Banditen reagiert auch Filauro, der mit Adonis im Gefängnis sitzt, mit staunenden Blicken auf Adonis:

Fu messo in compagnia libero e sciolto d'una fanciulla Adone e d'un donzello che nel bosco vicin, non era molto, fur presi e tratti a qual medesmo ostello. Non sì tosto il donzel mirò quel volto, unico e senza pari in esser bello, ch'avido d'involarne i rai leggiadri prese con gli occhi ad imitare i ladri.

$[\ldots]$

Il fanciul, che non sa ciò che nasconde di vero e di viril gonna bugiarda, or i bei lumi, or l'auree chiome bionde fiso contempla e cupido risguarda. Ma quanto mira più, più si confonde e più convien che se n'accenda et arda. Così sviata dietro al cor che fugge l'alma si perde et egli invan si strugge.

Mentre cerca or con gesti, or con parole scoprirgli di qual piaga ha il core offeso, Adon ben se n'accorge e ben si dole di sua follia che 'l sesso in cambio ha preso. ${ }^{176}$ (XIV, 29-32)

175 Als diese sich dem Jüngling genähert hatten, / strömte aus dessen Augen, die noch immer schläfrig schlummerten, / ein süsses und sehnsüchtiges Vergnügen; / sie blieben erstaunt und bestürzt stehen, / als wären sie quasi bei diesem ersten Anblick / von einem plötzlichen Blitz getroffen. / Vom Klang der Waffen, die ergriffen wurden und bewegt / rasselten, wurde er wachgerüttelt.

176 Befreit und losgebunden wurde Adonis / in Gesellschaft eines Mädchens und eines Jünglings gebracht, / die im benachbarten Wald, nicht weit weg, / gefangen und in die gleiche 
Filauros Staunen gilt den topischen lyrischen Merkmalen der weiblichen Geliebten: den «bei lumi» und den «auree chiome bionde»- wobei diese Züge, die Adonis bereits im dritten Canto zugeschrieben wurden, durch die Verkleidung unterstützt und legitimiert werden.

Die Episode erinnert an Bradamante und Fiordispina aus dem Orlando Furioso $(O F, \mathrm{XXV}) .{ }^{177} \mathrm{Im}$ Orlando Furioso löst die Rollenverwechslung sich auf, als Ricciardetto - die männliche Version von Bradamante - erscheint und Fiordispinas Liebe sich auf ihn richten kann: Die gleichgeschlechtliche Liebe wird abgewendet. Im Adone hingegen bringt Filauro sich um: Er sieht seine tote Schwester in den Kleidern von Licasta/Adonis vor sich und meint, es handle sich bei der Getöteten um Adonis. Die Täuschung wird nicht aufgelöst und endet im Selbstmord. Wiederum ist Adonis zum Objekt staunender Blicke geworden, die ihm mehr Leid als Freude bereiten und die er nicht erwidert.

Adonis selbst ist bereits weitergezogen und begegnet Sidonio, als dieser sich in Liebesklagen windet. Adonis bietet sich als Zuhörer seiner Geschichte an. Sidonio ist überrascht und erstaunt über die höflichen Worte und über die herausragende Schönheit des Adonis.

A questo favellar cortese e pio, a quella egregio e signoril presenza, il guerrier placò l'ira e ne stupio, mirando di beltà tanta eccellenza; né men ch'egli di lui, venne in disio d'averne a pien contezza e conoscenza, e gli occhi intento ne' begli occhi affise pensando pur chi fusse, onde venisse. ${ }^{178}$ (XIV, 191)

Unterkunft geführt wurden. / Sofort als der Jüngling das schöne Gesicht betrachtete, / einzigartig und unvergleichlich schön, / war er erpicht darauf, die lieblichen Blicke der Räuber abzuwenden / und sie stattdessen mit seinen Augen zu imitieren. // [...] Der Junge, der nicht wusste, was sich tatsächlich / und männlich unter dem trügerischen Rock versteckte, / versenkte seinen Blick erst in die schönen Augen, / dann in die goldblonden Haare und schaute begierig. / Doch je länger er ihn bestaunt, desto verwirrter ist er / und umso mehr schickt es sich, dass er sich entzündet und brennt. / Derart irregeführt hinter dem Herz, das flieht, / verliert sich die Seele und er verzehrt sich vergebens. // Dass er versucht, einmal mit Gesten, einmal mit Worten, / ihm zu offenbaren, mit welcher Wunde er sein Herz versehrte, / nimmt Adonis wohl wahr und bedauert / seine Torheit, den Tausch des Geschlechts ergriffen zu haben.

177 Russo, Commento, S. 143 o.

178 Bei diesen höflichen und ehrfurchtsvollen Worten, / diesem vortrefflichen und herrschaftlichen Auftreten, / besänftigte der Krieger seine Wut und staunte, / eine derart vorzügliche Schönheit bewundernd; / genauso wie diesem kam ihm der Wunsch, / ihn genau zur Kenntnis zu nehmen und kennenzulernen, / und er heftete die Augen fokussiert auf diese schönen Augen, / daran denkend, wer er wohl sei und woher er käme. 
Sidonio kündigt seine Geschichte als staunen- und mitleiderregend an - es wird eine der wenigen Liebesgeschichten des Adone mit glücklichem Ausgang sein, « Porträt einer wahren und treuen Liebe » (XIV, Allegoria).

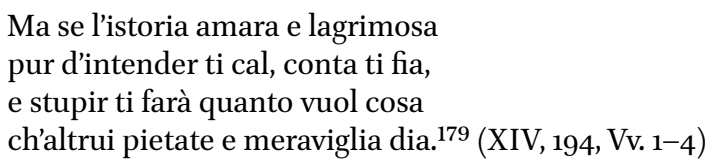

Adonis seinerseits präsentiert sich wiederum in veränderter Rolle und überrascht den Leser durch eine philosophische Redeweise. Er sinniert über die Liebe (XIV, 186, 314-317) und reagiert als cavaliere ${ }^{180}$ mit Bedacht, mitleidig und moralisierend auf Sidonios Geschichte (XIV, 309-310). Unter den staunenden Blicken seiner Gegenüber wandelt sich Adonis' Rolle von Begegnung zu Begegnung, so auch nach dem glücklichen Wiedersehen mit Venus, wenn er in seine (ursprüngliche) Rolle als Jäger zurückkehrt und fruchtlos zu jenem Ort schreitet, an dem sich ein grausames Wildschwein aufhalten soll. Das Bild eines ungeheuren Monsters wird aufgebaut:

Dà fiato allor subitamente al corno stupido Adon d'un animal sì grosso, ${ }^{181}$ (XVIII, 73 , Vv. 1-2)

Adonis versucht, das Wildschwein zu erlegen, wobei er zuerst erfolglos bleibt (XVIII, 82, Vv. 1-4). Als er schliesslich auf jenen Pfeil zurückgreift, den er Amor entwendet hat, flösst er der «alma inumana» «ardor umano» ein. Wenn selbst ein Wildschwein vor Liebe entbrennen kann, wen erstaunt es da noch, dass Byblis ihren Bruder, Myrrha ihren Vater geliebt hat?

Lo stral, che 'l miglior fianco al mostro colse, d'umano ardor l'alma inumana accese, onde quando al fanciul gli occhi rivolse, che da lunge il trafisse e non l'offese, vago del danno suo non se ne dolse, ma per meglio mirarlo il corso stese et ingordito di beltà si vaga, miracol novo, inacerbì la piaga.

179 Aber auch wenn du dich herabsenkst, / um die bittere und tränenreiche Geschichte zu hören, / wird dir erzählt werden, / und es wird dich zum Staunen bringen, wieviel es braucht, / damit in den anderen Mitleid und Verwunderung ausgelöst wird.

180 Russo, Commento, S. 1491.

181 Sofort richtet Adonis seine Puste auf das / Horn, über ein derart gewaltiges Tier staunend. 
Chi dunque stupirà che del fratello

ardesse Bibli con infame ardore?

E Mirra, di cui nacque Adone il bello, ad amar s'accendesse il genitore?

Qual meraviglia fia che questo e quello

per la propria sua specie infiammi Amore,

se nel cor d'una fera ebbe ancor loco

sì violento e mostruoso foco? ${ }^{182}$ (XVIII, 85-86)

Das Staunen über Adonis wird ins Komische transformiert: Das Wildschwein reckt sich, um Adonis besser bestaunen zu können, und vertieft dadurch seine Liebeswunde. Die humoristische Note wird verstärkt, als das Wildschwein wie Venus und Falsirena - versucht, Adonis zu küssen - wobei dieser Kuss derart heftig ausfällt, dass Adonis dabei stirbt.

Tutta calda d'amor la bestia folle, senza punto saper ciò che facesse, col mostaccio crudel baciar gli volle il fianco che vincea le nevi istesse, e, credendo lambir l'avorio molle, del fier dente la stampa entro v'impresse.

Vezzi fur gli urti: atti amorosi e gesti non le insegnò Natura altri che questi.

Vibra quei lo spuntone e gli contrasta ma l'altro incontra lui s'aventa e serra, rota le zanne infellonito e l'asta che l'ha percosso e che 'l disturba afferra, e di man gliela svelle e far non basta Adone alfin che non sia spinto a terra. Latterra e poi con le ferine braccia il cinghial sovra lui tutto si caccia. ${ }^{183}$ (XVIII, 95-96)

182 Der Pfeil, der die rechte Seite des Ungeheuers erwischte, / entflammte die unmenschliche Seele mit menschlicher Glut, / sodass, als es die Augen auf den Jungen richtete, / der von weitem ihn durchbohrte, ohne ihn zu beleidigen, / es seine Verletzung nicht beklagte, / sondern es seinen Lauf beschleunigte, um ihn besser bestaunen zu können, / und gierig nach einer derart anmutigen Schönheit - / neues Wunder - verschärfte sich die Wunde. // Wer also wird staunen über den Bruder, / für den Byblis mit schändlicher Glut brannte? / Und über Myrrha, die den schönen Adonis gebar, / die dafür entbrannte, den Vater zu lieben? / Welch Wunder wäre es noch, wenn dieser oder jener / für jemanden der eigenen Familie von Amor entzündet würde, / wenn gar im Herz einer Bestie Platz fand / ein derart gewaltsames und ungeheuerliches Feuer?

183 Die irrsinnige Bestie, völlig erhitzt vor Liebe, / ohne zu Wissen, was sie tat, / wollte ihn mit der grausamen Schnauze küssen / auf der Seite, die weisser als der Schnee ist, / und meinend, das weiche Elfenbein zärtlich zu lecken, / drückte sie ihm den kühnen Zahn 
Dass der Tod des Adonis derart humoresk dargestellt wird, gibt dem Mythos eine neue und unerwartete Wendung. Das tragische Finale wird suspendiert und - wie im vorangehenden Kapitel dargestellt - in ein episches Finale überführt.

Allen innamoramenti sind die staunenden Blicke vor der Schönheit des Adonis gemein - sie machen aus dem mythischen Helden eine feminisierte Figur der Liebeslyrik. Während Adonis die staunenden Blicke nur an Venus zurückgibt, sind sie in den weiteren innamoramenti - die gleichsam als rovesciamenti der Liebesszene mit Venus betrachtet werden können - Auslöser von Wandlungen, die der Mythos genauso wie die Figur des Adonis durchlebt.

\subsubsection{Die Kunst}

Wie in der Galeria spielt die Kunst auch im Adone eine zentrale Rolle. Die Beschreibungen von Palazzi und Gärten sowie kleinerer Kunstobjekte wie Gemälden und Vasen sind nahtlos in die Handlung eingefügt. Dabei erweisen sich Natur und Kunst als gegenseitige Abbilder: Die Natur wird als Kunstwerk dargestellt, während den Kunstwerken natürliche Lebendigkeit zugeschrieben wird. ${ }^{184}$ Über beides - die künstliche Natur und die lebendige Kunst - wird gestaunt. So bewundert die Natur die Eingangspforte zum Palast Amors:

Vero il finto dirà, vero et espresso uom che v'abbia le luci intente e fise.

L'opra, ch'opra è de l'Arte e quasi spira, com'opra di sua man, Natura ammira. ${ }^{185}$ (II, 22, Vv. $\left.5^{-8}\right)^{186}$

Auch Adonis bewundert den Eingang des Palastes.

Quanto Adon più da presso al loco fassi, più la mente gl'ingombra alto stupore.

- Questo è il ciel de la terra e quinci vassi

hinein. / Die Stösse waren Liebkosungen: andere Liebeshandlungen / und Gesten hat ihm die Natur nicht beigebracht. // Dieser schwingt die Lanze und tritt ihm entgegen, / aber der andere stürmt auf ihn zu und klemmt ihn ein, / noch wütender kreist er mit den Zähnen und ergreift den / Speer, der ihn getroffen hat und ihn stört, / und reisst ihn ihm aus der Hand, und Adone kann / nichts tun, um nicht zu Boden geworfen zu werden. / Das Wildschwein reisst ihn nieder und / wirft sich mit den bestialischen Armen auf ihn.

184 Vgl. dazu beispielsweise II, 22, oder VI, 134.

185 Als wahr wird er das Erfundene bezeichnen, wahr und klar, / der Mensch, der seine Augen fokussiert und fest darauf richtet. / Das Werk, das ein Werk der Kunst ist und quasi atmet, / wird die Natur als Werk ihrer Hände bewundern.

186 Vgl. dazu ebenso die Ekphrasis von Vasen, auf denen die Geburt der Venus dargestellt wird (VII, 133-136). 
a le beatitudini d'Amore. -

Così, colà volgendo i guardi e i passi,

in fronte gli mirò scritto di fore.

Tutto d'incise gemme era lo scritto,

tarsiato a caratteri d'Egitto. ${ }^{187}$ (II, 33)

Die Stanze liest sich als rovesciamento des Pilgerweges von Dante: Wie es die Inschrift an der Schwelle des Palastes anzeigt, ist Adonis unterwegs zu einer sinnlichen Liebeserfüllung, nicht zum himmlischen Paradies. ${ }^{188}$ Die Neuartigkeit des Palastes wird unterstrichen durch den Vergleich des staunenden Adonis mit einem « attonito villano » und Christoph Kolumbus:
Somiglia Adone attonito villano, uso in selvaggio e poverel ricetto, se talora a mirar vien di lontano pompa real di cittadino tetto. Somiglia il domator de l'oceano quando, d'alto stupore ingombro il petto, vide primiero in region remote meraviglie novelle e genti ignote. ${ }^{189}(\mathrm{~V}, 8)^{190}$

Kaum setzt Adonis einen Fuss in den Palast, wird er zum Gefangenen Amors (V, 10, Vv. 3-4). Adonis bleibt regungslos vor Staunen - « den Mund öffnet er nicht, die Augen bewegt er nicht » $(\mathrm{V}, 13, \mathrm{~V} .4)$-, bis Merkur sich seiner annimmt und mit den Mythen von Narziss, Ganimedes, Kyparissos, Ila und Atide sowie dem Schauspiel über Atteone sein Schicksal vorausweist.

187 Je mehr Adonis sich dem Ort nähert, / desto mehr verstellt grosses Staunen seinen Geist. / - Das ist der Himmel auf Erden und hier entlang geht es / zu den Freuden Amors. - / Darüber wunderte er sich, als er darauf den Blick und die Schritte richtet, / geschrieben am Eingang des Palastes. / In die ganze Schrift waren Edelsteine eingeprägt, / mit ägyptischen Intarsien verziert.

188 Ohne Konsequenzen wird er in den goldenen Apfel beissen, der im Palastgarten an einem diamantenen Baum hängt (II, 38-39). Es handelt sich dabei wiederum um ein «rovesciamento, in qualche misura la profanazione, del racconto di Genesi » - der süsse Apfel verheisst eine Verdoppelung der Liebe (Russo, Commento, S. 246). Diese neue Erzählung Marinos fliesst nahtlos in jene des Urteils von Paris ein. Marino transformiert die biblische und die mythologische Erzählung in seine eigene Version des Adonis-Mythos.

189 Adonis gleicht einem entgeisterten Bauernlümmel, / gewohnt an die Wildnis und eine ärmliche Unterkunft, / wenn dieser bisweilen von weitem herkommt, / um die königliche Pracht der städtischen Häuser zu bestaunen. / Er gleicht dem Bändiger des Ozeans, / als dieser, die Brust erfüllt von grossem Staunen, / zum ersten Mal in entfernten Regionen / neue Wunderwerke und unbekannte Menschen erblickte.

190 Vgl. ebenso V, 13 . 
Gemeinsam mit Venus gelangt Adonis in den «GARTEN DES VERGNÜGENS » (VI, Allegoria). Die Natur des Menschen, der bereits in den Dicerie sacre als vollendetes göttliches Kunstwerk gepriesen wurde, spiegelt sich an dieser Stelle wider: ${ }^{191}$

«Non pensar tu che senza alto disegno

(disse volto Mercurio al bell'Adone)

fondata abbia Ciprigna entro il suo regno

questa sì vaga e florida magione,

ch'intelletto divin, celeste ingegno

nulla a caso giamai forma o dispone;

misterioso il suo edificio tutto

a sembianza de l'uomo è qui costrutto.

Del corpo uman la nobile struttura

in sé medesma ha simmetria cotanta, chè regola infallibile e misura

di quanto il ciel con l'ampio tetto ammanta.

Tal fra gli altri animali il fe' Natura,

che solo siede e sol dritto si pianta

e, come l'alma eccede ogni altra forma,

così d'ogni altro corpo il corpo è norma.

Le meraviglie che comprende e serra non son possenti ad agguagliar parole; né nave in onda, né palagio in terra, né teatro, né tempio è sotto il sole, né v'ha machina in pace, ordigno in guerra, che non tragga il model da questa mole; trovano sì perfetta architettura il compasso e lo squadro ogni figura.

Miracol grande, in cui con piena intera Giove de' doni suoi versò l'eccesso, de la divinità sembianza vera, imagin viva e simulacro espresso. Quasi in angusta mappa immensa sfera, fu l'universo epilogato in esso: tien sublime la fronte, alte le ciglia, sol per mirar quel ciel che l'assomiglia. ${ }^{192}$ (VI, 8-11)

191 Vgl. dazu VI, 16, Vv. 1-4.

192 «Denk nicht, dass ohne hohen Plan / (sagt Merkur, dem schönen Adonis zugewandt) / Ciprigna in ihrem Reich begründet habe / ein derart reizendes, blühendes Domizil, / dass göttlicher Intellekt, himmlisches Talent / niemals etwas zufällig formt oder anordnet. / Ihr ganzes Gebäude ist geheimnisvoll / nach dem Aussehen des Menschen gebaut. // Vom menschlichen Körper trägt die edle Struktur / in sich so viel Symmetrie, / dass diese 
Während der Palastgarten eine «sembianza» des Menschen darstellt, ist der Mensch eine «sembianza vera» und eine «imagin viva» der «immensa sfera » des Universums, wobei insbesondere Letzterer das Staunen gilt. ${ }^{193} \mathrm{Im}$ Mittelpunkt steht somit weder der Mythos noch die Ekphrase des wunderbaren Gartens, sondern der Mensch.

Die Gärten sind den fünf Sinnen des Menschen nachgebildet; Seh-, Geruchs-, Geschmacks-, Hör- und Tastsinn - kulminierend im Liebesakt werden physiologisch und philosophisch erläutert. Adonis betritt den ersten Garten, den Garten der Sehkraft, voller Staunen:

Qui tacette Cillenio, e con tai detti

da lo stupore il giovane riscosse, che de l'orto gioioso era in quel punto già nel primo sogliare entrato e giunto. ${ }^{194}\left(\mathrm{VI}, 18, \mathrm{Vv} .5^{-8}\right)$

Nach der Beschreibung des Auges werden Adonis und Venus zu bemalten Loggien geführt - berühmte Maler und Motive werden vorgestellt. Die Aufforderung zum Betrachten und Staunen - «vedi » und «mira» - leitet die Blicke von Adonis und dem Leser gleichermassen, ebenfalls wird die Narration in den Stanzen 59-73 dadurch strukturiert und vorwärtsgetrieben.

Die Betrachtung der Bilder im Garten des Sehsinns findet ihren Höhepunkt darin, dass Adonis sich vor lauter Staunen selbst in eine Statue bzw. ein Bild transformiert:

unfehlbare Regel und Mass ist, / insofern sie den Himmel mit weitem Dach bedeckt. / Unter den anderen Tieren hat die Natur ihn so gemacht, / dass er seinen alleinigen Vorsitz und sein alleiniges Recht pflanzt, / und so, wie seine Seele jede andere Form übersteigt, / ist auch sein Körper die Norm jedes anderen Körpers. // Den Wunderwerken, die er umfasst und einschliesst, / kann nicht mit Worten beigekommen werden; / weder gibt es ein Schiff auf Wellen, noch einen Palast auf Erden, / weder ist ein Theater, noch ein Tempel unter der Sonne, / weder gibt es eine Maschine im Frieden, noch Geräte für den Krieg, / die nicht das Modell dieses Werkes in sich tragen; / eine derart perfekte Architektur finden / der Zirkel und der Winkel jeglicher Figur. // Grosses Wunder, in das Jupiter mit Fülle / seine Geschenke im Übermass goss, / mit dem wahrhaftigen Aussehen der Göttlichkeit, / lebendiges und ausdrückliches Abbild. / Sozusagen eine immense Sphäre auf einer kleinen Karte, / wurde das Universum in ihm zusammengefasst: / Er hat eine erhabene Stirn, hohe Augenbrauen, / nur um den Himmel zu bestaunen, der ihm gleicht.

193 Vgl. dazu DS, I, 106-107, 234.

194 Hier schwieg Cillenio, und mit dem Gesagten / wurde der Jüngling vom Staunen vereinnahmt, / als er an diesem Punkt im freudvollen Garten / über die erste Schwelle eingetreten und angekommen war. 
Sì dice l'un, l'altro gli sguardi e l'orme

a le mura superbe intento gira,

e mentre queste et altre illustri forme,

di cui son tutte effigiate, ammira,

sembra, né sa s'ei vegghia o pur s'ei dorme,

statua animata, imagine che spira,

anzi più tosto un'insensata e finta

tra figure spiranti ombra dipinta. ${ }^{195}(\mathrm{VI}, 74)^{196}$

«Gira - ammira - spira » ebenso wie «finta - dipinta » sind Reime, die in Marinos Werken mehrfach vorkommen. ${ }^{197}$ Sie sind thematisch zentral: Das lebendig Wirkende wird bewundert und bestaunt, wobei der artifizielle und fiktive Charakter stets betont wird. Das Verb girare markiert die „verdrehte“ Konstitution des Betrachteten: Das Lebendige wirkt künstlich, das Künstliche lebendig.

So werden denn auch die Blumen im Garten des Geruchsinns nicht als Pflanzen, sondern als «raffinierte [...] Gemälde» und «vortreffliche Werke » präsentiert. Sie wurden als «ungewöhnliche Wunderwerke» («meraviglie inusitate ») von Amor geschaffen (VI,122-124). Zwar geben die wohlriechenden Blumen Anlass zur Beschreibung des menschlichen Riechorgans, in erster Linie aber sind in ihnen mythologische und enkomiastische Erzählungen verkörpert. Die Rolle des Erzählers ist an dieser Stelle sehr präsent, er bricht bewusst mit der erzählten Zeit: So nimmt er die Metamorphose des Adonis in eine Blume vorweg (VI, 133) oder preist die Lilie als Symbol des französischen Königshauses, dem er eine gloriose Zukunft sowie blutige Kriege voraussagt (VI, 135-136). Ausserhalb der Lesererwartung situiert sich insbesondere die Beschreibung der Passionsblume. Der Erzähler verdeutlicht, dass die Passionsblume nicht (zwingend) Teil des Palastgartens ist, sondern seiner Imagination entspringt und einen neuen Inhalt in den Mythos einbringt: die Passionsgeschichte Christus'.

195 So sagt der eine, und der andere dreht seinen Blick und seine Füsse / fokussiert auf die herrlichen Mauern, / und während er diese und jene illustren Formen, / die alle abgebildet sind, bewundert, / scheint es, als ob er nicht mehr wüsste, ob er wach sei oder schlafe, / eine beseelte Statue, ein Bild das atmet, / ja sogar ohne Sinne und künstlich, / ein gemalter Schatten zwischen atmenden Figuren.

196 Russo, Commento, S. 623: «Tale é lo stupore di Adone che rimane attonito, immobile, tanto da sembrare anch'egli immagine dipinta (un'insensata e finta ... ombra dipinta), persino meno vivida di quelle che vi sono soltanto effigiate e che pure sembrano viventi (figure spiranti).»

197 Vgl. z. B. die Statue [4A.] der Medusa in der Galeria oder die nachfolgend zitierte Stanze 78 aus dem sechsten Canto. 
Non so se v'era ancor la granadiglia, ch'a noi poscia mandò l'indica piaggia, di natura portento e meraviglia, e ceda ogni altra pur stirpe selvaggia. ${ }^{198}$ (VI, 137, Vv. 1-4)

Die Passionsblume ist « grösstes Wunder der Erde », sie ist sowohl ein Buch, in das Christus seine Leiden eingeschrieben hat, als auch ein Bild Gottes, in dem die Leiden Christus' und die Erlösung der Menschheit dargestellt sind.

$[\ldots]$

fiore, anzi libro, ove Gesù trafitto

con strane note il suo martirio ha scritto. ${ }^{199}$ (VI, $\left.138, \mathrm{Vv} .7-8\right)$

Ahi, qual pennello in te dolce e pietoso

trattò la man del gran pittore eterno?

E con qual minio vivo e sanguinoso

ogni suo strazio espresse et ogni scherno?

Di quai fregi mirabili pomposo

al sol più caldo, al più gelato verno

dentro le tue misteriose foglie

spieghi l'altrui salute e le sue doglie? ${ }^{200}$ (VI, 141)

Te sol l'Aurora in oriente ammiri, tue pompe invidi e tua beltà vagheggi;

in te si specchi, a te s'inchini e giri

stupido il Sol da' suoi stellanti seggi. ${ }^{201}$ (VI, 144, Vv. 1-4)

Die Passionsblume übertrifft die Blumen der Antike (VI, 139), sie wird von Aurora bewundert und beneidet, sie ist Mittelpunkt der staunenden Sonne, wird gar von ihr umkreist. Die Passionsblume erweitert den Lustgarten um eine neue Dimension - den körperlichen Schmerz Christus' - und verkehrt damit seine ursprüngliche Bedeutung.

198 Ich weiss nicht, ob es auch Passionsblumen hatte, / die uns danach die indischen Ufer schickten, / von Natur aus Wunder und Wunderwerk, / vor der jede andere Wildblumenart zurückweicht.

$199[\ldots]$ / Blume, eher ein Buch, in das der gekreuzigte Jesus / mit sonderbaren Zeichen sein Martyrium eingeschrieben hat.

200 Ah, welchen Pinsel hat an dir, lieblich und erbarmungsvoll, / die Hand des grossen ewigen Malers angewandt? / Und mit welch lebendigem und blutigem Rot / hat er alle seine Leiden und jede Verhöhnung ausgedrückt? / Mit welch wundervollen Verzierungen, prunkvoll / in der warmen Sonne; im gefrorenen Winter, / in deinen geheimnisvollen Blättern, / drückst du das Wohl und die Schmerzen des anderen aus?

201 Dich alleine bewundert Aurora im Orient, / deinen Prunk beneidet und deine Schönheit ersehnt sie; / in dir spiegelt sich, vor dir verbeugt und wendet sich / erstaunt die Sonne von ihren gestirnten Sitzen aus. 
Bisweilen tritt die Kunst selbst an die Stelle der Erzählung, wenn beispielsweise die Geburt der Venus im siebten Canto (LE DELIZIE) in der Form von darstellenden Vasen erzählt wird. Auch in der Abbildung der mythischen Figur wird die Nähe zur Realität hervorgehoben - Fiktion und Realität überschreiben sich.

In un de' vasi il simulacro altero de la diva del loco è sculto e finto, ma sì sembiante è il simulato al vero che l'esser dal parer quasi n'è vinto. Il sanguigno concetto e 'l suo primiero fortunato natal v'appar distinto. Miracolo a veder come pria nacque, genitrice d'Amor, figlia de l'acque. ${ }^{202}$ (VII, 133)

Mit «[v]edresti» richtet sich der Erzähler im Konditional an den Leser: Du könntest sehen, wie der Schaum sich in Gold und schliesslich in goldene Haare verwandelt, wenn du die Vasen genauso wie Venus und Adonis vor Augen hättest. Der Erzähler überbrückt die fehlende Nähe des Lesers zu den Vasen, indem er die statische Darstellung in eine dynamische wandelt. Bis - «O meraviglia » - der Körper der Göttin zum Vorschein kommt.

Vedresti per lo liquido elemento nuotar la spuma gravida e feconda, poscia in oro cangiarsi il molle argento e farsi chioma innanellata e bionda. La bionda chioma incatenando il vento serpeggia e si rincrespa, emula a l'onda. Ecco spunta la fronte a poco a poco, già l'acque a' duo begli occhi ardon di foco.

O meraviglia, e trasformar si scorge in bianche membra alfin la bianca spuma. Novo sol da l'Egeo si leva e sorge, che 'l mar tranquilla e l'aria intorno alluma; sol di beltà, ch'altrui conforto porge e dolcemente l'anime consuma.

202 In einer der Vasen ist das erhabene Abbild / der lokalen Göttin geformt und dargestellt, / aber derart ähnlich ist das Abbild der Realität, / dass das Sein vom Schein beinahe besiegt wird. / Die leidenschaftliche Empfängnis und ihre / glückliche Geburt erscheinen deutlich. / Es ist ein Wunder, zu sehen, wie sie geboren wurde, / die Mutter Amors, Tochter der Meere. 
Così Venere bella al mondo nasce, un bel nicchio ha per cuna, alghe per fasce. ${ }^{203}$ (VII, $135^{-136)}$

Die Transformation als Verlebendigung wird vom Erzähler geleistet. Schaum wandelt sich zur Göttin, während das Bild sich in der Erzählung verlebendigt. Die mythische und die mediale Transformation überlagern sich.

Im zehnten Canto wird Adonis nach dem Himmelskreis, der die Natur verkörperte, zum Himmel Merkurs und zum Palast der Kunst geleitet, der jedes Gebäude, jedes Kunstwerk (X, 117, V. 4) übertrifft. Merkur weist Adonis an, das Gesehene zu bestaunen - «mira » leitet erneut den Blick von Protagonist und Leser. ${ }^{204}$ Im Palast der Kunst werden die Künste des Triviums und des Quadriviums gelehrt, ${ }^{205}$ wobei die klassischen Fächer um Malerei, Bildhauerei, Geographie, Recht, Medizin und Philosophie erweitert werden. In der Poesie sind alle Wissenschaften vereint:

Or mira a l'ombra de la sacra pianta, fregiata il crin de l'onorate foglie, la Poesia, che mentre scrive e canta il fior d'ogni scienza insieme accoglie. La favola è con lei, ch'orna et ammanta le vaghe membra di pompose spoglie; l'accompagna l'Istoria, ignuda donna, senza vel, senza fregio e senza gonna. ${ }^{206}(X, 139)$

Gleichsam im Palast der Kunst befindet sich ein grosses Arsenal (X, 142, V. 2), in dem die Erfindungen der berühmtesten Künstler (X, 142, V. 8) versammelt sind. Die Ideen zu diesen Erfindungen sind ursprünglich der Kunst entsprungen

203 Du wirst durch das flüssige Element / den Schaum schwimmen sehen, voll und fruchtbar, / und dann das nasse Silber sich in Gold / und in eine Haarpracht verwandeln, lockig und blond. / Das blonde Haar, den Wind fesselnd, / schlängelt und kräuselt sich, den Wellen nacheifernd. / Da erscheint die Stirn, Stück für Stück, / und schon brennt das Wasser mit zwei schönen Augen. // Oh Wunder, und verwandeln sieht man / in helle Glieder schliesslich den weissen Schaum. / In der Ägäis sieht man eine neue Sonne, / die das Meer beruhigt und die Luft erhellt; / Sonne der Schönheit, die Trost bringt / und lieblich die Seelen vereinnahmt. / So kommt die schöne Venus zur Welt, / eine schöne Muschel hat sie als Wiege, Algen als Windeln.

$204 X, 118,119,129,136,137,139,146$.

205 Russo, Commento, S. 1011.

206 Jetzt bestaune im Schatten der heiligen Pflanze, / das Haar verziert mit den ehrwerten Blättern, / die Dichtung, die, während sie schreibt und singt / die Blume jeder Wissenschaft in sich versammelt. / Die Erzählung ist mit ihr, und schmückt und umhüllt / die lieblichen Glieder mit prunkvollen Kleidern; / es begleitet sie die Geschichte, eine nackte Frau / ohne Schleier, ohne Schmuck und ohne Kleid. 
(X, 143, V. 4). Als Höhepunkt der Erfindungen preist Merkur die «sfera rotante», ${ }^{207}$ die er selbst nach dem Vorbild des «grossen souveränen Schöpfers » (X, 170, V. 7) geschaffen hat:
Ma più non dimoriam, ché poi ch'a questi
t'ho scorto eterni e luminosi mondi, converrà ch'altro ancor ti manifesti de' secreti del fato alti e profondi, e vie molto maggior che non vedesti meraviglie vedrai, se mi secondi. » Qui tacque e 'n ricca loggia e spaziosa il condusse a mirar mirabil cosa. ${ }^{208}(\mathrm{X}, 167)$
E che sia ver, rivolgi a questa mia adamantina fabrica le ciglia; dì se vedesti o s'esser può che sia istromento maggior di meraviglia. Composta è con tant'arte e maestria ch'al globo universal si rassomiglia; mirar nel cerchio puoi limpido e terso quanto l'orbe contien de l'universo. ${ }^{209}(\mathrm{X}, 172)$

Die «sfera rotante» Merkurs ist in einer Loggia des Kunstpalastes angelegt. Selbst ein Kunstwerk und «istromento maggior di meraviglia », ist in ihr genauso wie im Menschen - das ganze Universum abgebildet.

The intuition that $[\ldots]$, there exists an invisible center from which all the arts arise" is finally verbalized in this period. The favored term for this "invisible center," the emotional and intellectual "hub" around which such discourse revolved, was, of course, „meraviglia," the achknowledged initiator, producer, and product of art itself. ${ }^{210}$

207 Russo, Einleitung zum zehnten Gesang, S. 951.

208 Aber halten wir uns nicht länger auf, denn nachdem / ich dich zu diesen ewigen und leuchtenden Welten geführt habe, / wird es sich lohnen, dass ich dir noch mehr zeige / von den grossen und tiefen Geheimnissen des Schicksals, / und weit grössere Wege, die du noch nicht gesehen hast, / Wunder wirst du sehen, wenn du mir folgst. » / Hier schwieg er und führte ihn in ein eine reiche / und geräumige Loggia, um eine wunderbare Sache zu bestaunen.

209 Und dass es wahr sei, wende deine Augen / zu dieser meiner diamantenen Schöpfung; / sag, ob du je gesehen hast oder ob es je / ein grösseres Instrument der Wunder geben könne. / Es ist geschaffen mit derart viel Kunstfertigkeit und Meisterschaft, / dass es der Kugel des Universums gleicht; / bestaunen kannst du im Kreis, klar und rein, / wie viel die Kugel vom Universum beinhaltet.

210 Terri LeE Frongia, The aesthetics of the marvelous: Baroque „meraviglia“ and Marino's „Galeria“, Riverside 1990, S. 202. 
Die «sfera rotante» ist in der Mitte des Adone angesiedelt und bildet den Höhepunkt der Abbildungen, von denen in den vorangehenden Canti die Rede war. In ihr kulminieren die meraviglie der Kunst und des Erzählens, aus ihr gehen die Transformationen des Mythos und der Figuren hervor.

\section{$7 \cdot 5 \quad$ Konklusion}

Im Gegensatz zu Francesco Colonna, der in der Hypnerotomachia Poliphili die Artifizialität der literarisch-architektonischen Landschaft in den Vordergrund rückt, fasst Marino nicht nur die Dichtung, sondern auch das Universum und den Menschen als genuin poetische und damit erstaunliche Kunstwerke. Entsprechend werden in den Dicerie sacre die christlichen Reliquien, aber auch Christus und seine Passionsgeschichte als göttliche Kunst und als Inkarnation des göttlichen Wortes gefasst. Aus dem verbo eterno ist die Schöpfung hervorgegangen, die in den Dicerie sacre als Bild gepriesen und im Adone vom Erzähler als sfera rotante nachgebildet wird. Das schöpferische Wort wohnt Gott und dem Dichter gleichermassen inne, wobei der Dichter in seinen Werken die Vielfältigkeit und Vielgestaltigkeit des göttlichen Universums genauso wie dessen Ordnung und perfekte Architektur ( $A D, \mathrm{VI}, 10, \mathrm{~V}$. 7) wiederzugeben vermag.

Die Betrachtung der Welt und des Menschen als Kunstwerke führt in $\mathrm{La}$ Galeria dazu, dass die Abbildungen religiöser, historischer und mythischer Figuren gleichberechtigt nebeneinanderstehen, dass das Bild lebendiger wirkt als die reale Figur und die Wirkung des Bildes bzw. der Statue - sei diese emotionaler oder sinnlicher Natur - jene der dargestellten Inhalte übertrifft. Die bildliche Darstellung wird zudem durch die poetische überhöht, denn noch stärker als die pittura entspringt die Dichtung dem ingegno des Poeten. Die „Bilder“ der Galeria sind keine Ekphrasen, sondern fiktive Gebilde, die in ihrem Kern ein originelles concetto des Autors transportieren. Der abbildende und nachahmende Charakter der Kunst tritt damit ganz hinter den kreativen Aspekt zurück - genauso hat schon Patrizi den schöpferischen Aspekt der Dichtung betont.

Im Adone wird ein literarisches Universum präsentiert, das die Vielgestaltigkeit der poetischen Darstellung in einem fortlaufenden Transformationsprozess vorführt. Dieser umfasst die Sprache und die Narration genauso wie den Mythos und dessen Figuren. Wie schon in den Dicerie sacre, in denen das Staunen über die göttlichen und das Staunen über die poetischen Schöpfungen zusammengeführt werden, und in der Galeria, in der das Staunen die Transformation der Bilder in Gedichte und deren Wirkung betraf, wird es auch im 
Adone zur zentralen Reaktion auf die vielgestaltige dichterische Gestaltung. Zum einen wird es als Staunen über die Schönheit des Protagonisten zur Oberfläche, unter der sich die vielfältigen Metamorphosen des Adonis - das eigentlich Erstaunliche des Werkes - vollziehen, zum anderen stellt es dessen Kunstcharakter heraus, wenn sich sogar Adonis vor den poetischen Gebilden aus lauter Staunen in eine Statue zu verwandeln droht.

Die Rolle des Staunens als übergeordnete Reaktion auf die Dichtung, wie sie in den eingangs erwähnten Briefen thematisiert wird, bestätigt sich in der Analyse von Marinos Werken. Ebenso finden wir in ihnen die zum Staunen gehörenden poetischen Qualitäten verinnerlicht: 1. novità, 2. stravaganza, 3. vivezza, 4. spiritosità und fantasia sowie 5. libertà. Die drei untersuchten Texte sind neu in ihrem Inhalt und insbesondere in ihrer Form, sie sind extravagant, insofern als sie die Kunst - allen voran die Dichtung - auf eine Ebene mit der Schöpfung, den Dichter auf eine Ebene mit dem göttlichen Schöpfer stellen, sie sind lebendig und geistreich, insofern sie nur bedingt auf Vorlagen zurückgreifen und diese vielfältig erweitern, verbinden und transformieren. Alles in allem zeugen die Werke Marinos von grosser künstlerischer Freiheit einer Freiheit, wie sie vor ihm schon von Colonna und Patrizi, ansatzweise auch schon von Poliziano, Pontano und Fracastoro propagiert wurde.

Als Kulminationspunkt einer Poetik der meraviglia kann Marino insofern bezeichnet werden, als er den schöpferischen Aspekt der Dichtung konsequent zu seiner Vollendung führt, wenn er ihn mit der göttlichen Schöpfung und dem Staunen über diese gleichsetzt. Weiter richtet er seinen Fokus gezielt auf die Wirkung der Dichtung, die sich im Staunen über die Fähigkeit der poetischen Sprache und des Dichters manifestiert. Diese Fähigkeit gründet insbesondere auf der Fiktion und Transformationskraft dichterischer Sprache - zwei Elementen, die von Pontano bis hin zu Patrizi zentrale Bestandteile einer Poetik des Staunens darstellen. 